المعنى: من اللغة إلى الأهن

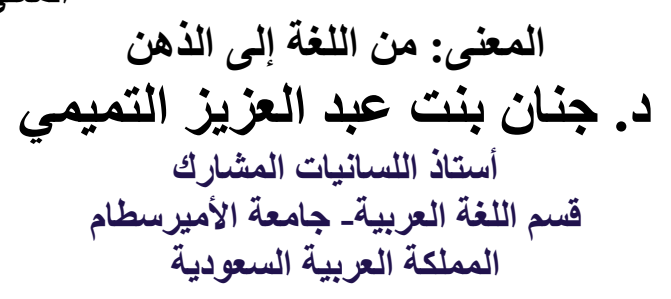

تتطلق اللسانيات الإدر اكية من مسلّمة مفادها أن اللغة إحدى مكونات المعرفة الإنسانية. وأن

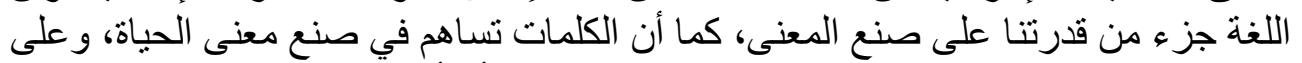

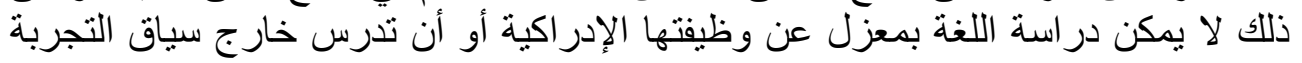

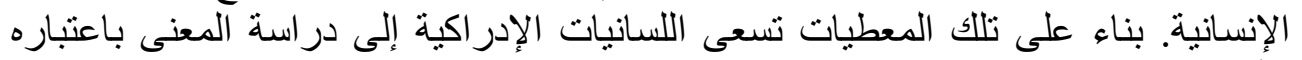

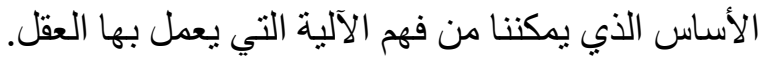

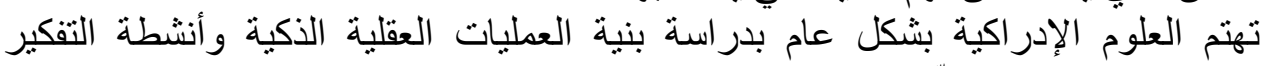

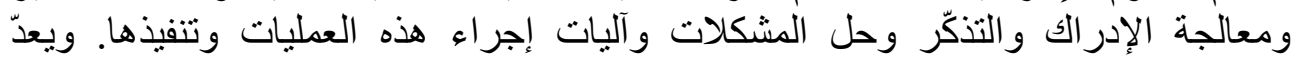

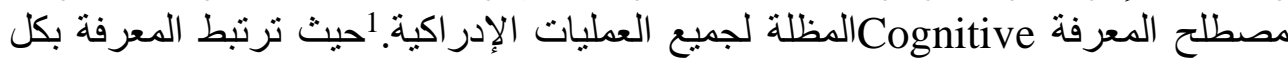

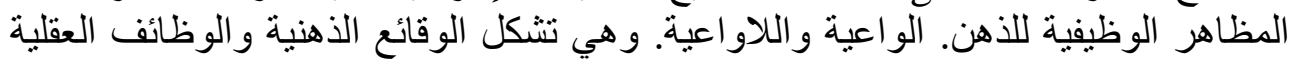

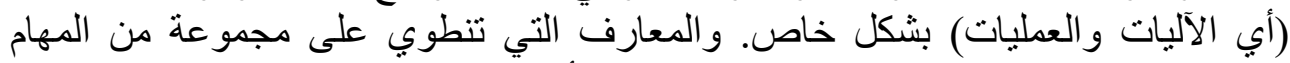
الممتدة من إدرالك الثي المحسوس في المستوى الأدنى إلى مهام اتخاذ القرار في في المعلى المستوى تقدّم هذه الورقة لمحة عامة عن الدلالة الإدراكية cognitive semantics وتحدد أهم الهاني

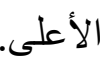

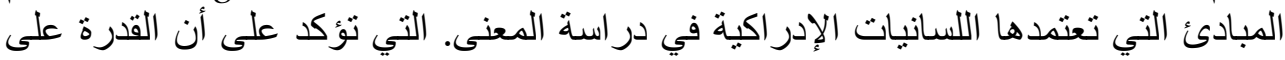

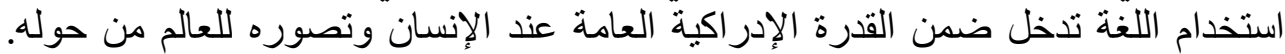

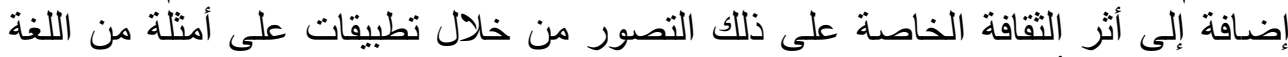

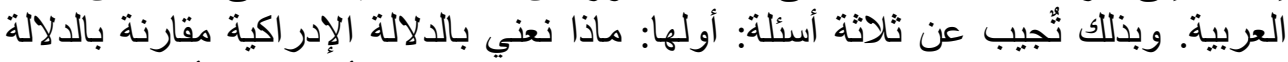

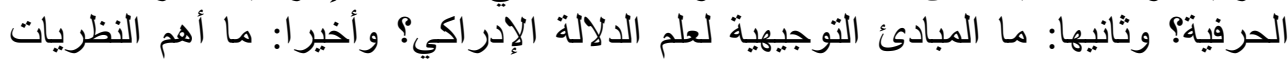

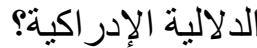

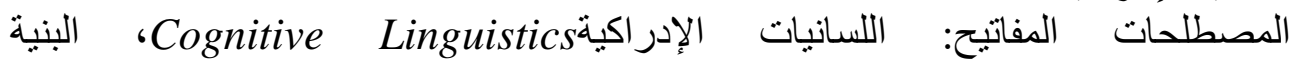

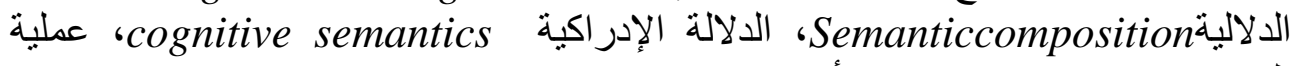

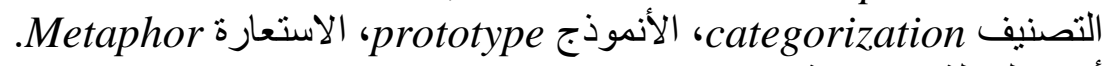
ألا: الدالاتة الإدراكية:

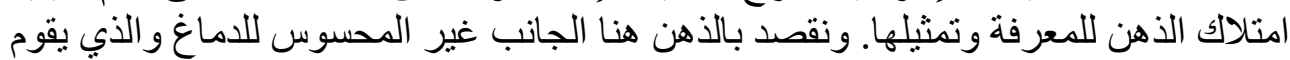

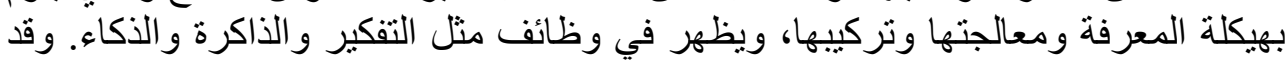

1 ـ يُنظر: الزغلول، رافع، الزغلول، عماد، علم النفس المعرفي، دار الثروق، عمان، الأردن،

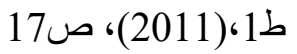




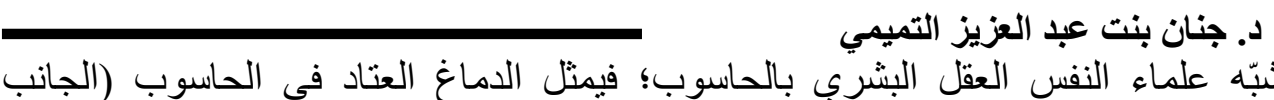

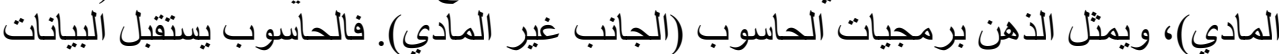

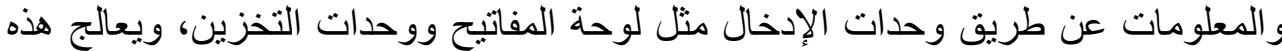

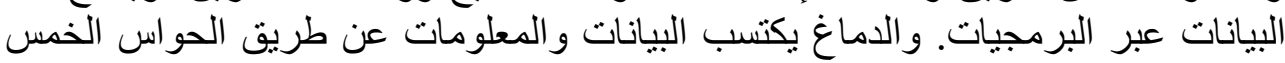
ويعالجها عن طريق الذهن. تتصل النظرية الدلالية في ظل العلوم الإدر اكية بنظريات الفكر و المعرفة بشكل عام اللغوية

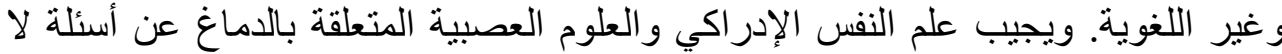

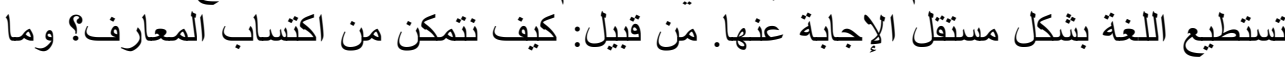

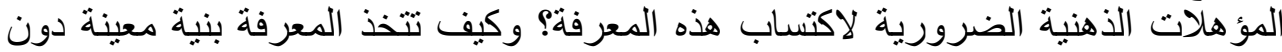

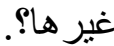

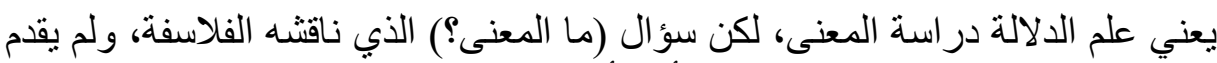
واحد منهم إجابة مرضية عليه، وقد يكون أحد أسباب عدم القدرة على لإلى تقديم إجابة مرضية

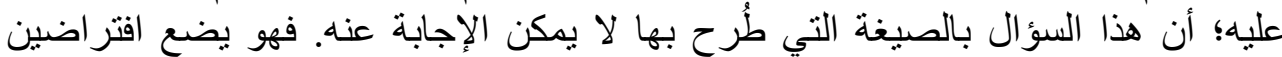

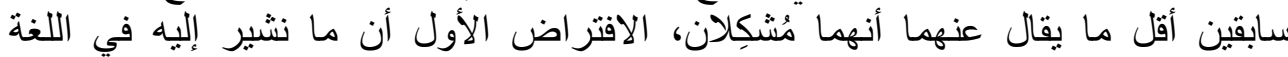

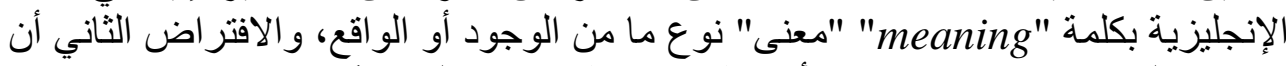
ما يشار إليه باعتباره معنى يتشابه أو يتطابق في طبيعته مع الو الو اقع. 1

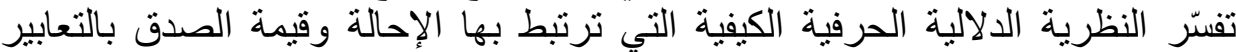

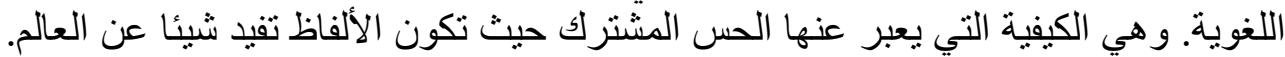

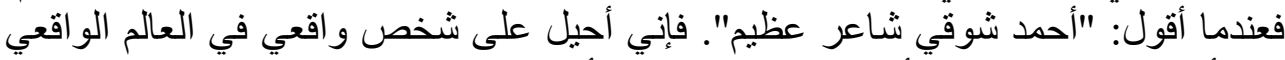

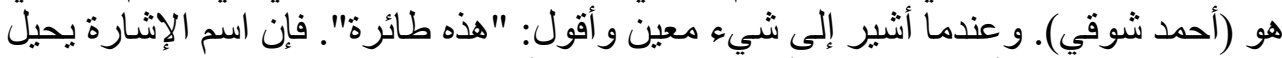

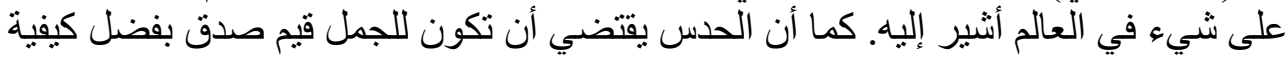

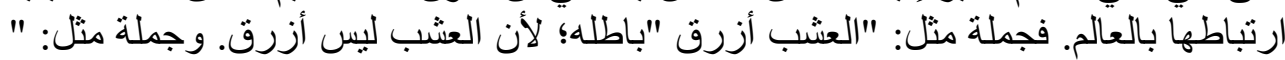

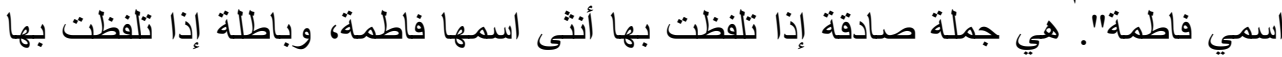
أنثى ليس اسمها فاطمة. وبذللك ترتبط معالجة المعنى اللغوي بالعلاقات التي تقيمها اللغة التها بما

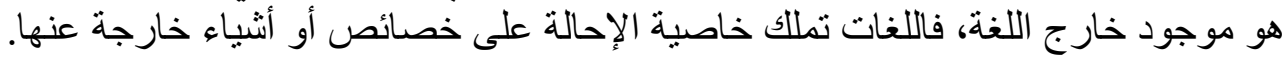

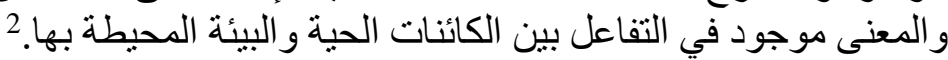

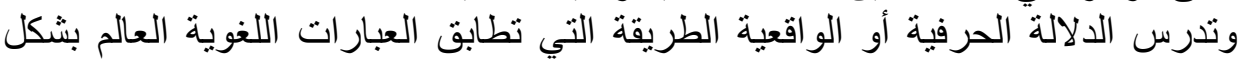

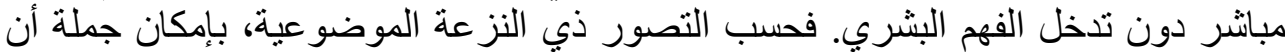

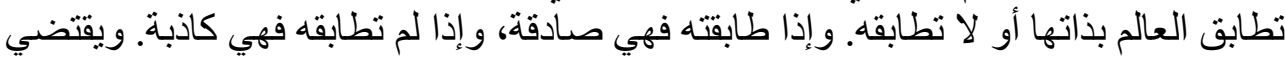

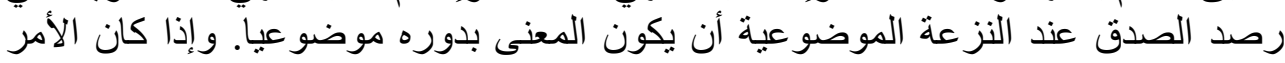

1 ا -جون ليونز، (Lyons, John)، اللغة و علم اللغة، تر. مصطفى التوني ، دار النهضة العربية،

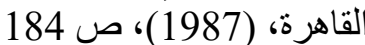
2 ـ يُنظر : غاليم، محمد. "المعنى و الإحالة في الإطار التصوري." مجلة أبحاث لسانية ـ معهر

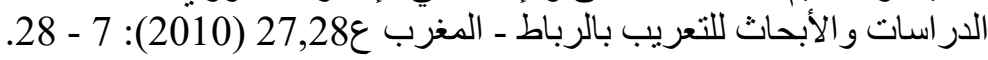


المعنى: من اللغة إلى الذهن الذهن

كذللك، فإنه ينبغي إقصاء كل العناصر الذاتية، أي كل ما هو مميز لسياق خاص، أو مرتبط اللى لأل

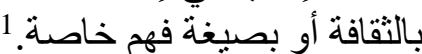

إن الإحاطة بالمعنى بصورة دقيقة قضية غير سهلة و لا متيسرة، فالدلالة صورة ذهنية

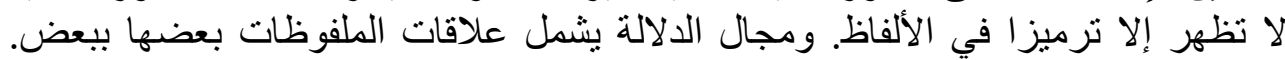

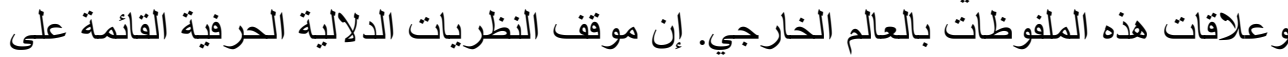

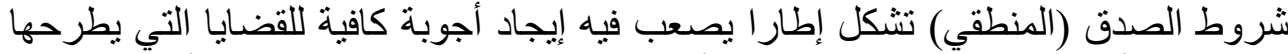

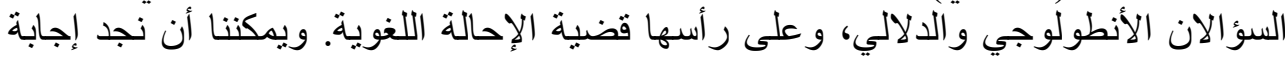

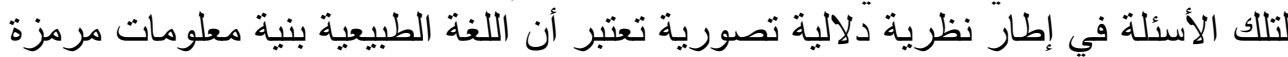

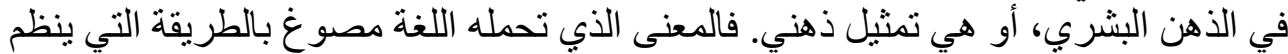

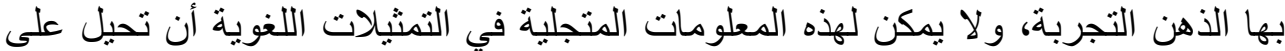

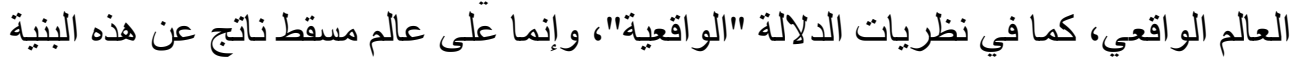

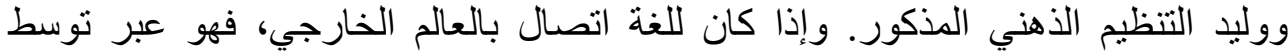

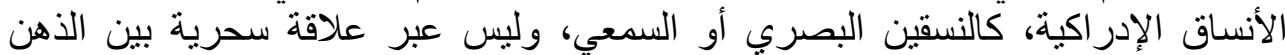

و العالم كعلاقة القصدية أو غير ها.

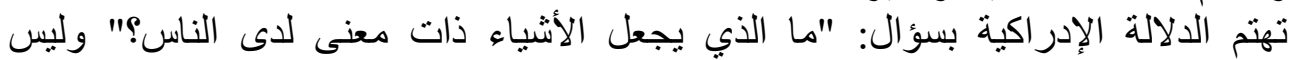

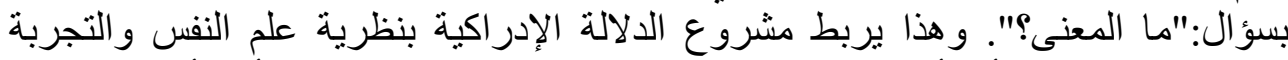

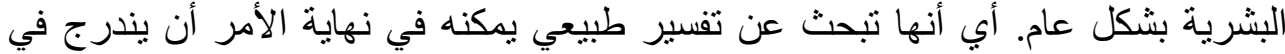

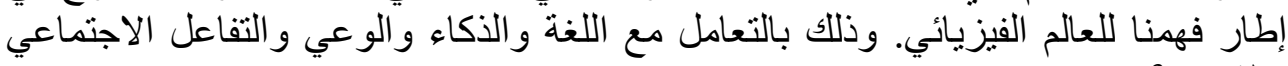
و الثقافي.3

يستهُف علم الدلالة الإدراكي ابراز الوظيفة الإدراكية للغة، وأنه لا يمكن أن تدرس

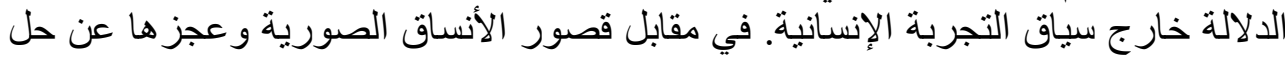

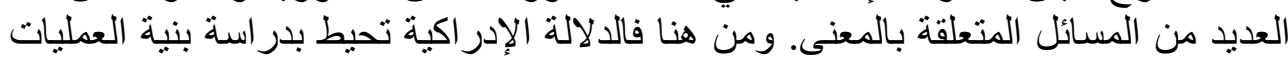

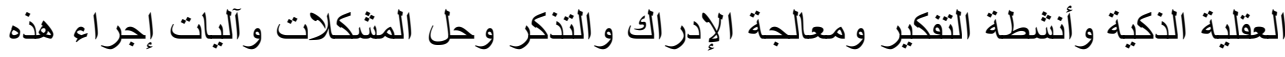

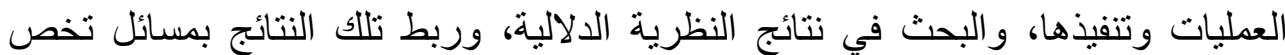

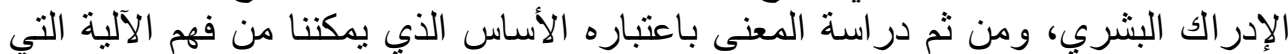

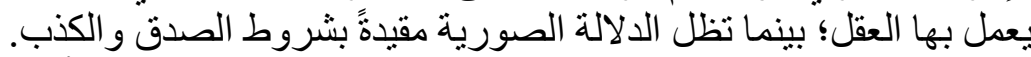

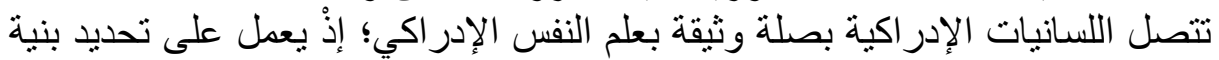
المفاهيم وطبيعتها. ومن أهم اللسانيين المؤثرين في هذا المجال (Langacker) و

1ـ يُنظر : لايكوف و جونسن، (Lakoff\& Johnson)، الاستعار ات التي نحيا بها، ت. عبد المجيد

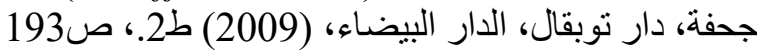

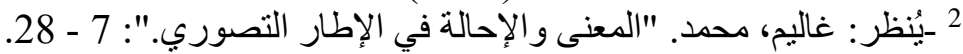

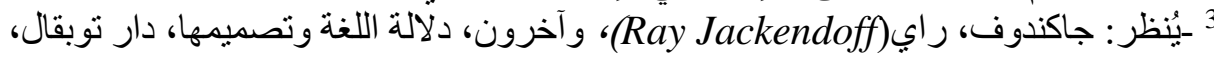

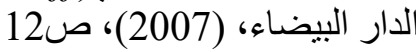


د. جنان بنت عبد العزيز التميمي الإنات الإدر اكية تعالج اللغة باعتبار ها تعكس الكيفية التي يعمل بها

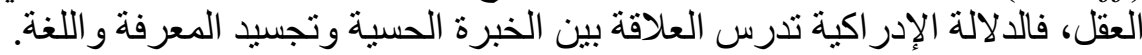

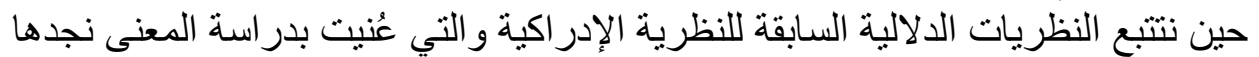

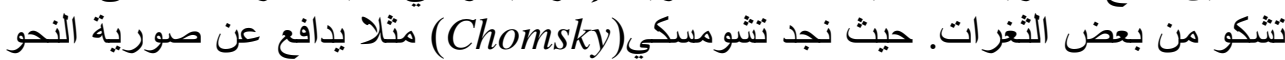

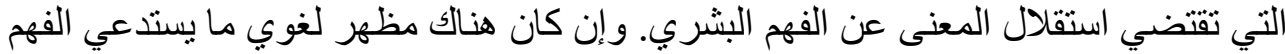
البشري، فإنه يكون بالضرورة خارج دراسة النحو. واستعماله لمفهوم القدرة في مقابل التابل

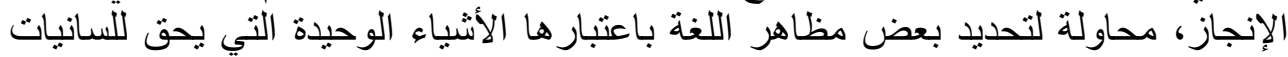

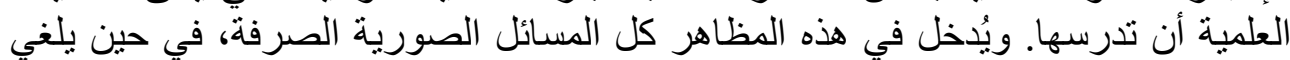

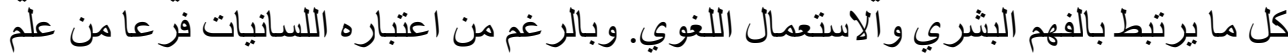
النفس إلا أن هذا الفرع لا يرتبط بالطريقة التي يفهم بها الإنسان اللغة.

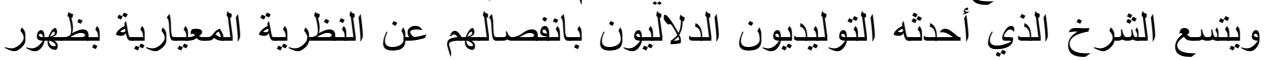

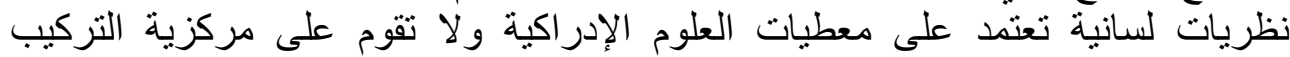

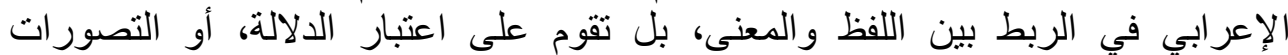
و العمليات الذهنية، هي أساس الأبنية اللفظية سو اء كانت صوتية لإنية أو صرفية معجمية أم كانت إعر ابية أو تداولية.

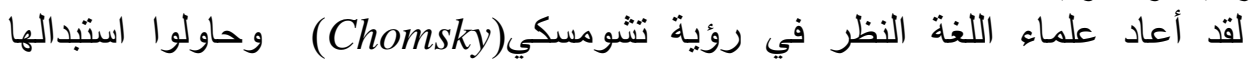
بنظريات جديدة أقرب إلى الحس اللغوي البديهي. ومن أهم هذه النظريات التي كانت تعديلا

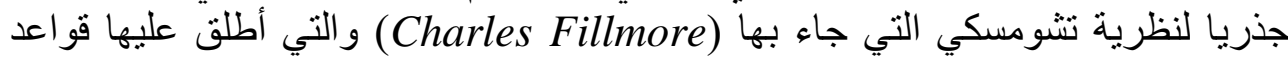

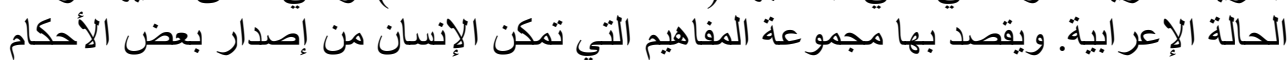

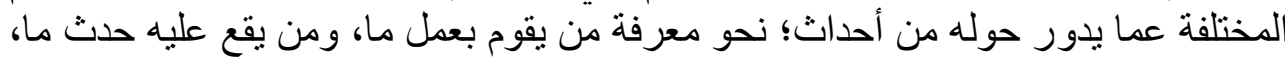
وما الذي حدث ومتى وقع ذلك الحدث، وأين. وهكذا نرى أنه أنه في حين بيدأ أنصار المدرسة

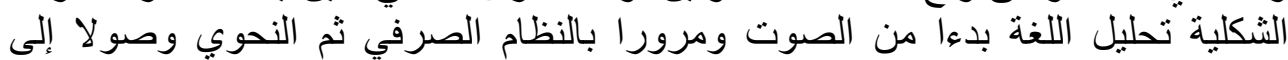

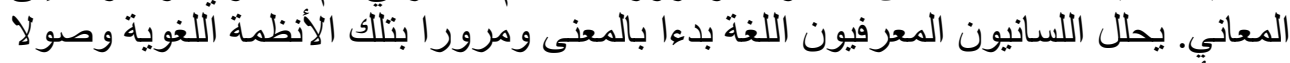
إلى الأصوات الفعلية للغة.

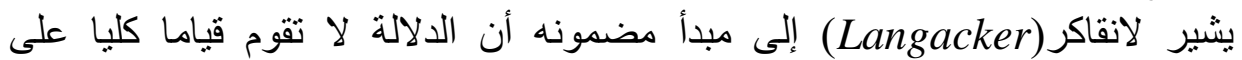

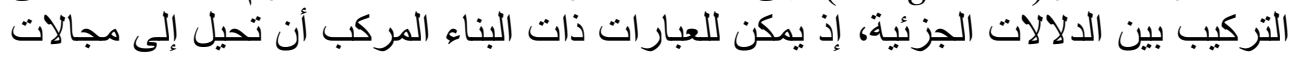

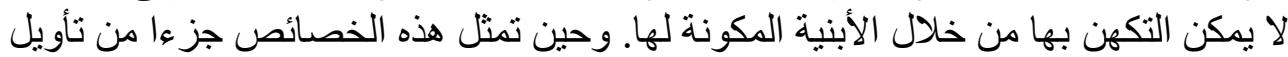

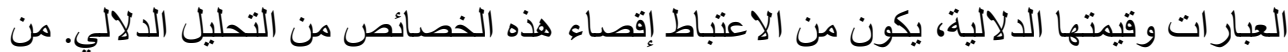

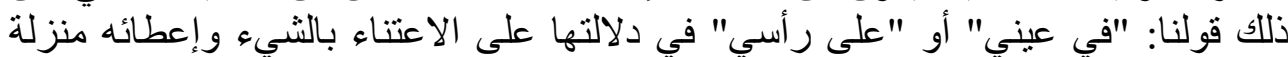

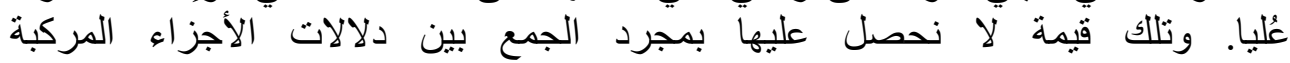

1 ـ يُنظر: Cruse, Alan, A Glossary of. Semantics and. Pragmatics, Edinburgh University Press, (2006), P.26

2ـ يُنظر :لايكوف و جونسن، (Lakoff\& Johnson)، الاستعار ات التي نحيا بها، ص197 (2019

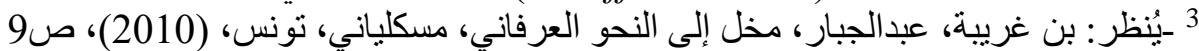

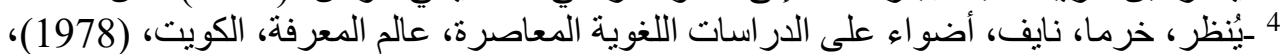

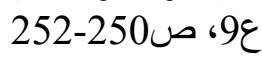


المعنى: من اللغة إلى الذهن الهن

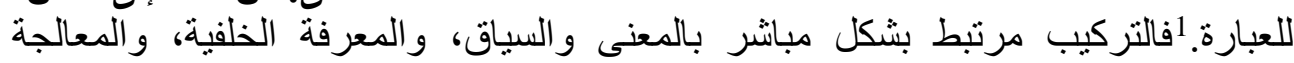
الذهنية، والمقاصد التواصلية، ومظاهر التجسيد. و و"تستقي النماذج اللغوية التهية أهميتها من صعوبة دراسة اللغة تشريحا بالثكل الذي تتحقق به في ذهن الإلها الإنسان، من هنا تأكدات

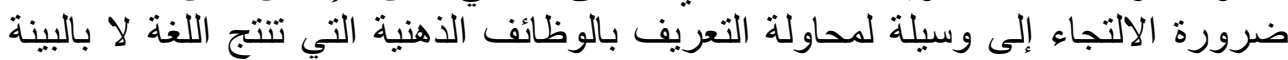

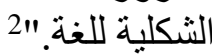

وتفترض نظريات المعنى التقليدية أن كل التصورات المركبة يمكن أن تجز أ وتفكك إلى إلى

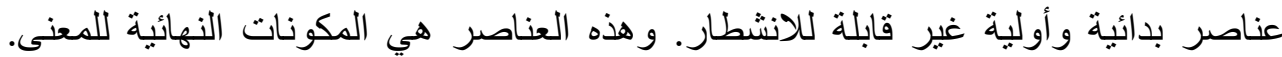

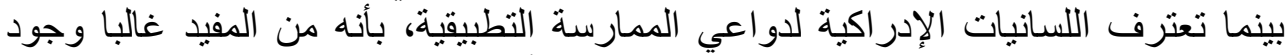

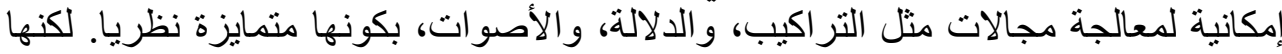

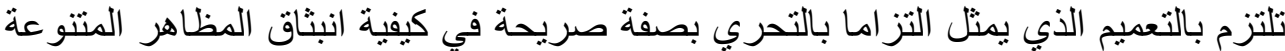

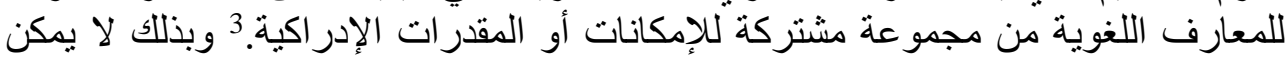

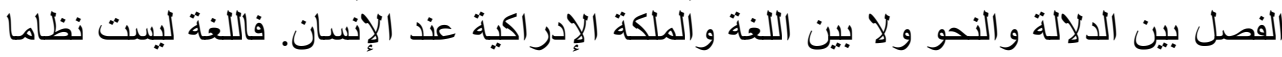

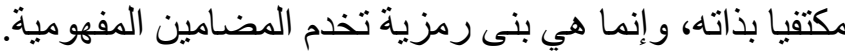

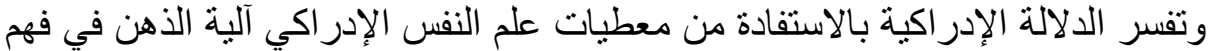

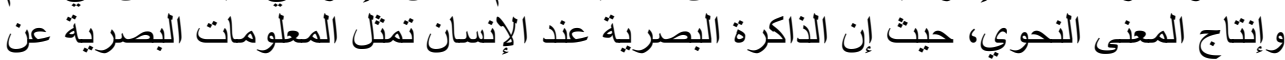

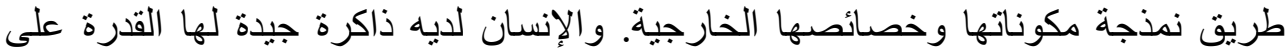

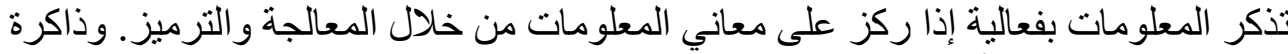

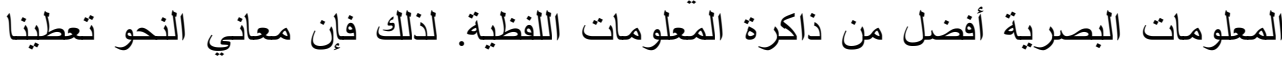

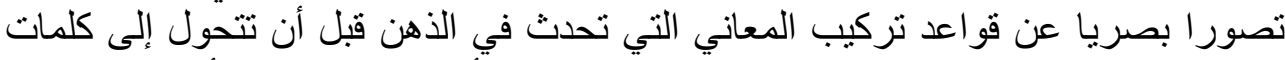

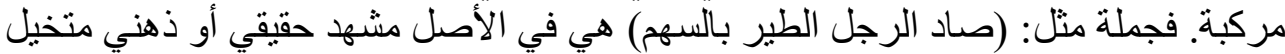

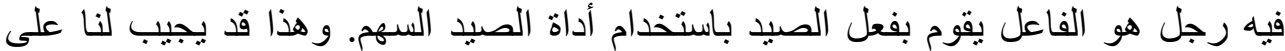

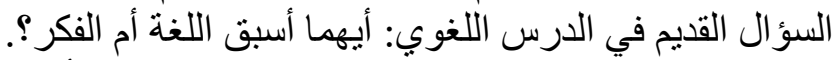

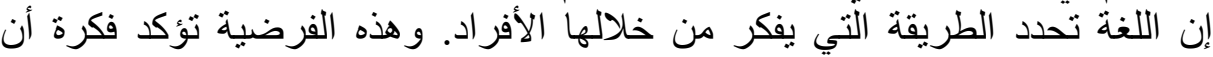
المجتمعات المختلفة تنظر إلى هذا العالم وتدركه بطريقة مختلفة تبعا لطبيعة اللغة الخاصة التهات بكل مجتمع. و إدراك الأفراد للأشياء وأساليب تفكير هم بها يختلف تبعا لتعا لطبيعة المفردات

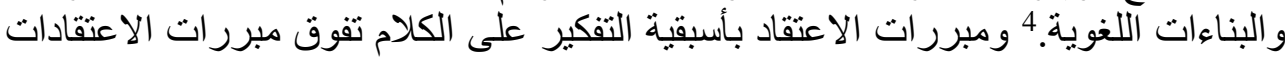

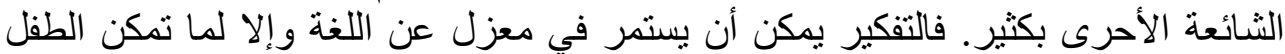

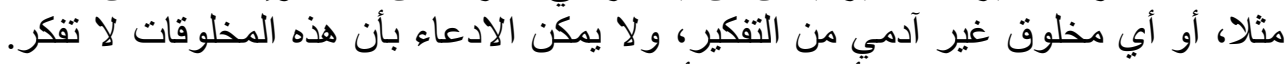

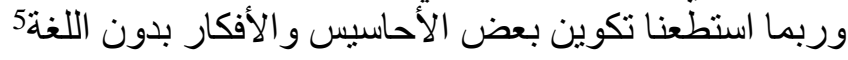

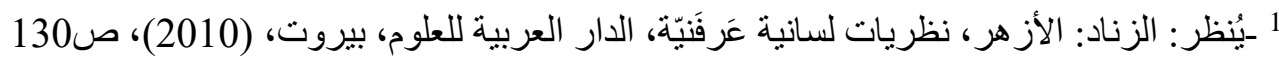

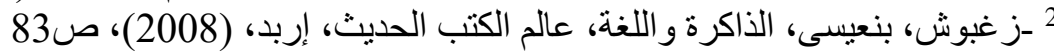

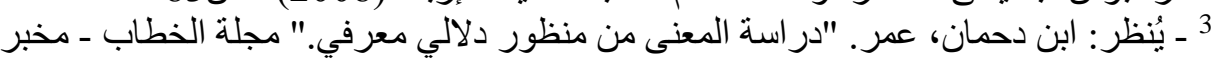

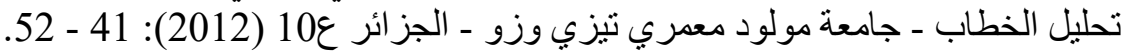

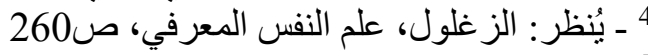

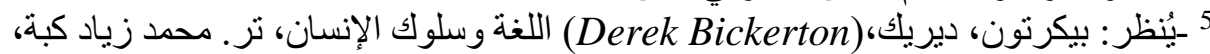

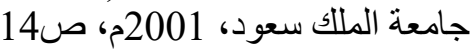




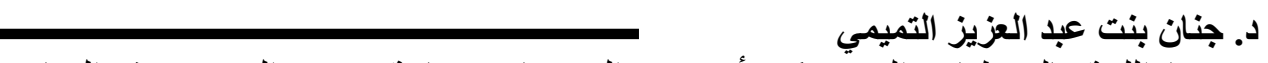

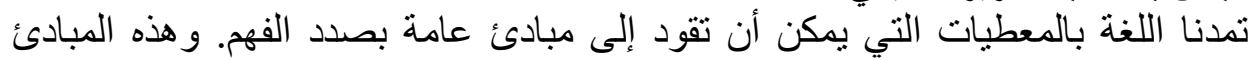

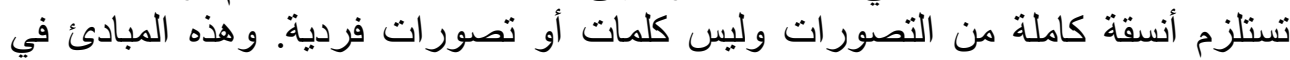

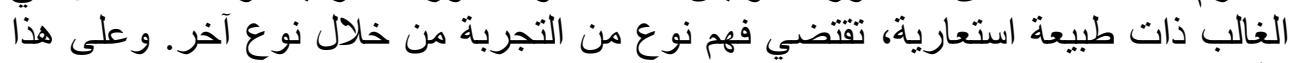

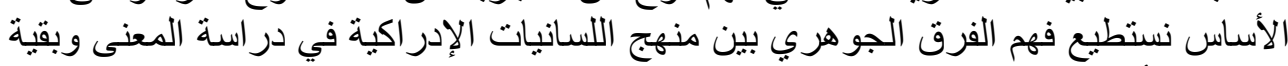

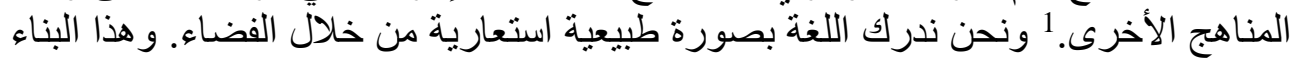

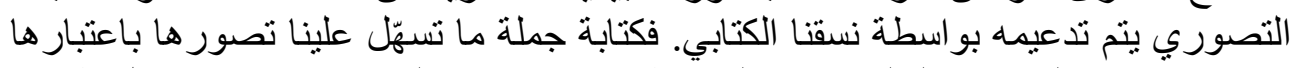

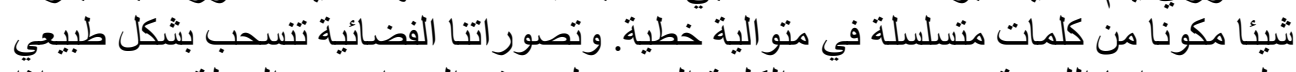

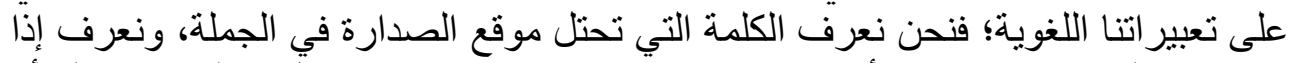

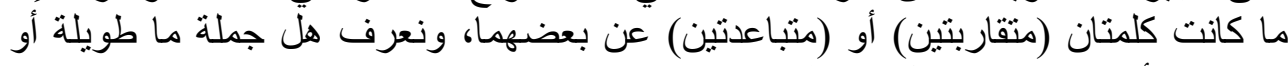

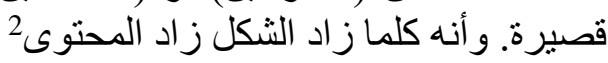

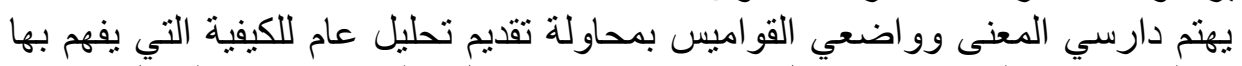

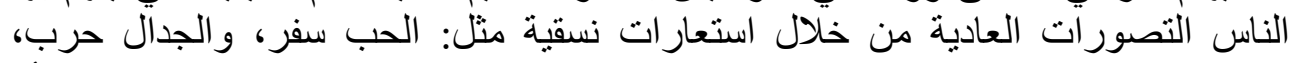

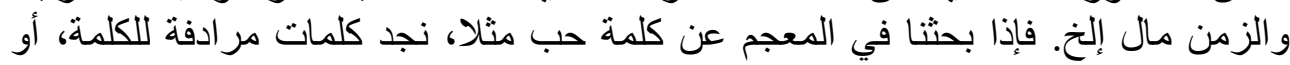

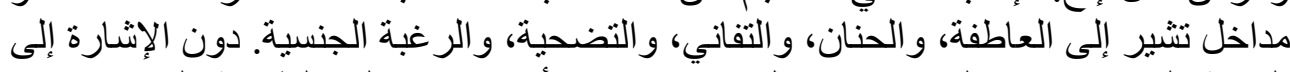

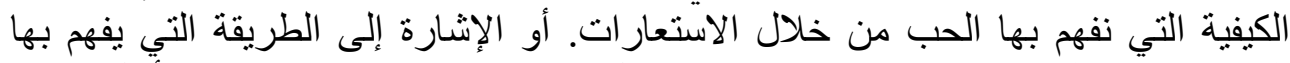

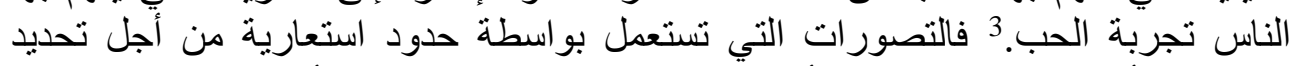

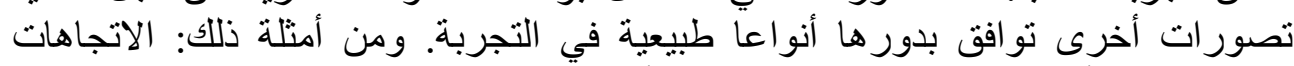

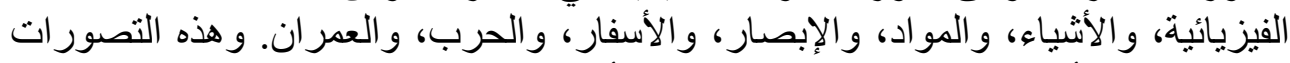

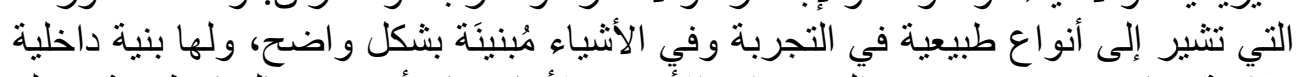

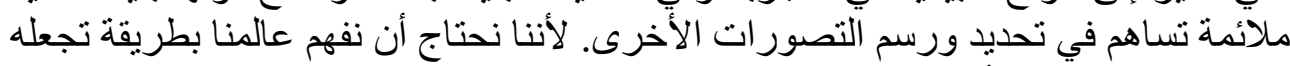

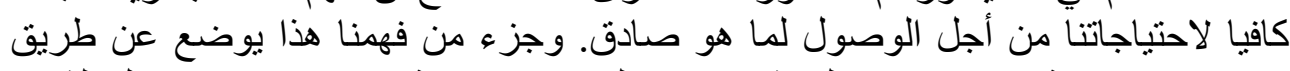

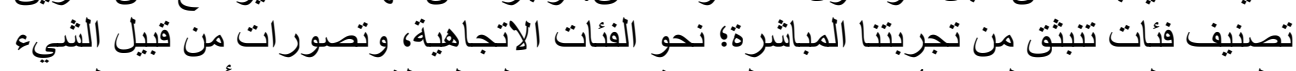

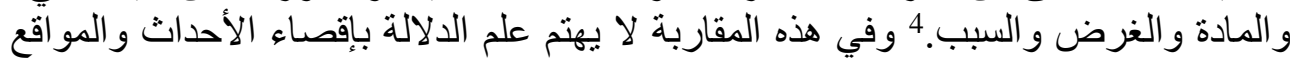

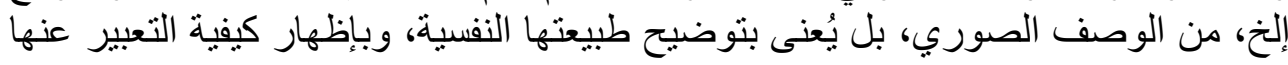
نحويا ومعجميا.

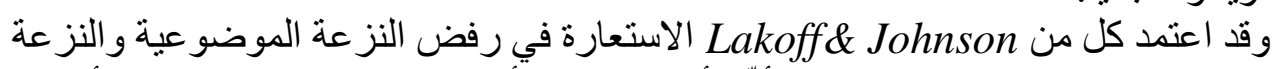

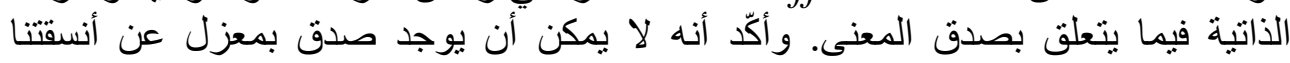

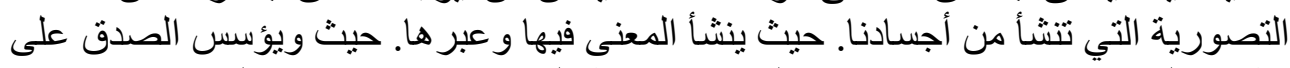

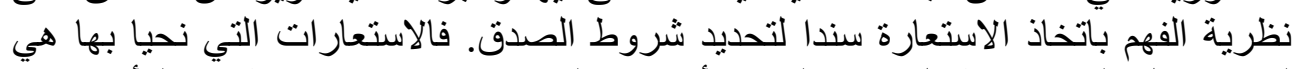

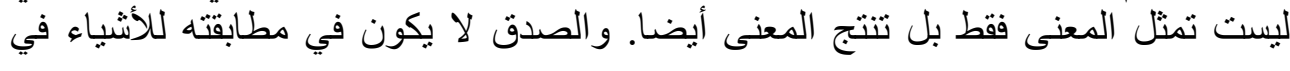

1 ـ يُنظر :لايكوف و جونسن، (Lakoff\& Johnson)، الاستعار ات التي نحيا بها، ص128

2 ـ ـ يُنظر : السبابق:ص133

3

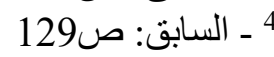

5 ـ ـ اكندوف، رابي صاب(Ray Jackendoff)، علم الدلالة و العرفانية، تر.عبدالرزاق بنور ، المركز

الوطني للترجمة، تونس، (2010)، ص117 
المعنى: من اللغة إلى الذهن فئن إلهن

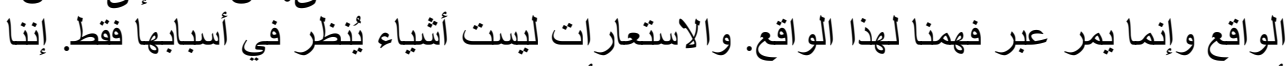

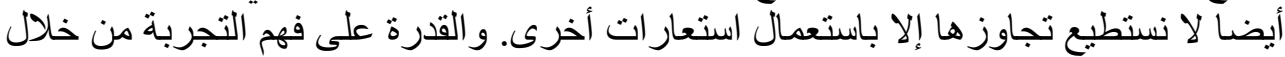

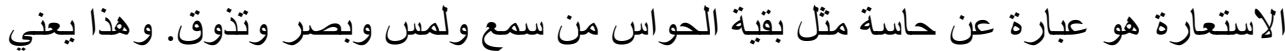

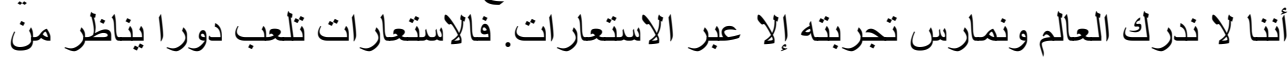

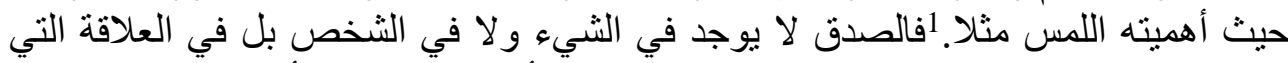

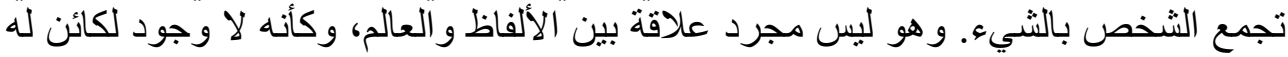

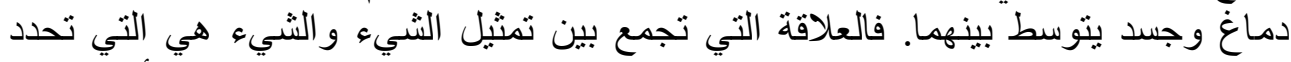

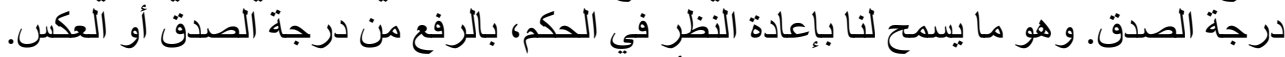

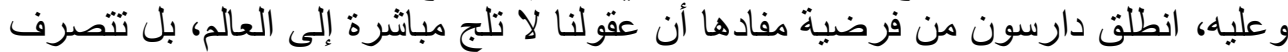

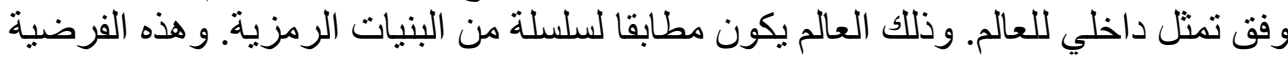

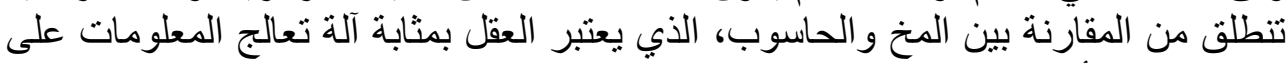

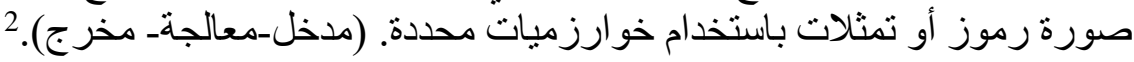

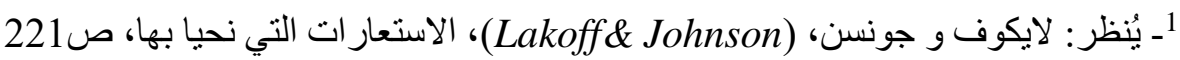

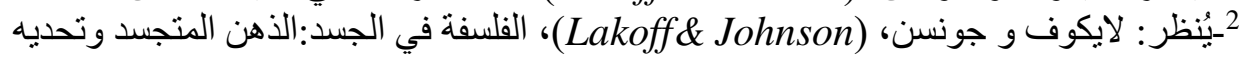

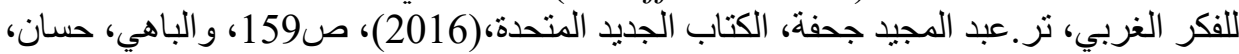
الذكاء الاصطناعي وتحديات مجتمع المعرفة، أفريقيا الثرق، الدار البيضاء، (2012)، ص294- صئ 


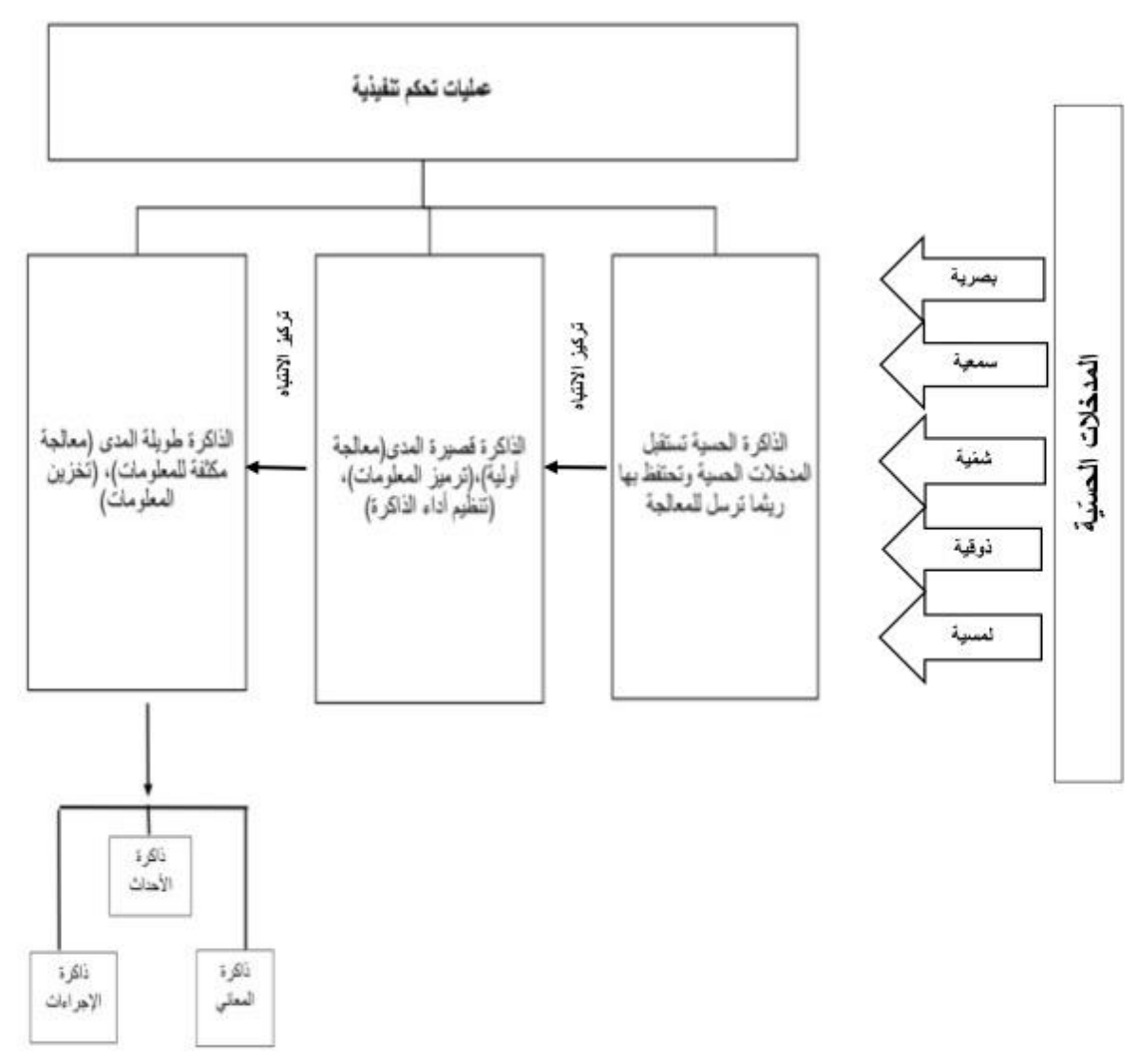

شكل 1

في الرسم الشكل(1) مخطط يوضح آلية معالجة المعرفة في الذاكرة.

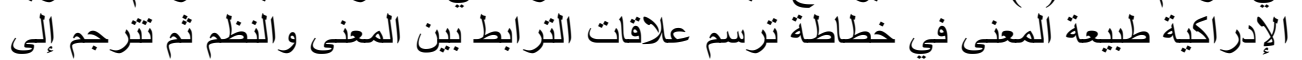

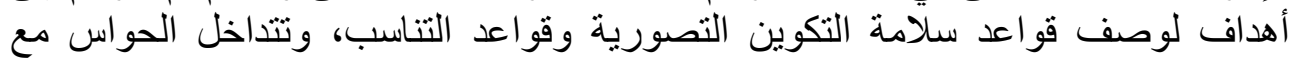

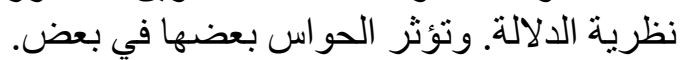

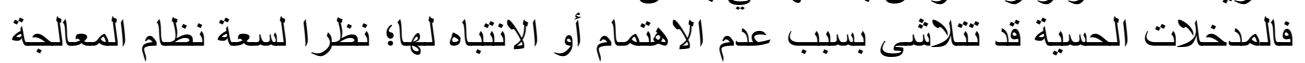

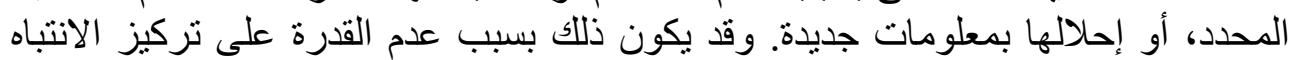

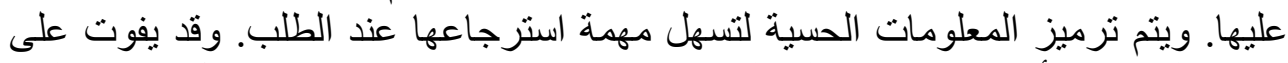

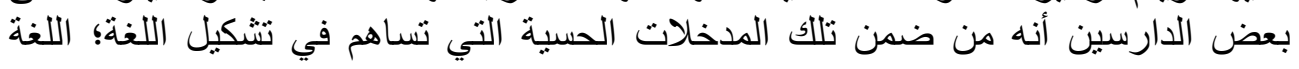

1 ـ يُنظر :الز غلول، علم النفس المعرفي، ص67

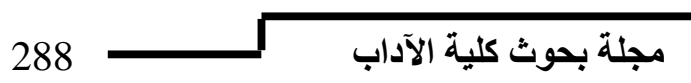


المعنى: من اللغة إلى الذهن دلهن

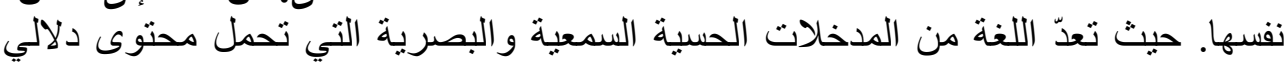
متتوع ينقل تصور الثقافة التي ينشأ فيها الفرد عن العالم. وبذللك تكون اللغة مؤثر في التشكل

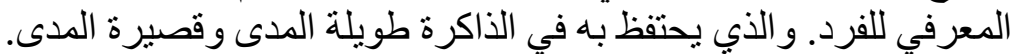

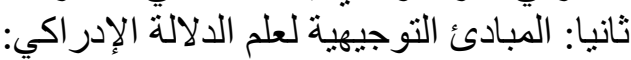

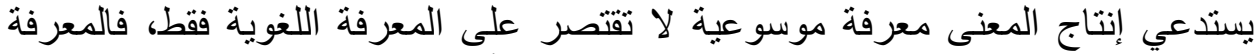

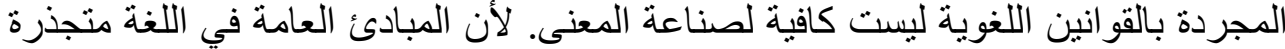

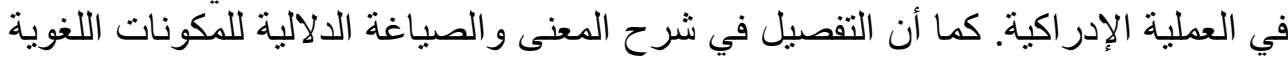

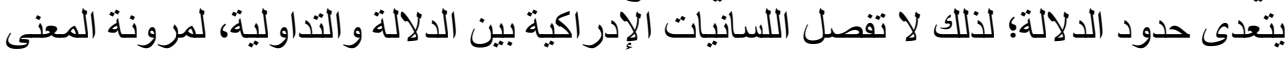

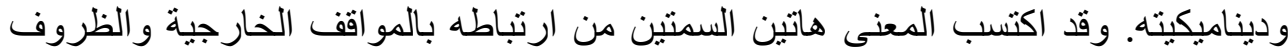

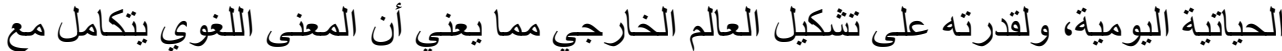

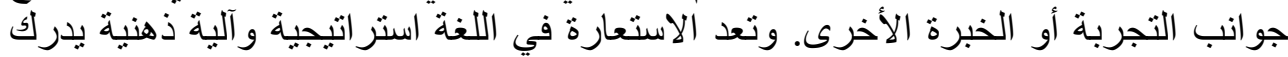

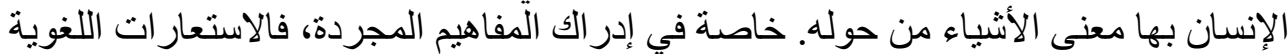

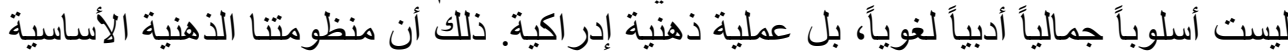

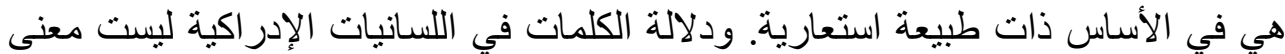

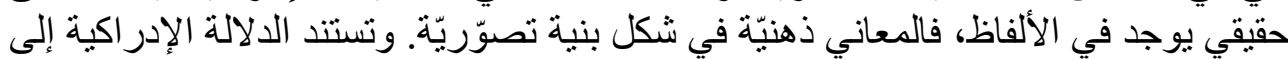

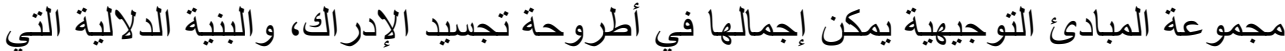
تعكس البنية التصورية، وأخير ا؛ التمثيل الموسو عي للمعنى التهي.

\begin{tabular}{|c|c|}
\hline \multicolumn{2}{|c|}{ المبادئ التوجيهية للدلالة الإدر اكية } \\
\hline توضيحها & المبدأ \\
\hline أن النسدية. النظام المفاهيمي/التصوري ينشأ من التجربة & أطروحة تجسيد الإدر الك. \\
\hline 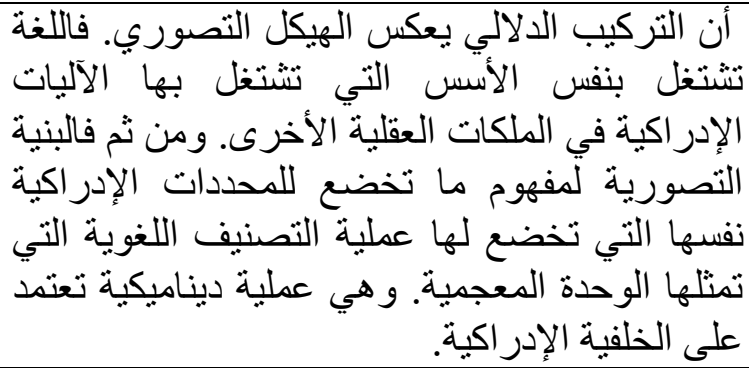 & البنية الدلالية تعكس البنية التصورية. \\
\hline 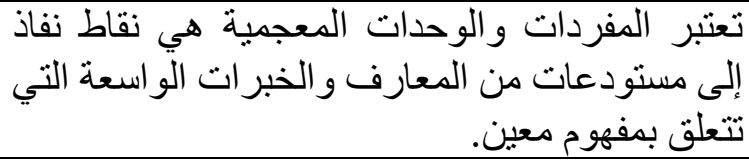 & التمثيل الموسوعي للمعنى. \\
\hline
\end{tabular}

درست الأدبيات الفلسفية القديمة العلاقة بين الفكر والمادة؛ في إطار مشكل الارتباط بين الروح/العقل(الذهن) والجسم/الجسد(الدماغ). وهو المشكل الذي يمكن بسطه كالتالي: هل 


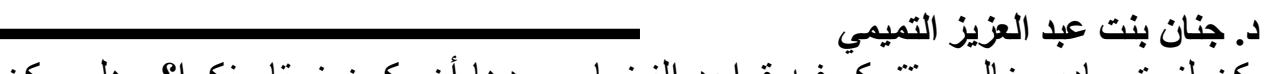

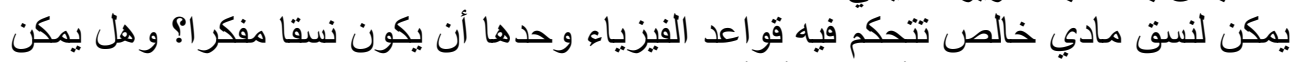

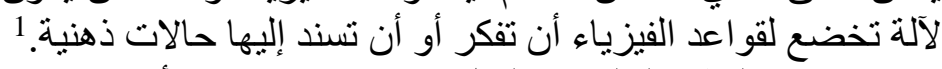

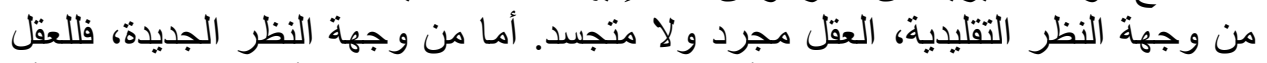

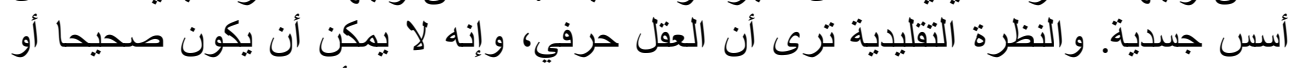

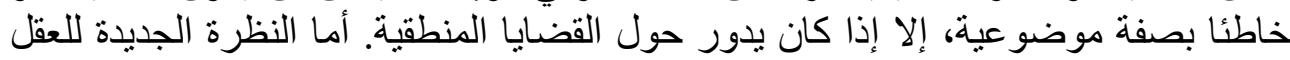

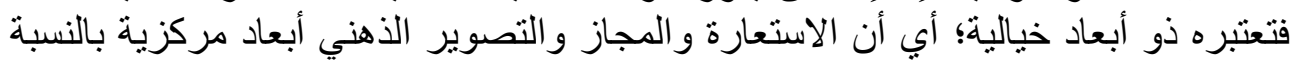

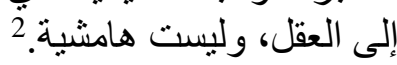

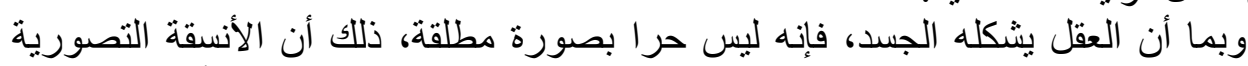

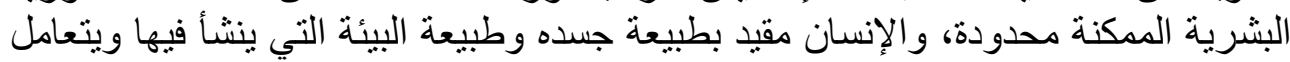

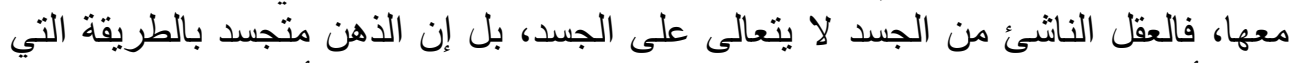

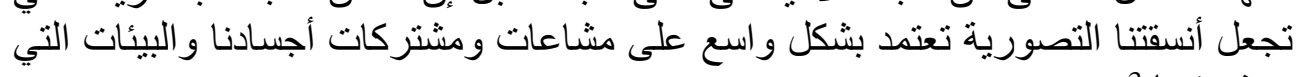
نعيش فيها.

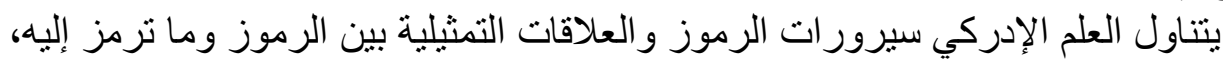

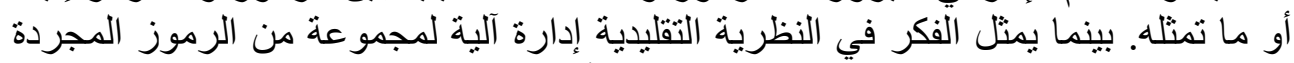

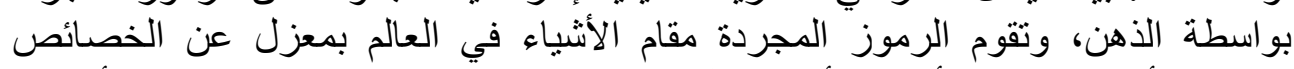

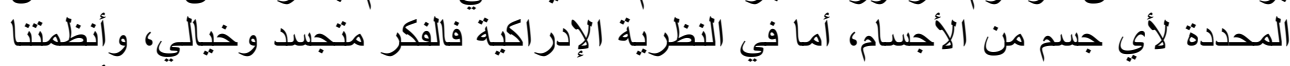

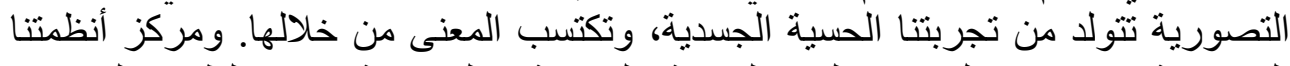

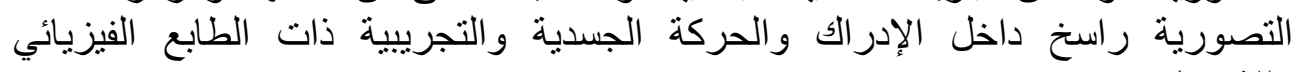
والاجتماعي.

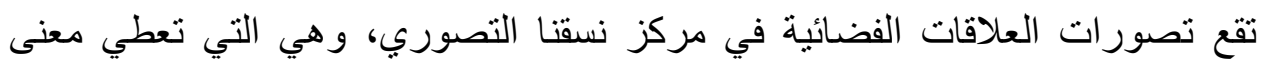

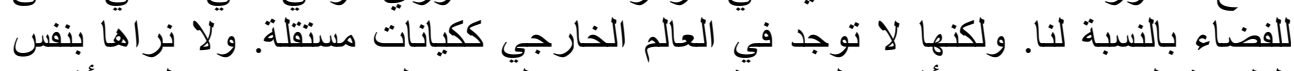

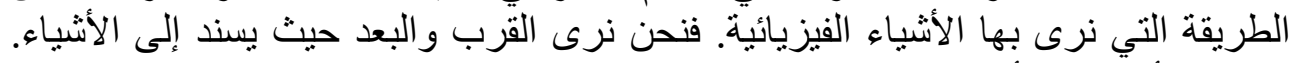

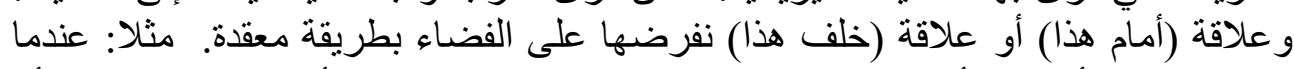

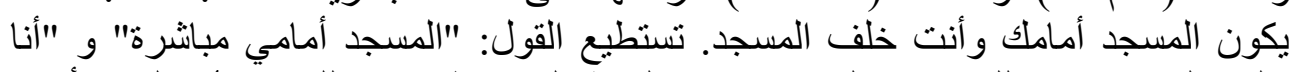

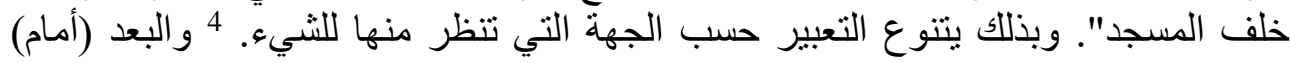

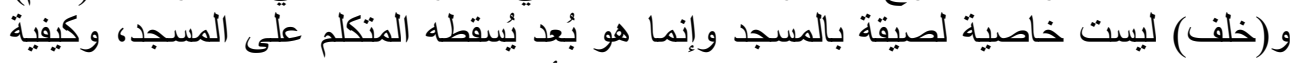
إسقاط هذا البُعد تختلف من شخص لآخر ومن ثقافة لأخرى.

1ـ لايكوف و جونسن، (Lakoff\& Johnson)، الفلسفة في الجسد:الذهن المتجسد وتحديه للفكر

George Lakoff, Women, Fire, and Dangerous Things: What : ئنظر

$$
\text { الغربي، صايكوف صون }
$$

Categories Reveal about the Mind

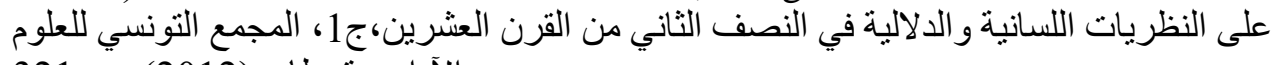

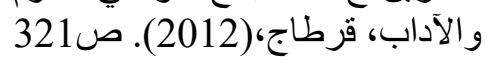

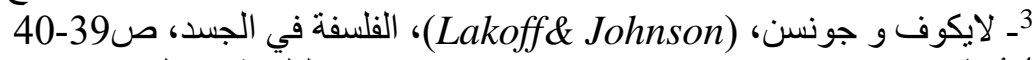

4-يُنظر: لايكوف و جونسن، (Lakoff\& Johnson)، الفلسفة في الجسد ، ص71 صال 
المعنى: من اللغة إلى الأهن

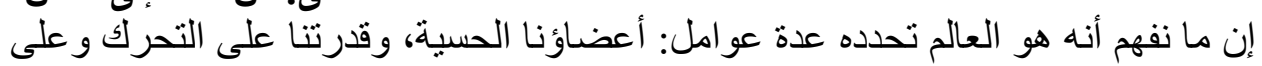

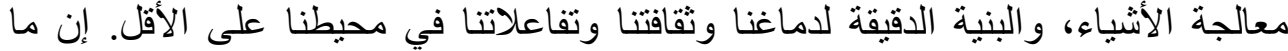

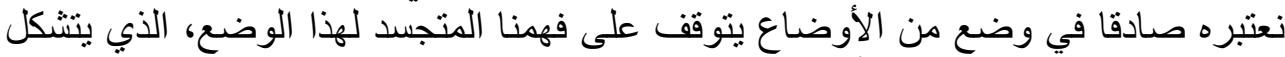

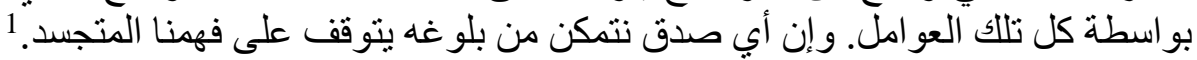
ب- البنية الدلالية تعكس البنية التصورية.

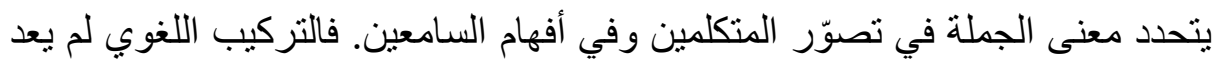

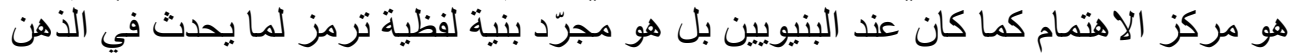
من بنية دلالية تصوّريّة. فلا وجود لكائن تشومسكاوي (نسبة إلى تشومسكي/Chomsky)

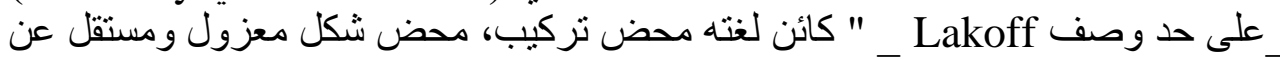

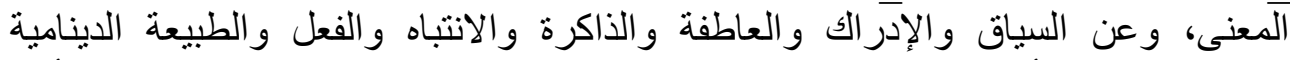

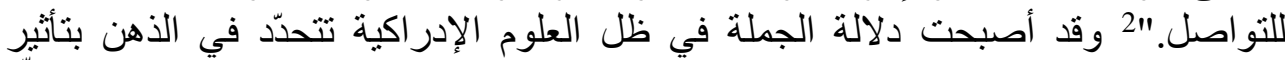

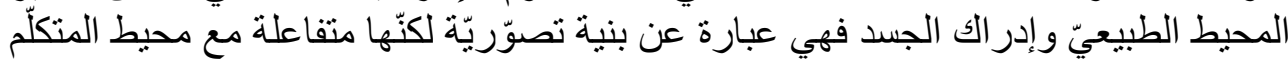
وحضوره المادّي المتجيّي والديّد.

وتتكون البنية الإدراكية من خلاصة خبّة خبرات الفرد الناتجة عن تفاعله مع العوامل البيائية

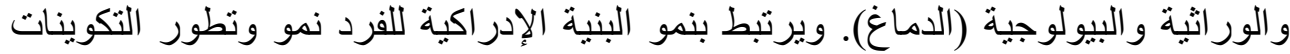

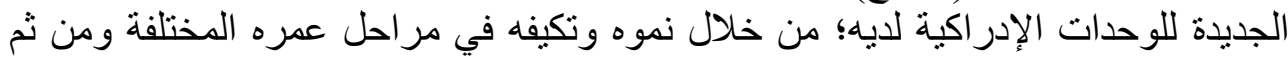

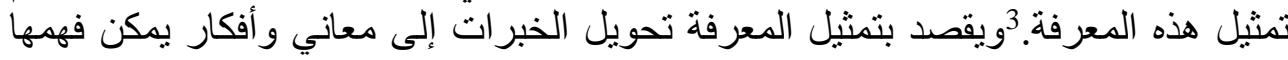

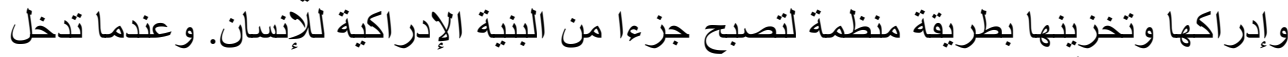

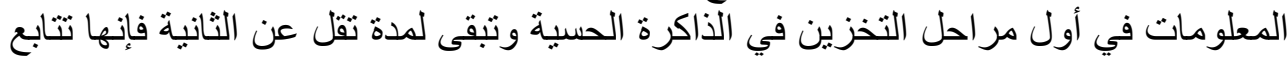

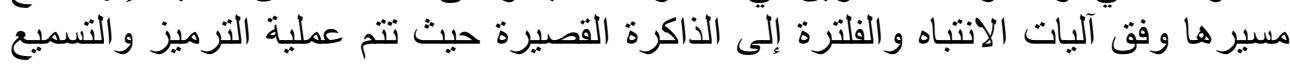

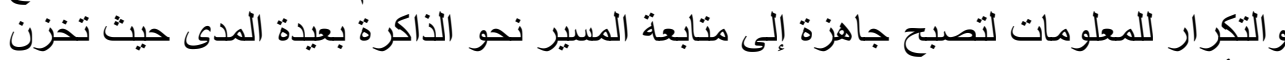
إلى أجل غير مسمى. تشتغل اللغة بنفس الأسس التي تعمل بها الآليات الإدراكية في الملكات العقلية الأخرى.

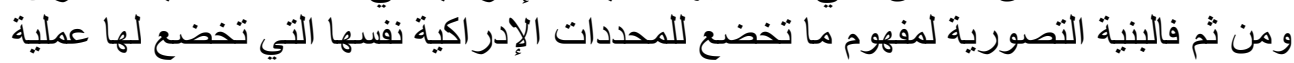

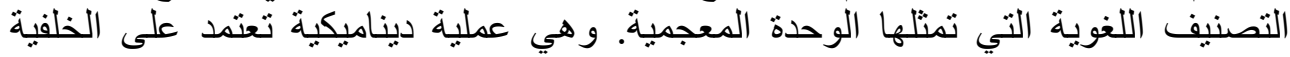

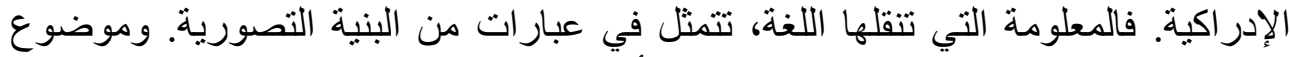

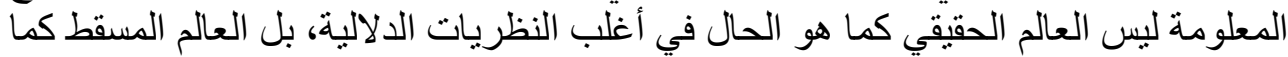

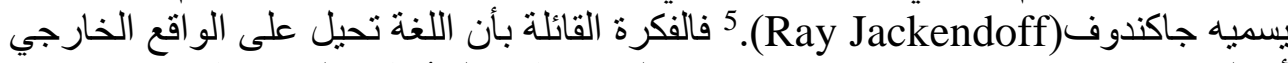
أو الحقيقي غير صحيحة. فإن ما نعرفه هو عالم مسقط، عالم يُنظمه الذهن بطريقة لإنه لا واعية.

1

2

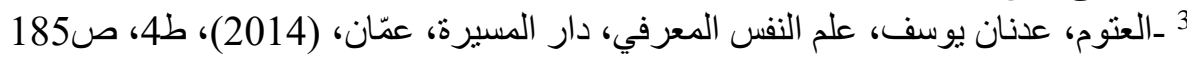

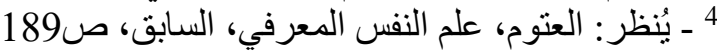

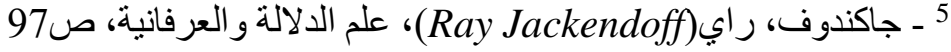


ولا يمكن أن يتحدث عبد العزيز التميمي الإنسان عن الأشياء إلا إذا انتظمت في التمثيل الذهني. فالمعلومات التي

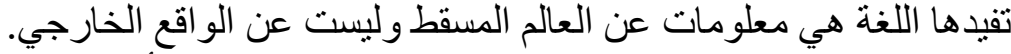

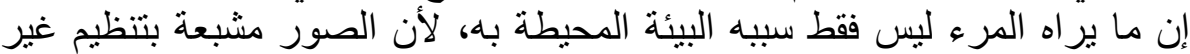

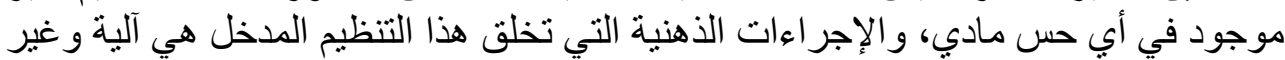

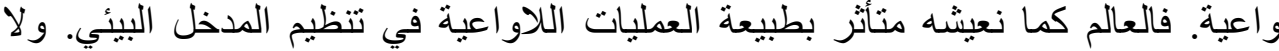

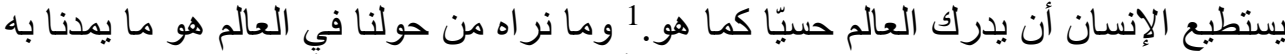

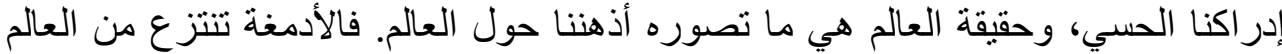

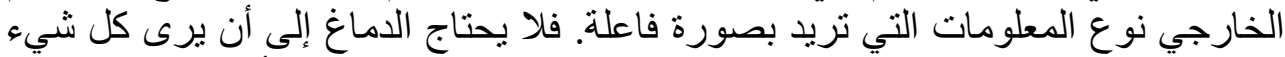

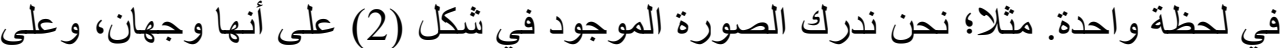

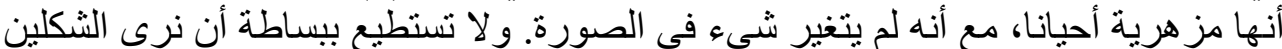

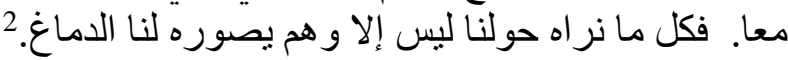

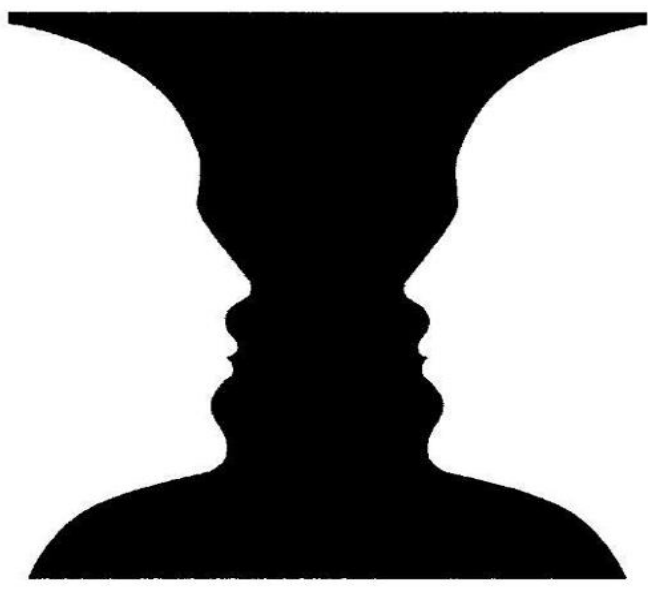

شكل2

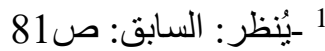

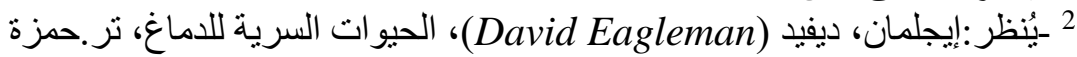
المزيني،جداول، الكويت، (2013)، صيفيد (56 مجلة بحوث كلية الآداب 


\section{المعنى: من اللغة إلى الذهن}

\section{شكل3}

وتبدو النقاط الأربع في الثكل (3 ) مربعا، رغم غياب أي رابط خطي ظاهر بين تلك النقاط،

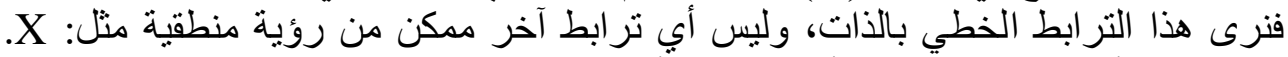

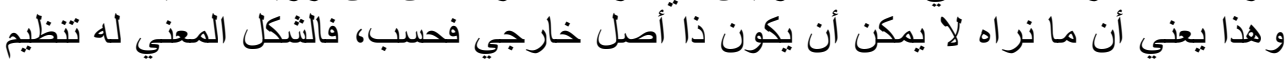

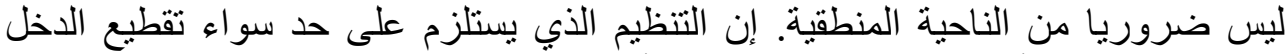

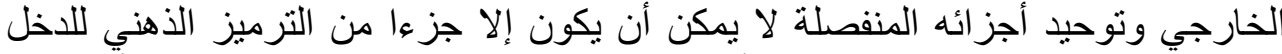

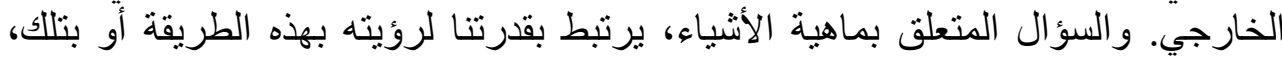

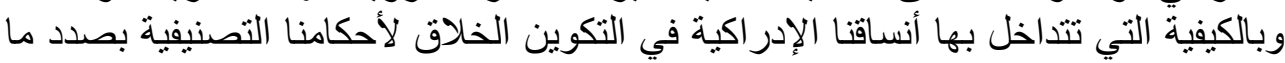
نز 1.0

تفسر الدلالة في ظل العلوم الإدراكية بشكل مباشر كيف يعكس الثكل التركيبي في اللغة

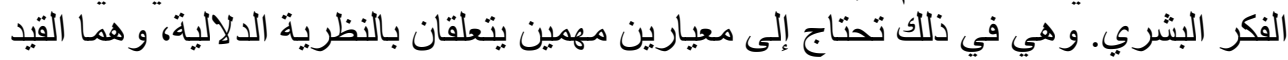
النحوي، و القيد الإدري. واكي.

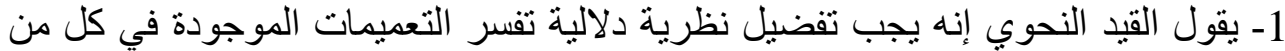
المعجم والتركيب، على اعتبار أن المعجم يعطينا المحتوى، ولئه التركيب يعطينا الثكل الصوري الملائم لذلك المحتوى. على اعنار

2- يقول القيد الإدر اكي إن نظرية البنية الدالالية في اللغة الطبيعية هي في ذاتها نظرية لبنية التفكير، وجز القيد من القدر ات الإدر اكية الثاملة لإى الإنسان.

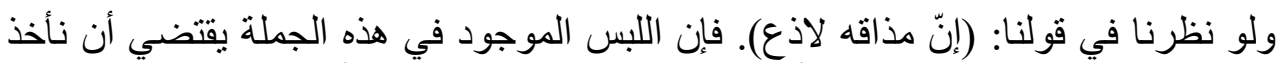

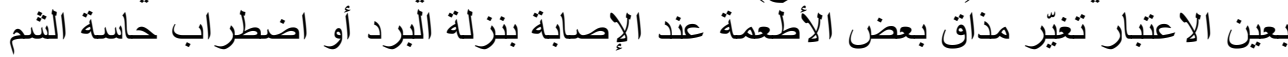

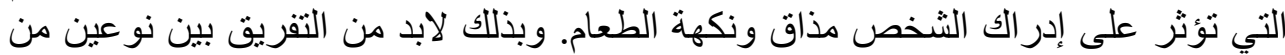
الو آقع: الو اقع الذهني، و الذر الو اقع الخارجي.

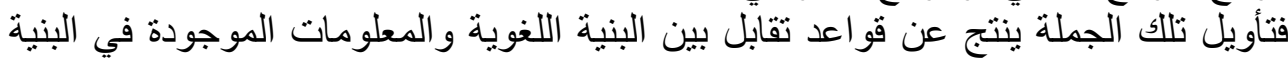

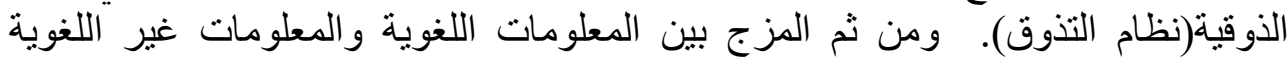

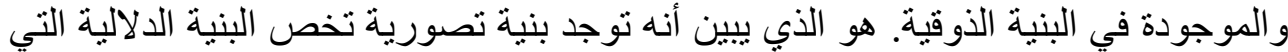

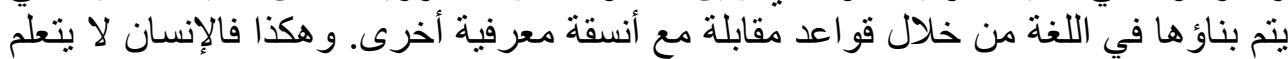

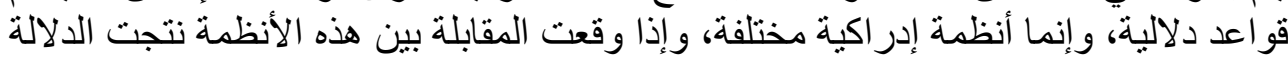
التي نر غب فيها.

ويسلك المعنى خطاطات معينة تشكّلها العمليات الإدر اكية الذهنية المتعددة و المتو اصلة

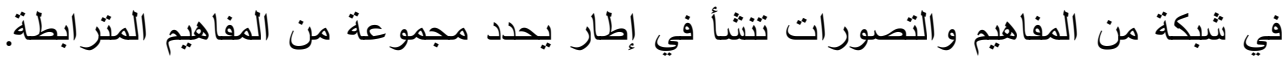

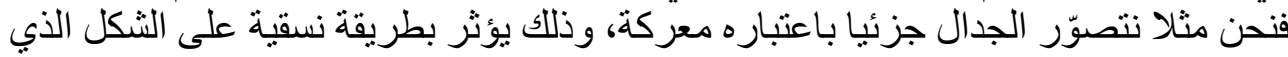

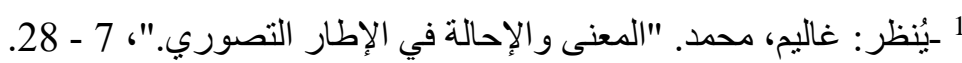
2 ـ ـُينظر : جحفة، عبدالمجيد، مدخل إلى الدلالة الحديثة، دار توبقال، الدار البيضاء، (2014)،

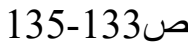

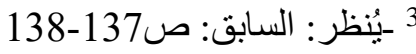




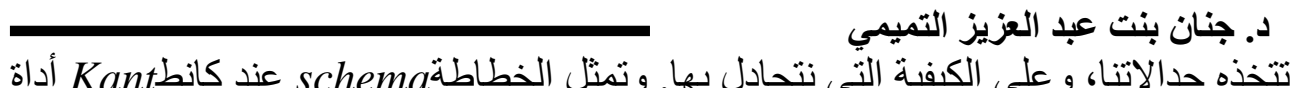

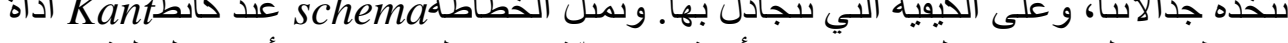

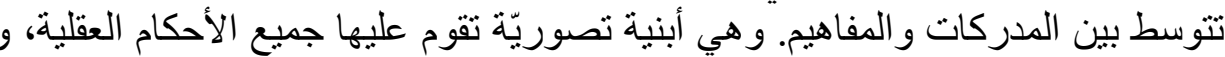

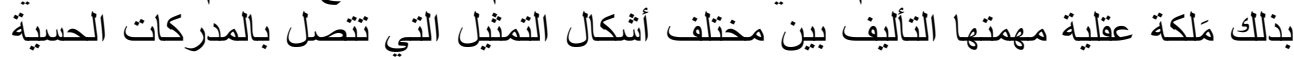

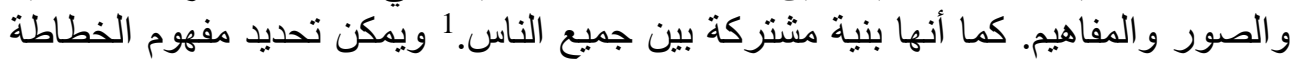

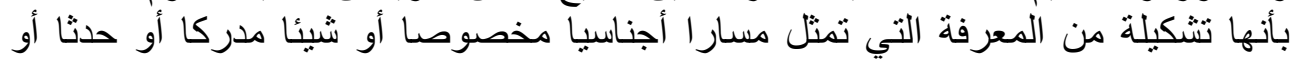

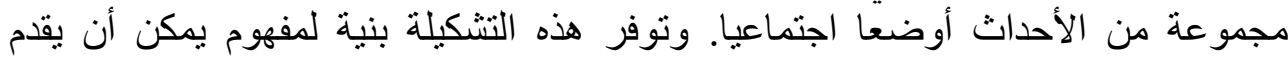

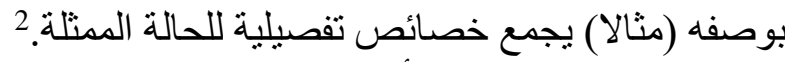

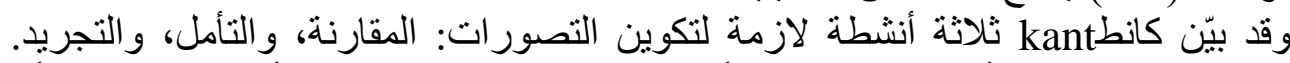

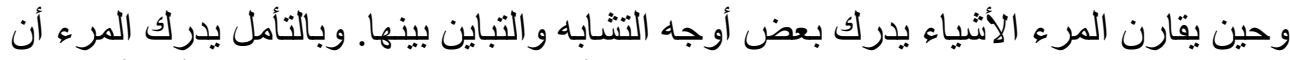

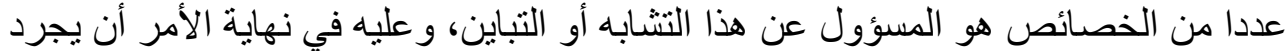

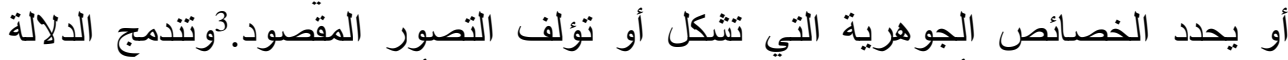

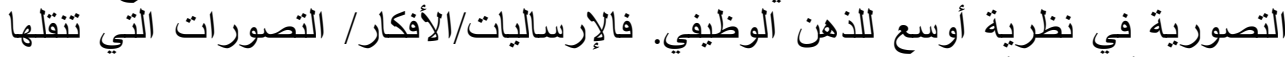

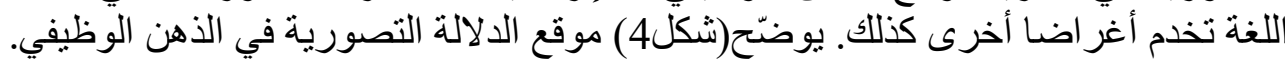

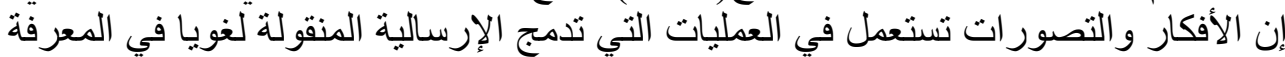

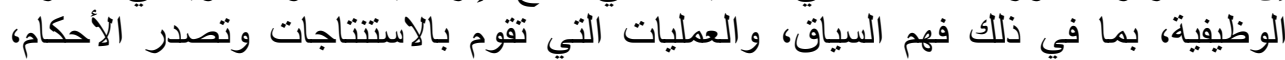

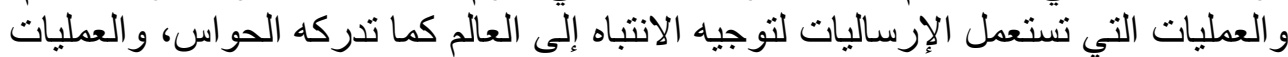

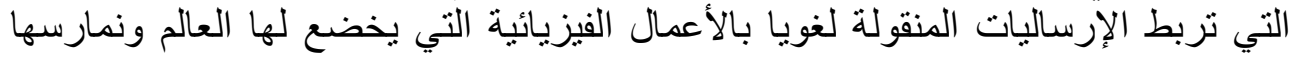

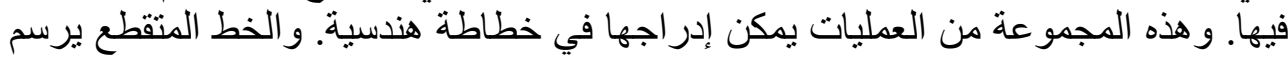

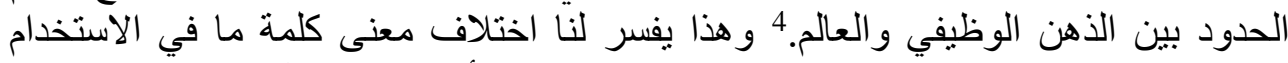

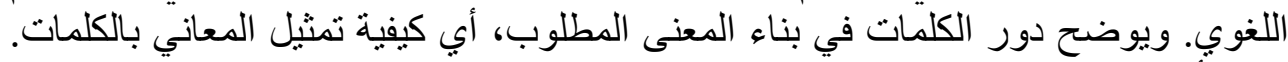

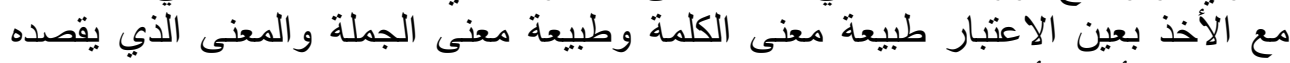

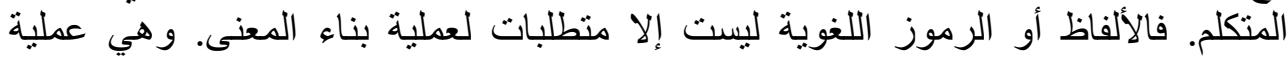

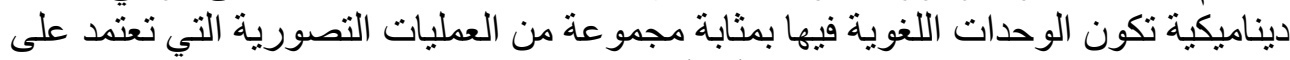

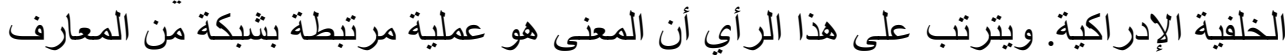

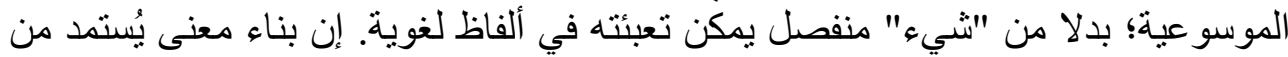

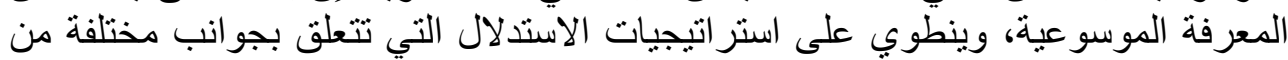

البنية التصورية.5 التوبو

$$
\begin{aligned}
& 1 \\
& 2 \text { ــيُنظر : الحبطر : الشناد، صابر، في المعنى: مباحث دلالية معرفية، المركز الثقافي العربي، الدار }
\end{aligned}
$$

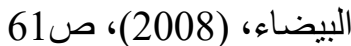

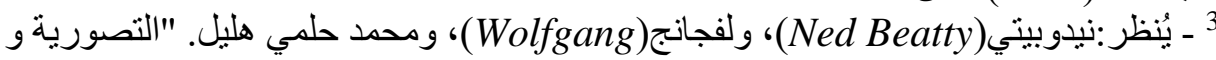

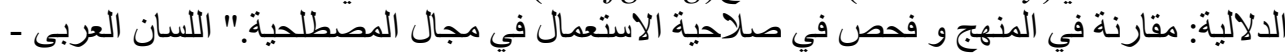
المغرب ع 29 (1987): 110 - 110

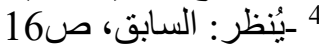

Evans: Vyvyan\& Green: Melanie(2006) Cognitive Linguistics: An 5 introductions, Edinburgh University Press Ltd,p.162 
المعنى: من اللغة إلى الذهن

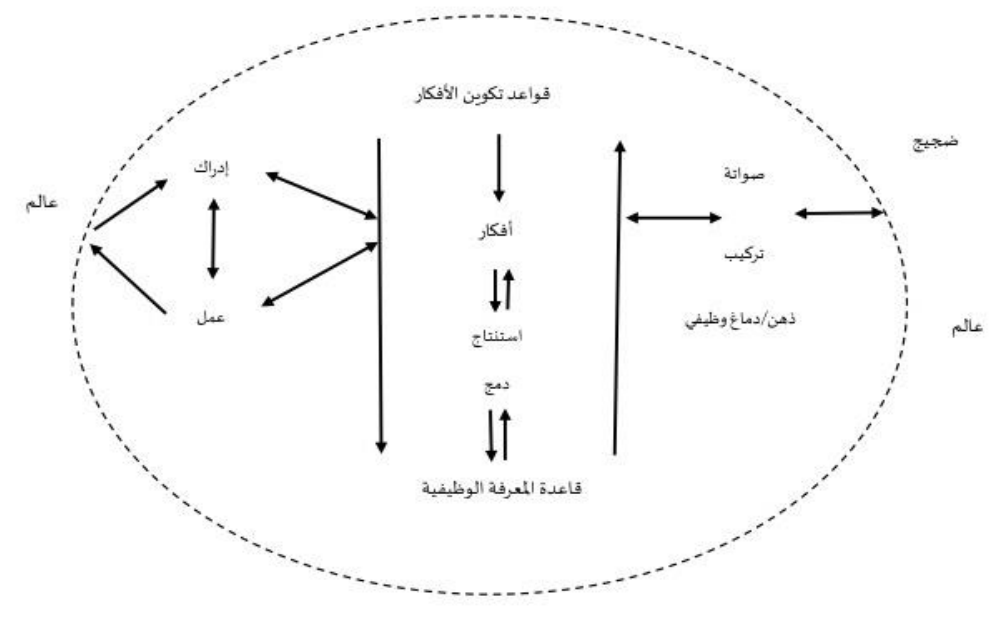

شكل 14

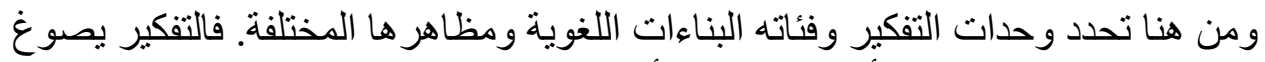

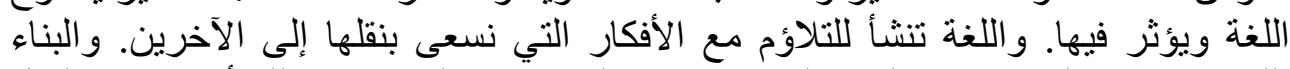

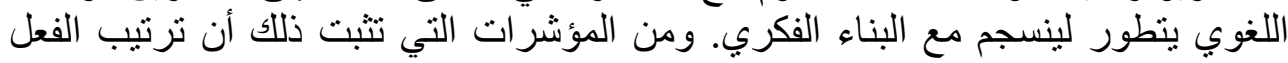

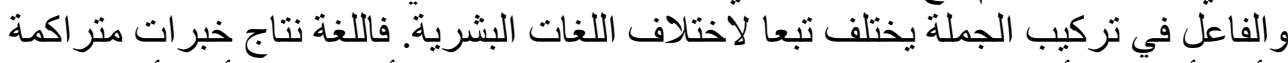

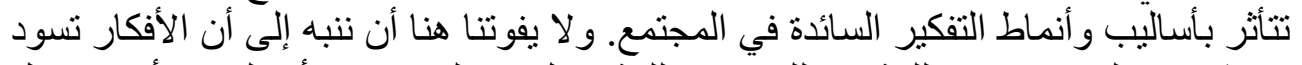

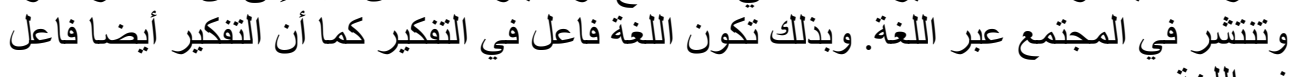
في اللغة. جـ- التمثيل الموسو عي للمعني: حين يمثل القاموس مصديل المورا لمعرفة المعني المعنى اللغوي، يمثل المعنى الموسوعي نموذجا لنظام

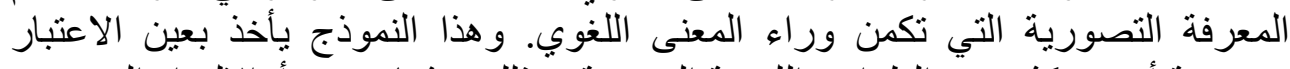

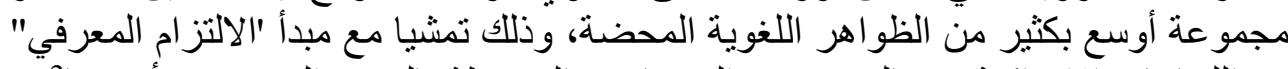

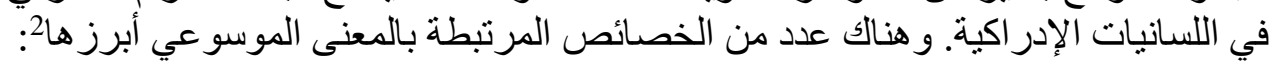

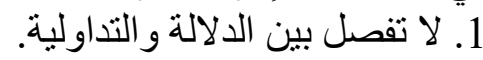
2. المعرفة الموسو عية بنية منظمة. لالية. 3. هنالك فرق بين المعنى الموسوعي ولة والمعنى السياقي.

1 - جاكندوف، راي(Ray Jackendoff)، وآخرون، دلالة اللغة وتصميمها، ص12 : 2 - يُنظر : Evans: Vyvyan \& Green: Melanie, Cognitive Linguistics: An introductions, Edinburgh University Press Ltd,(2006),P.215 


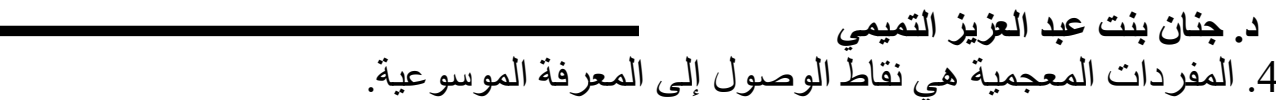

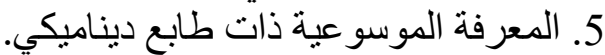

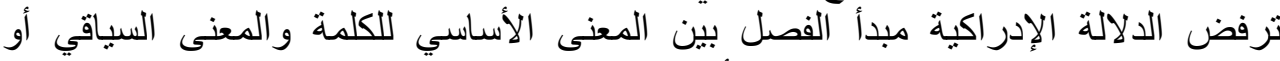

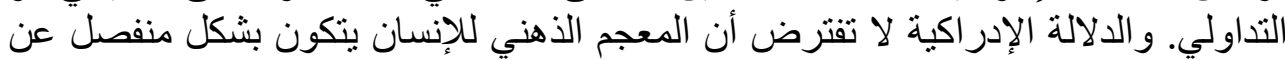

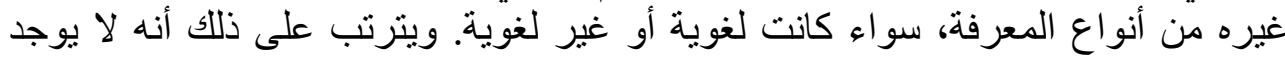

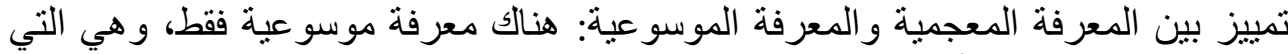
تضم ما نسميه بالمعجم أو القاموس. 1

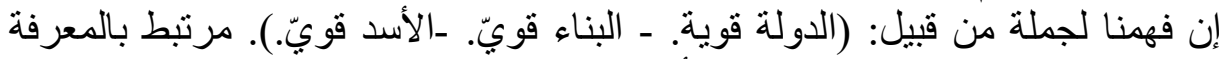

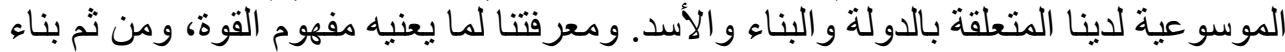

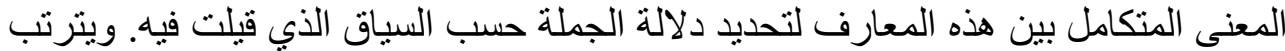

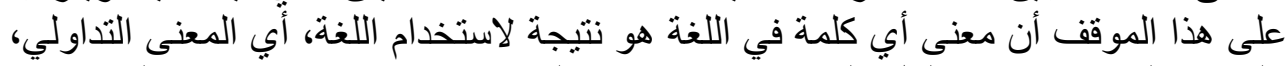

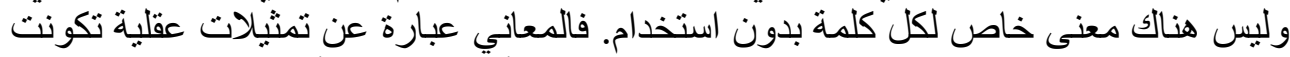

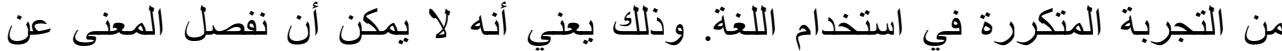

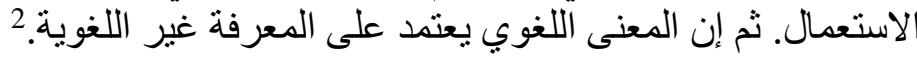

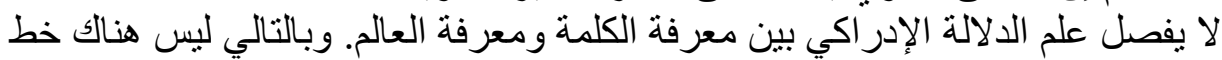

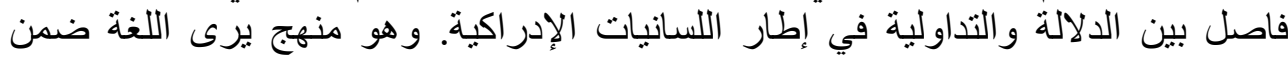

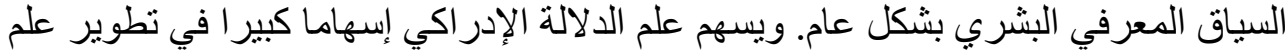

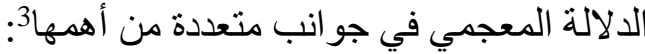

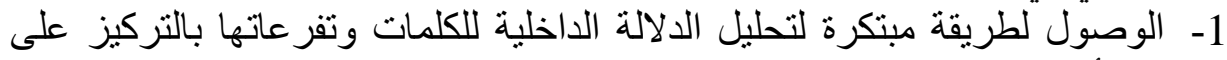

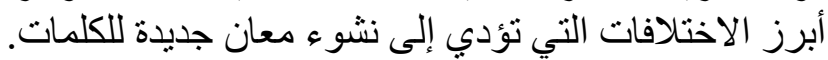

2- تجديد الاهتمام بالعلاقات الدلالية بين عناصر البنية الدلالية في إعادة النظر إلى بلى مفهوم الاستعارة و الكناية و التفاعل بينهما.

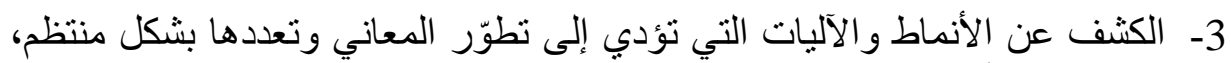

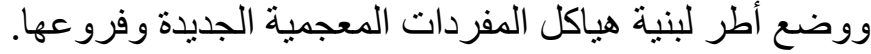

4- توضح نماذج شبكة المفاهيم في علم الدلالة الإدر اكي الطريقة التي يفهم بها العقل

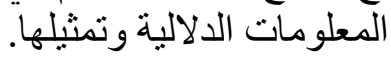

P.216: بـ يُنظر :السابق:P.

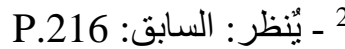

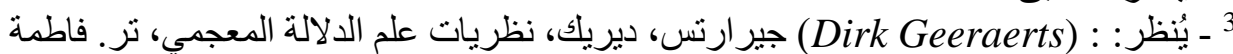

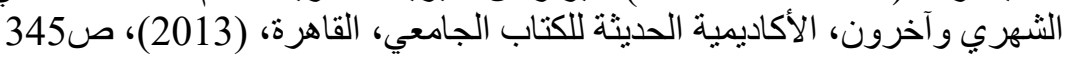


المعنى: من اللغة إلى الأهن

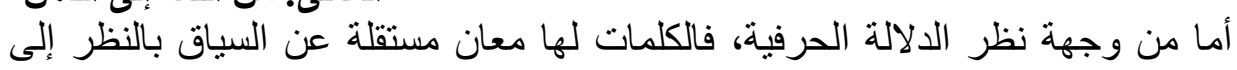

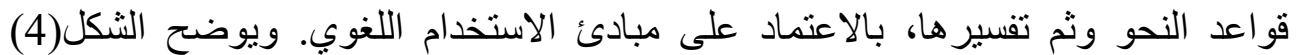

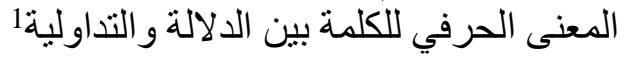

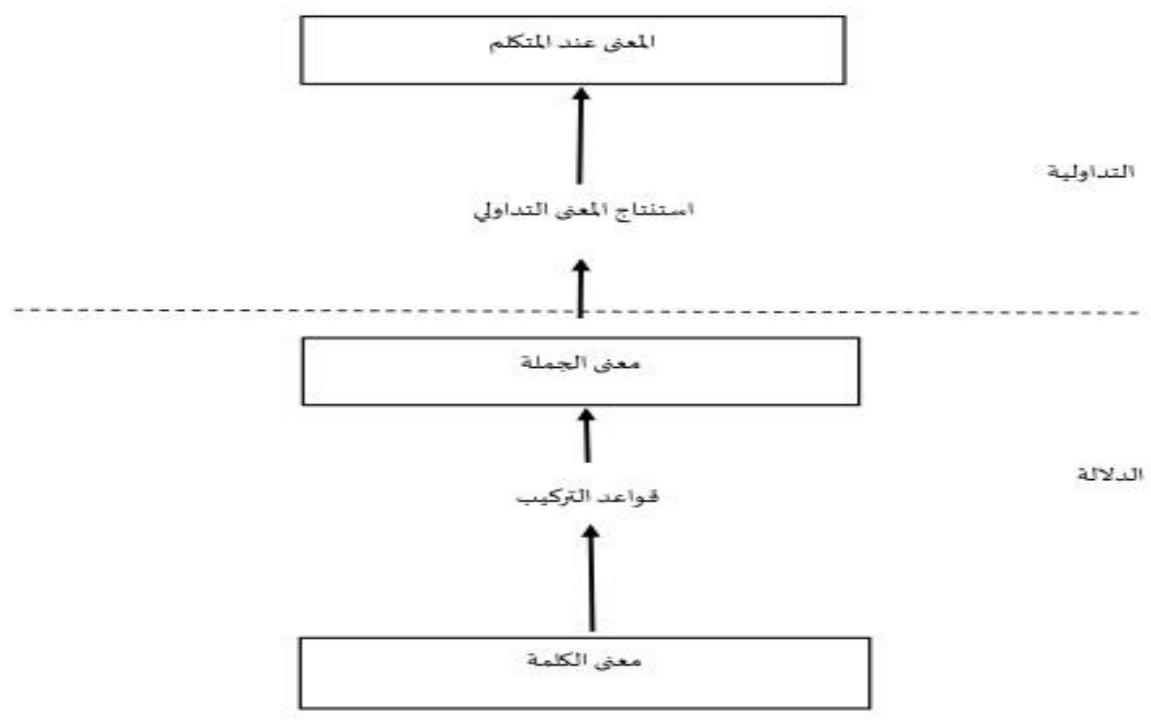

شكل(4) الدلالة الحرفية

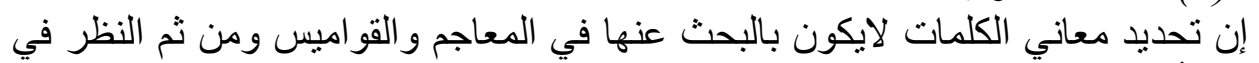

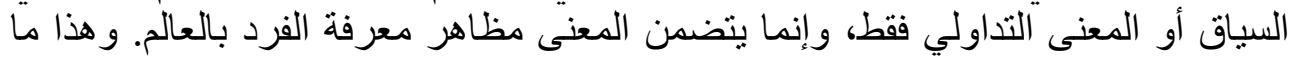

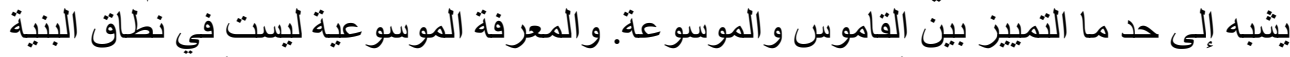

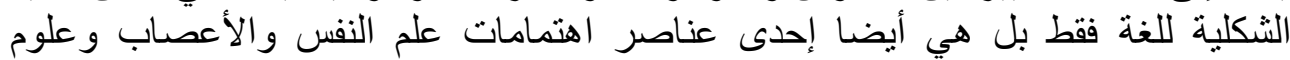

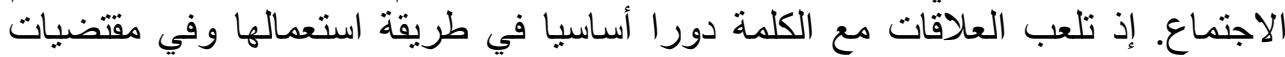
تكرارها. وترتبط آلية بناء الذاكرة المعجمية بكيفيات التمييز بين الموقف حول الكلمة،

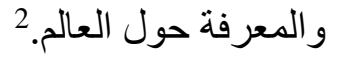

Evans, Vyvyan, How words mean, Oxford University 1 Press,(2009),P.8 2 ــيُنظر : ز غبوش، بنعيسى، الذاكرة و اللغة، عالم الكتب الحديث، إربد، (2008)، ص93 


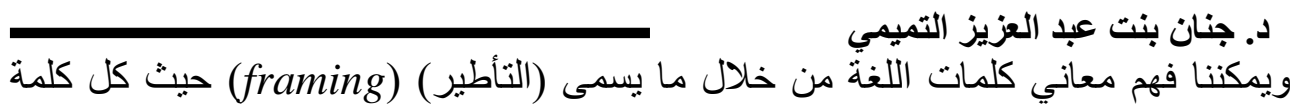

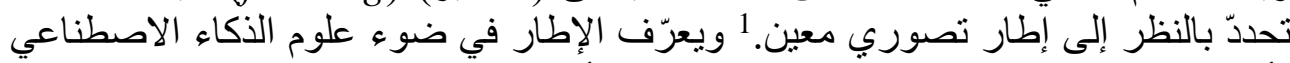

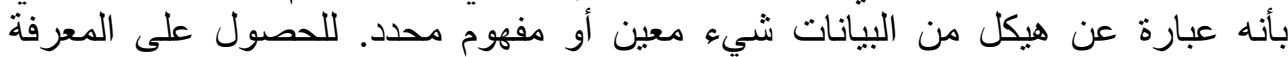

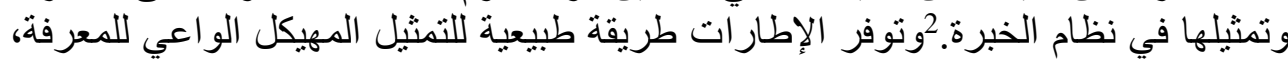

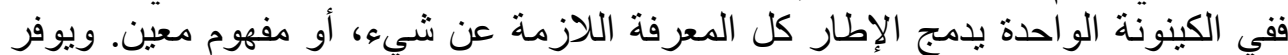

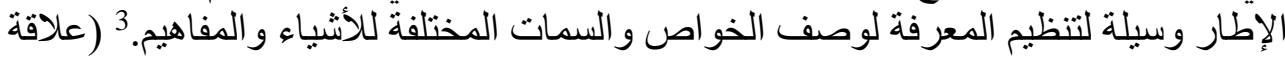

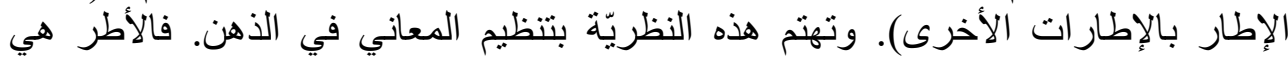

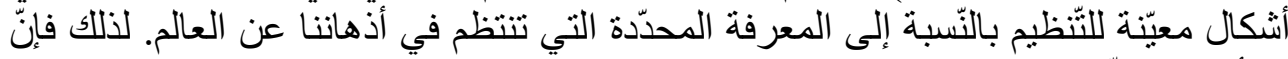
"الأطر " تشكّل جز عاء من ذاكرتنا الدّلاليّة.

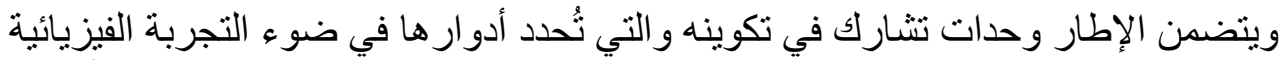

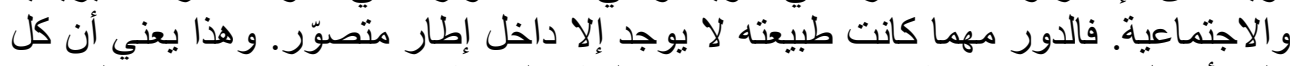

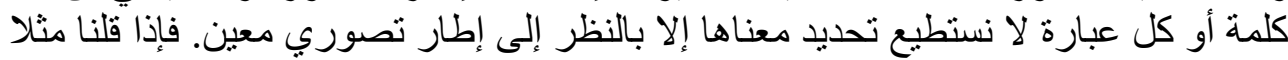

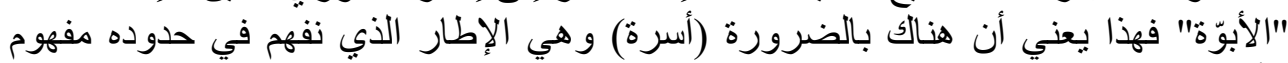

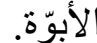

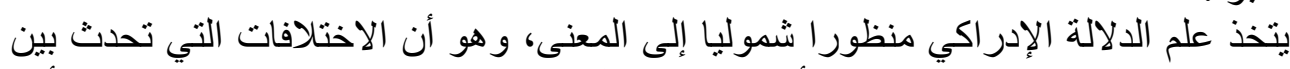

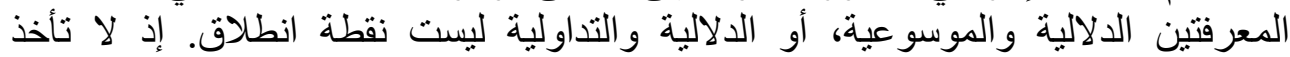

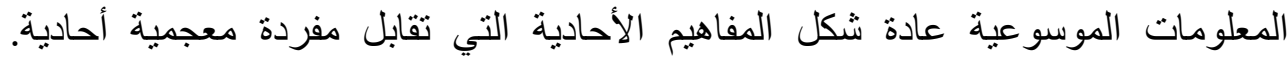

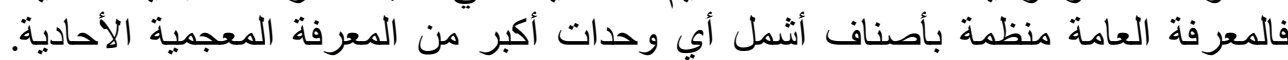

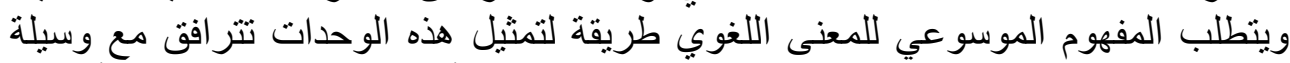

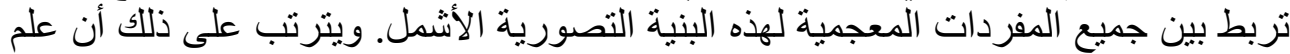

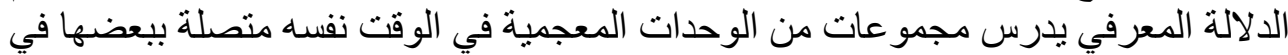

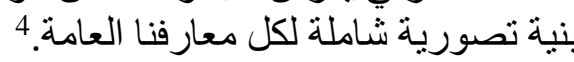

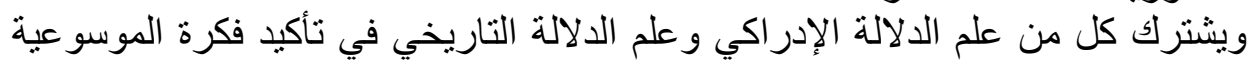

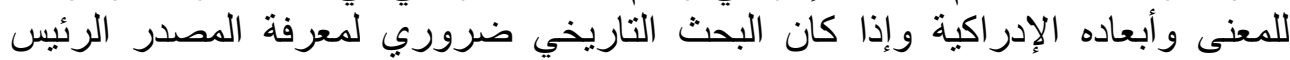

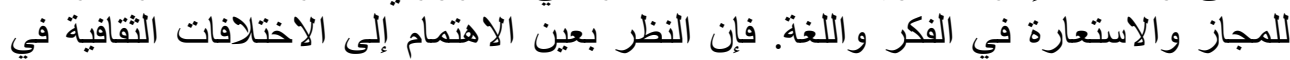

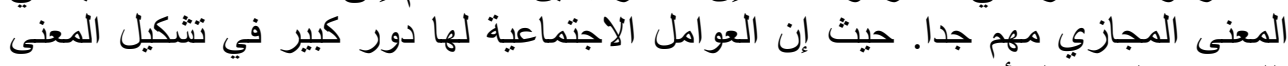
اللغوي. و المعنى لله أبعاد تاريخية وثقافية واجنماعية.

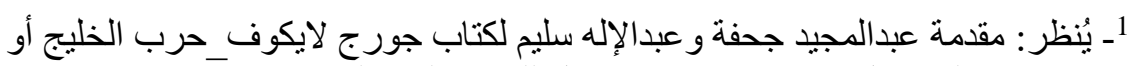

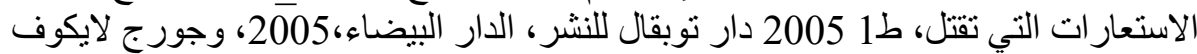

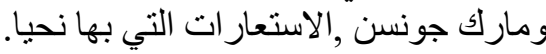

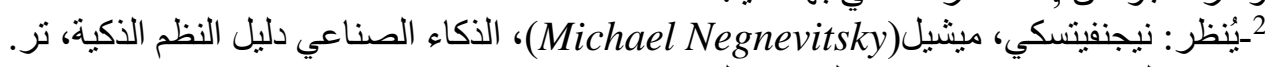
سرور علي إبر اهيم سرور، دار المريخ، الرياض، (2004)، ص203 3

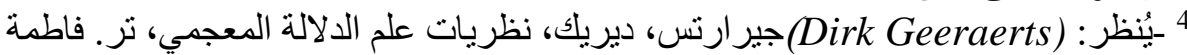

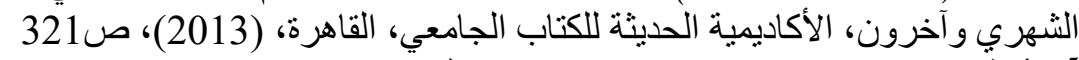

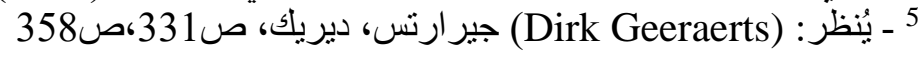




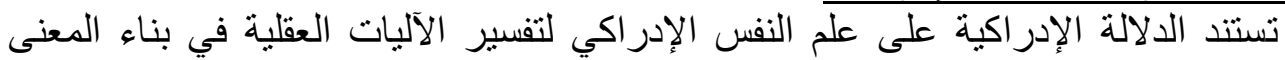

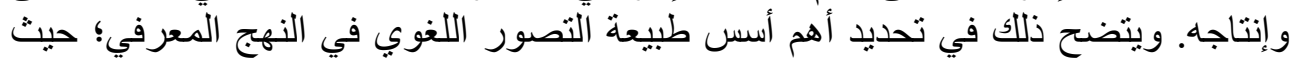

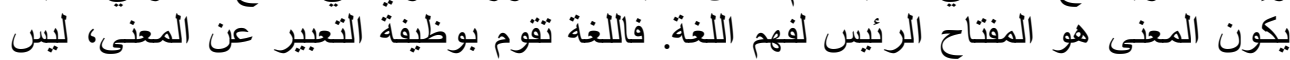
بوصفه محتوى سابقا يحمله و عاء الألفاظ، و إنما بوصفيه عملية دينامية يتشار كو فيها الاستقبال المعرفي والتمثيل التصوري. ويرى (Lakoff) أن هناك التزاماً أساسياً في اللسانيات

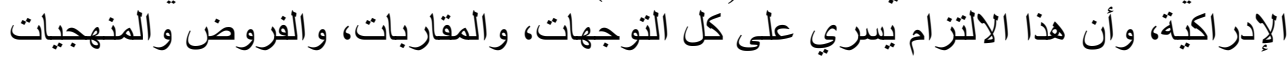

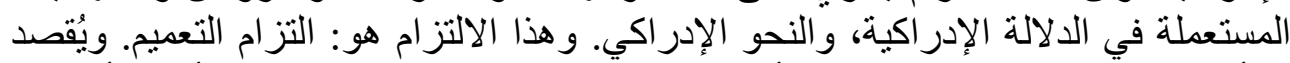

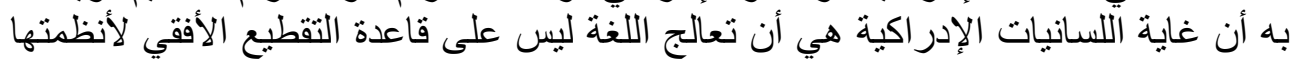

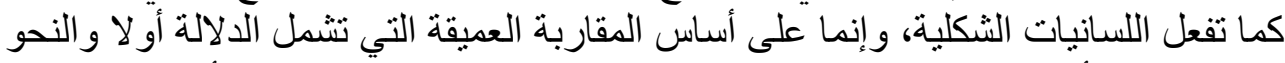

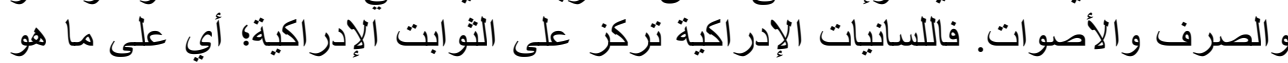

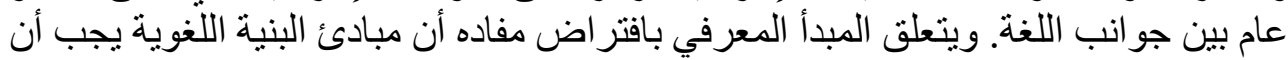

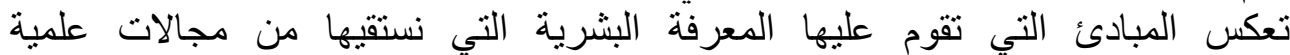

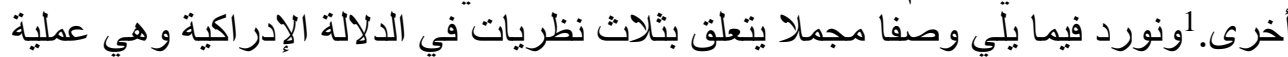

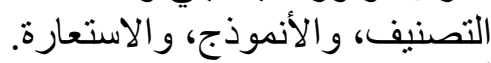
أـ عملية التصنيف categorization

يقول الخليل: "التَّصنيف: تمييز الأشياءِ بعضها عن بعض"2. وتعدّ عملية التصنيف آلية

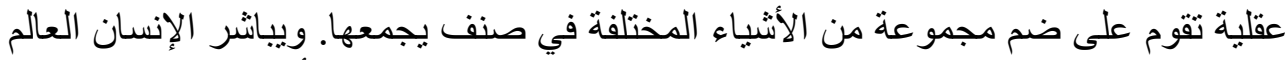

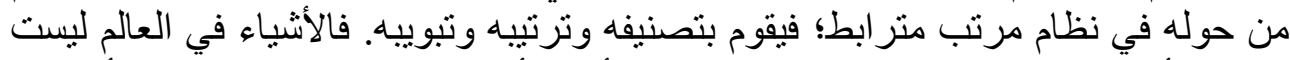

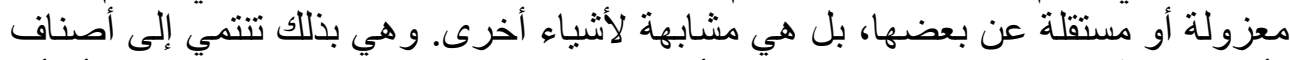

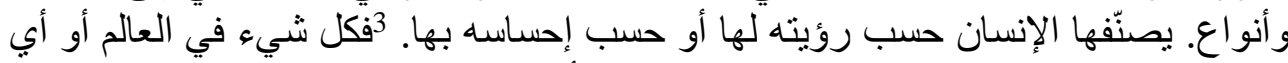

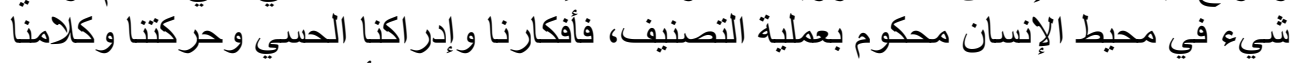

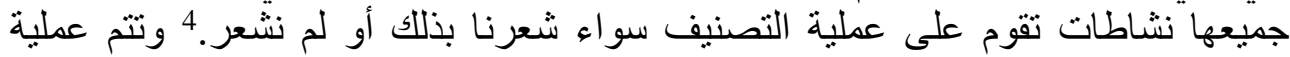

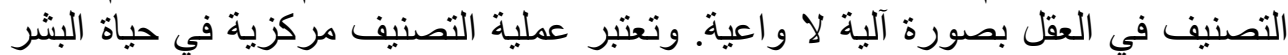

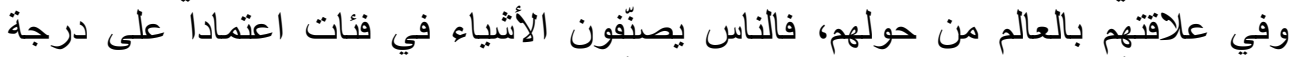

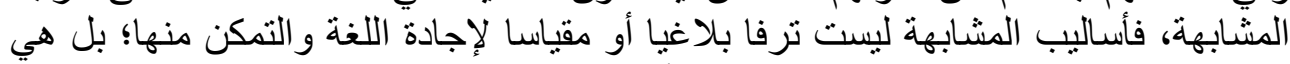

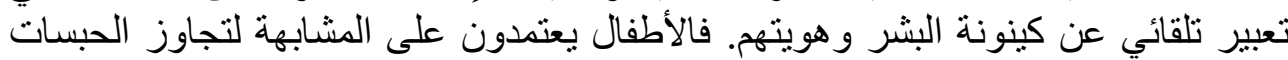

1 ــلمزيد من التفصيل راجع: د. محي الدين محسب : "منهجية در اسة الاستعارة من الأساس اللغوي إلى التأسيس الإدر اكي" في كتاب الندوة الدولية : قضايا المنهج في الدراسات اللئ اللغوية و الأدبية:

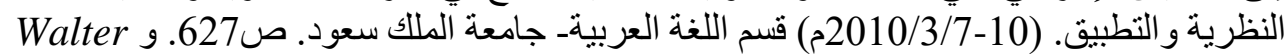
http:/Www.intelligent-systems.com.ar عritz

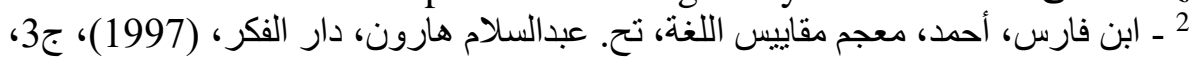

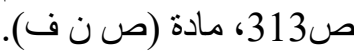

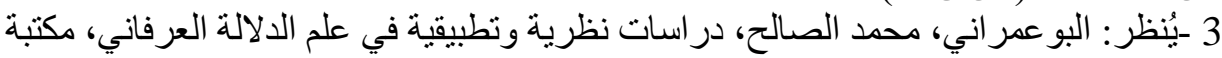

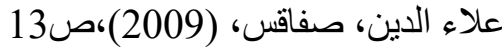

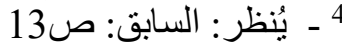




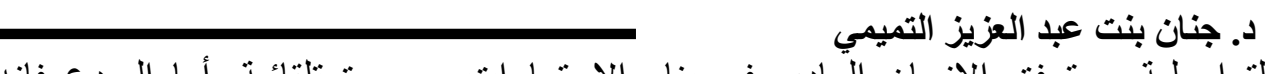

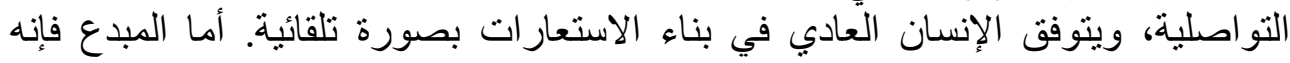

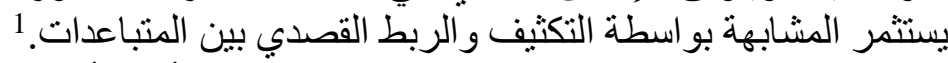

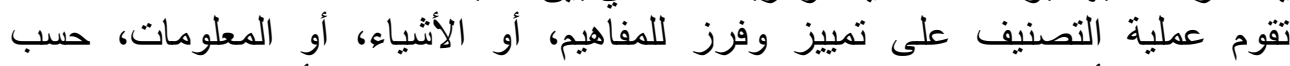

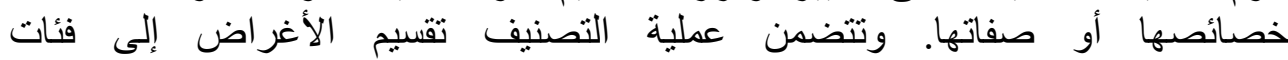

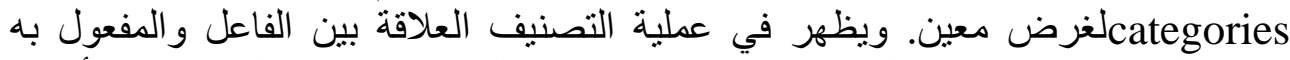

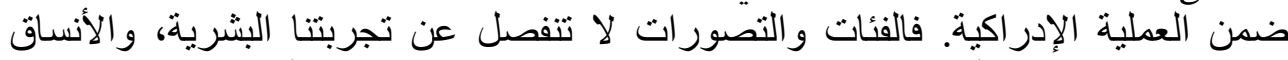

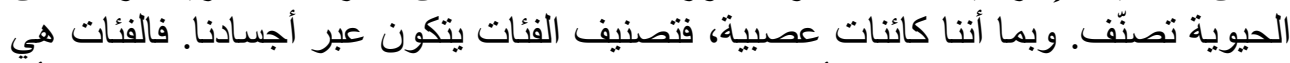

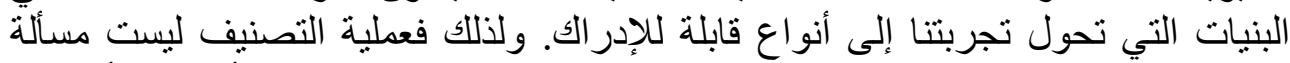

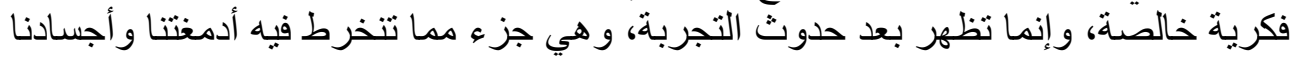

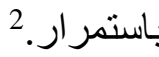
تستقبل الذاكرة بعيدة المدى المعلومات المرمزة والتي تتحول التحول إلى تمثيلات عقلية معينة من

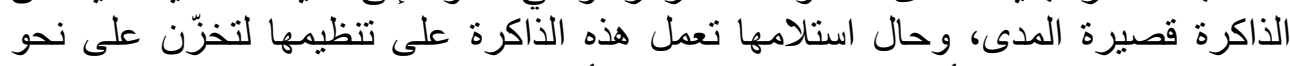

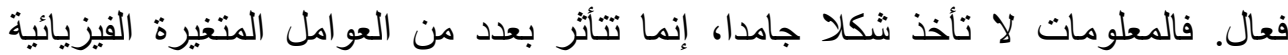

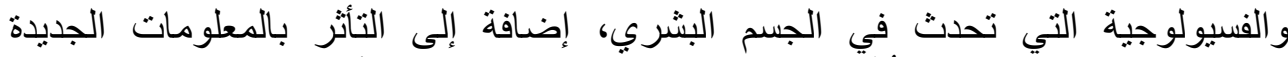

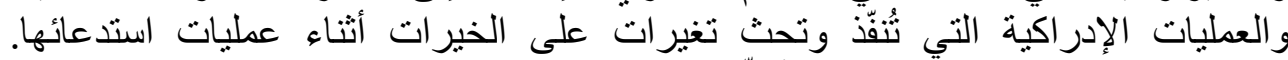

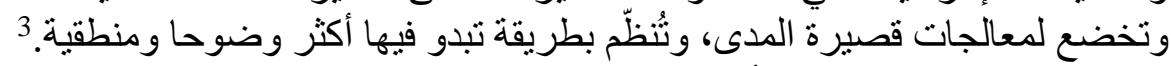

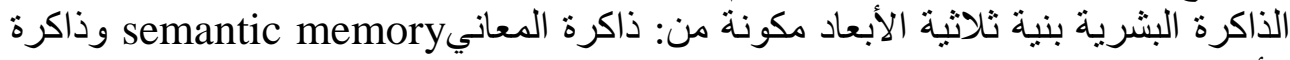

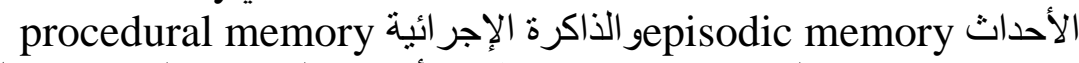

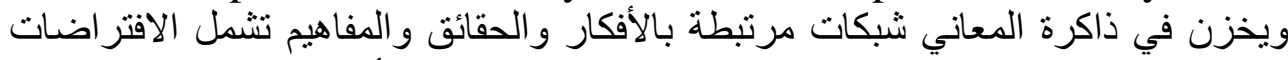

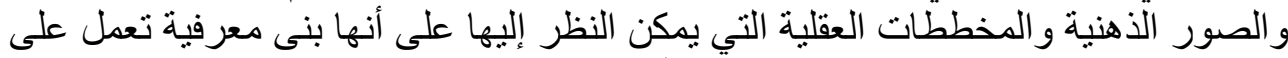

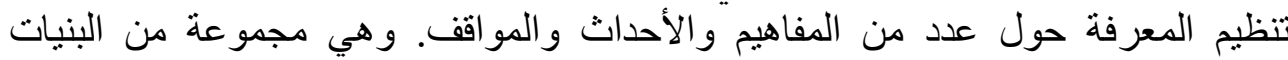

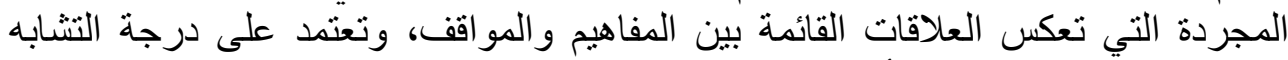

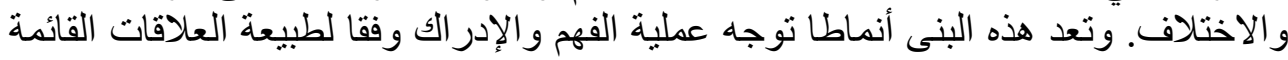

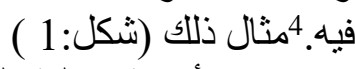

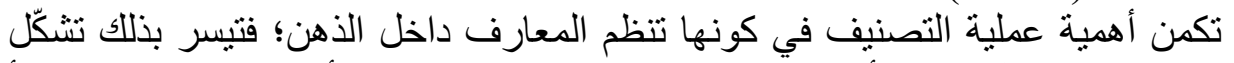

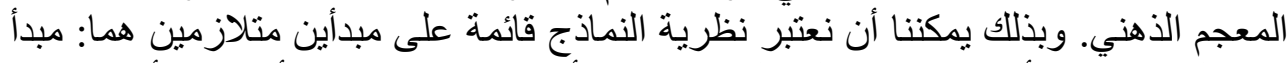

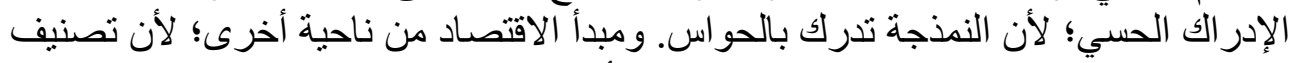

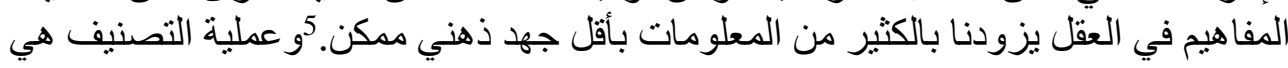

1 ـ يُنظر :سليم، عبد الإله. "بنيات المشابهة في اللغة العربية: مقاربة معرفية." مجلة أبحاث لسانبة -

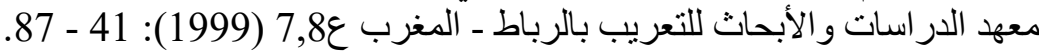

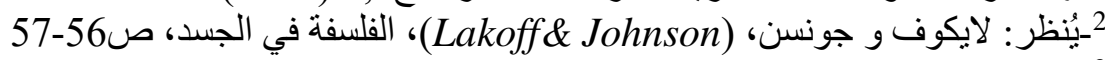

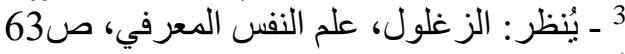

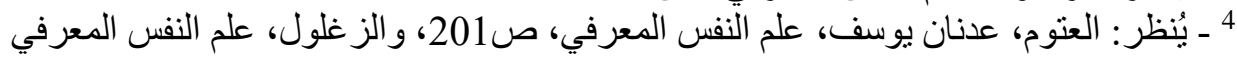

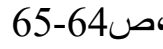

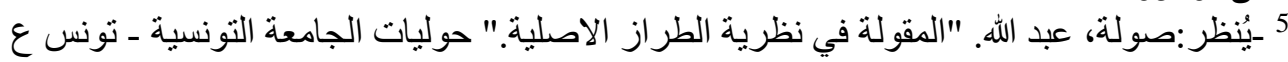
388 - 369 - 46 
المعنى: من اللغة إلى الذهن

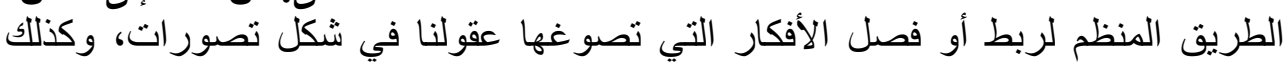

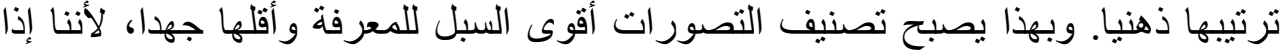

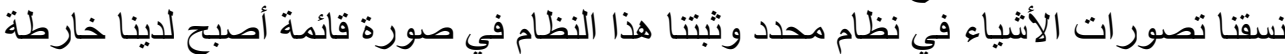

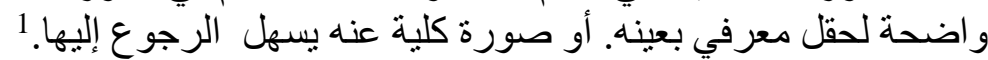
وتستخدم عملية التصنيف بطريقة ممانتة في البرمجة الثيئية في الحاسب باعبة باعنبار ها طريقة طبيعية لتمثيل العالم الواقعي، التي تكون جوهرية في البرامج التقليدية. فعندما ينتج

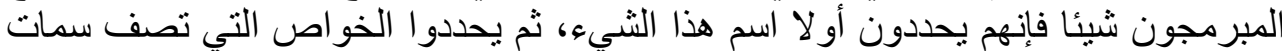

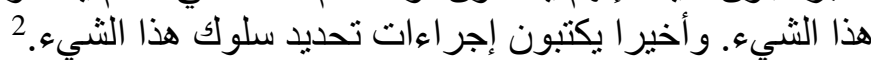

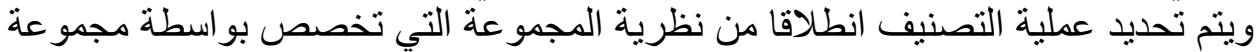

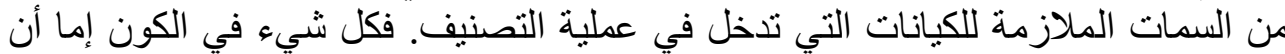

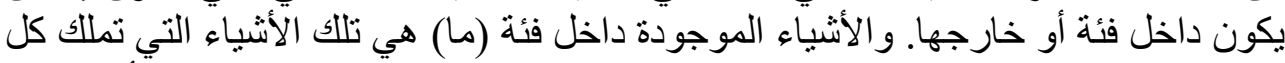
السمات الملازمة الضرورية الكافية. وكل شيء يعجز عن امتلاكك سمة ملازمة أو سمتين التين يسقط خارج الفئة.

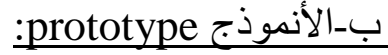

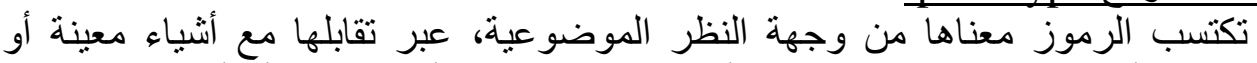

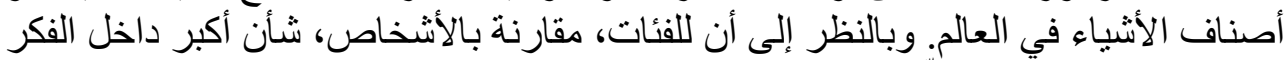

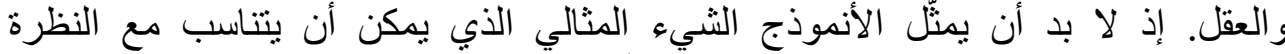

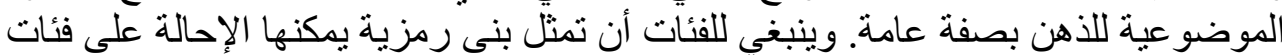

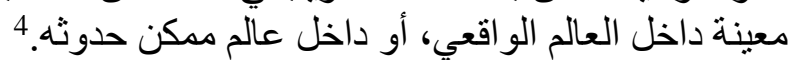

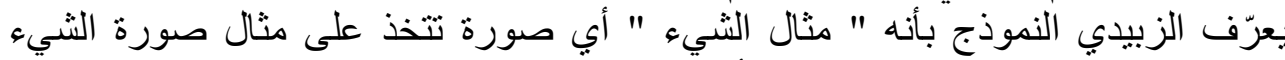

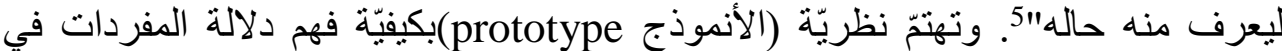

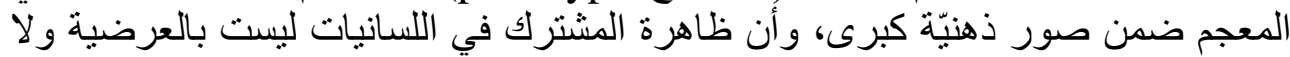

\footnotetext{
1

2

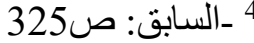

3ـ يُنظر : لايكوف و جونسن، (Lakoff\& Johnson)، ، الاستعار ات التي نحيا بها، ص132 5 - أرى أن يكون المقابل العربي لـ prototype الأنموذج، وذذانك أفضل من ترجمة بعض الباحثين

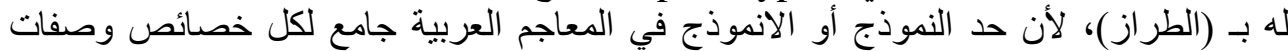

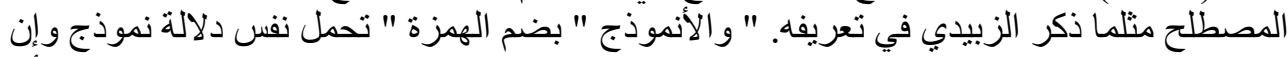

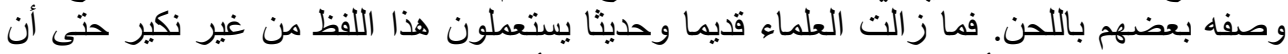

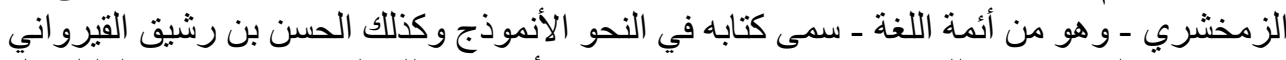

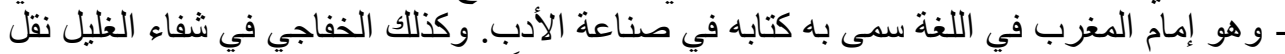

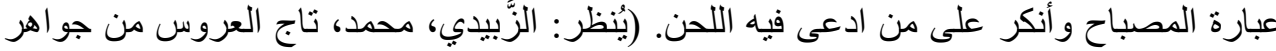




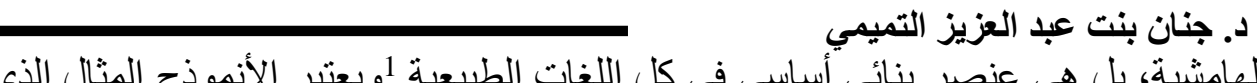

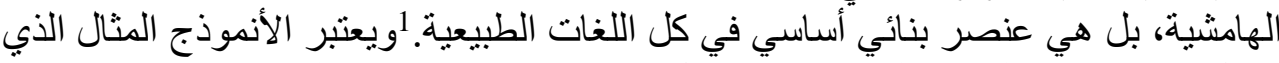

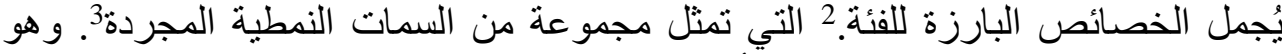
تمثيل ذهني لا يمتلك بالضرورة ممثنا أو معبر او اقعيا. 4

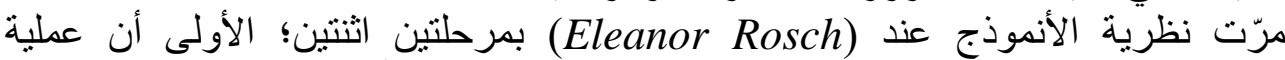

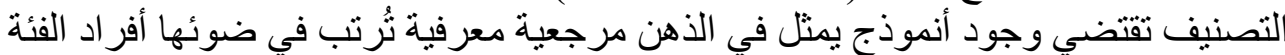

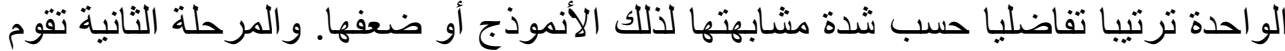

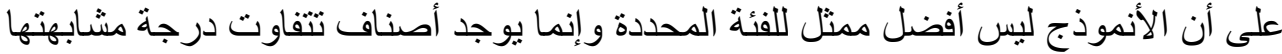
له. وتقوم على مدى التشابه الأسري ولو في سمة ولفي واحدة بين المعنى المركزي للفئة وبين

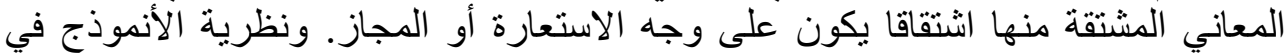

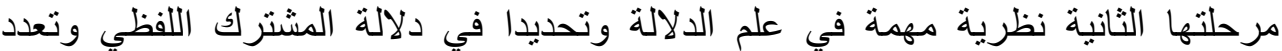

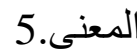

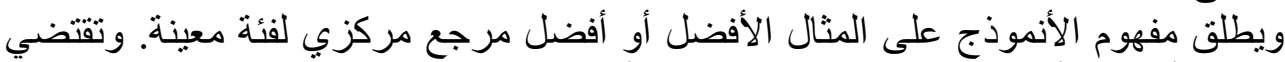

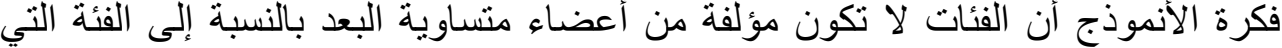

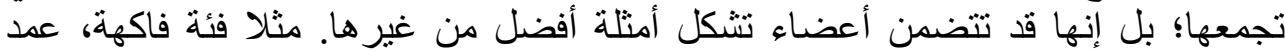

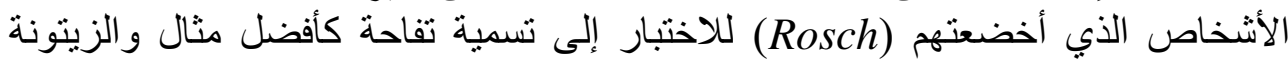
كالعضو التمثيلي الأضعف. وقد تبنت اللسانيات الإدر اكية نتائج Rosch و اطروحتها التي تسعى لاستتباط نماذج شكلية

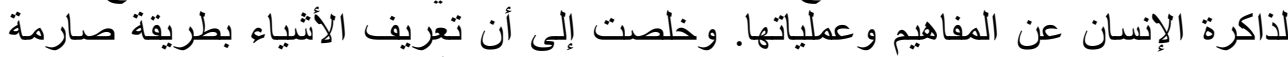

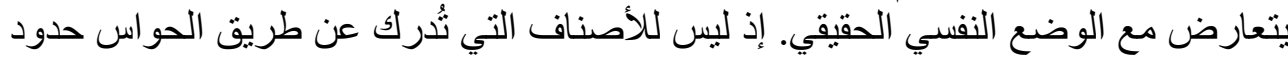

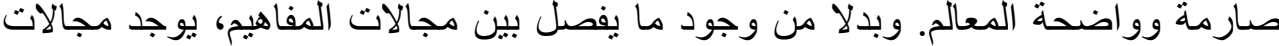

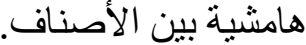
تعتمد نظرية الأنموذج على مبدأ الاقتصاد: إذ يلجأ الاماغ إلى إلى تصنيف الأشياء

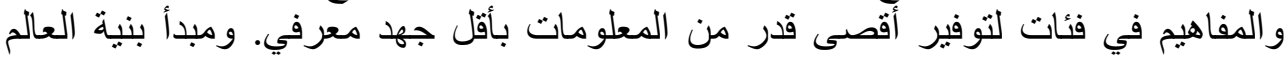
المحسوس الذي يعني أننا نرى العالم الخارجي بصورة منظمة تصنف الأشياء في مجموعات

1 - يُنظر : الحباشة، صابر ، من قضايا الفكر اللساني في النحو والدلالة و اللسانبة، صفحات للار اسة

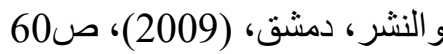
2- كليبر(kleiber)، علم دلالة الإنموذج،: الفئات و المعنى المعجمي، نر. ريتا خاطر، منشورات

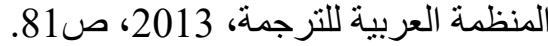
3 - صولة، عبد الله. "أثر نظرية الطر از الاصلية في دراسة المعنى." حوليات الجامعة التونسية ـ تونس ع 45 (2001): 259 - 284.

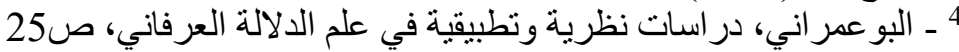

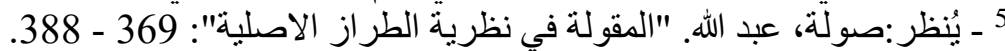

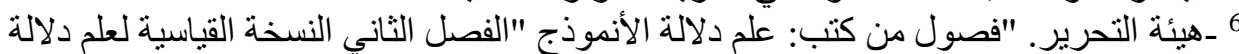

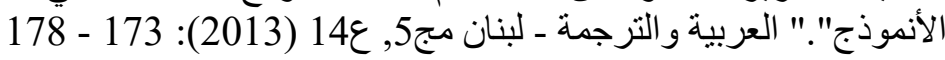


المعنى: من اللغة إلى الذهن ألهاء

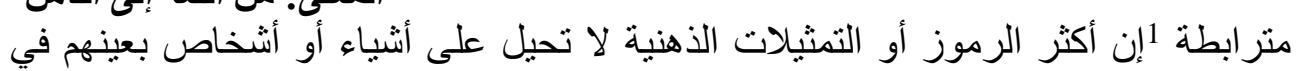

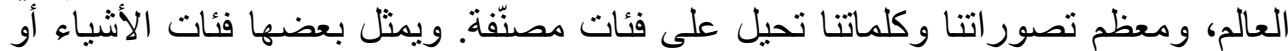
الكائنات في العالم الفيزيائي، مثل الأشجار و القطط. أما بعضها الآخر الخر فيمثل أصناف الأنشطة

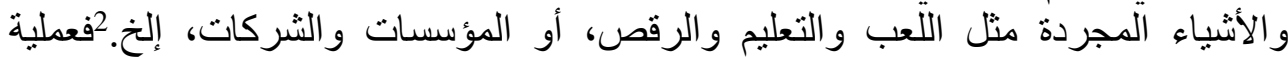

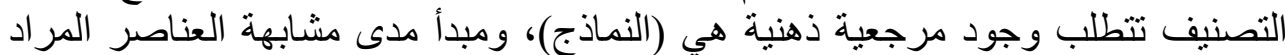

مقولتها لذلك النموذج الذي يجمع إجمالا الخصائص النمطية المجردة للفئة للفئة. 3

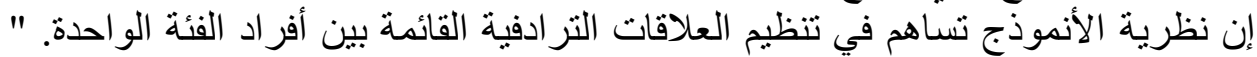

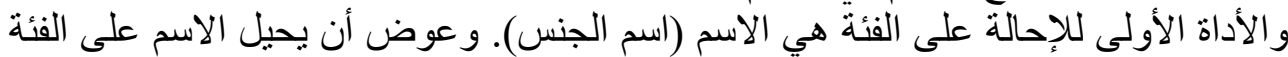

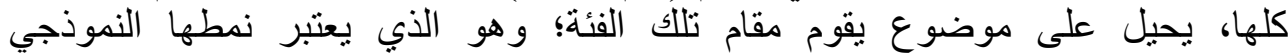
(prototype)

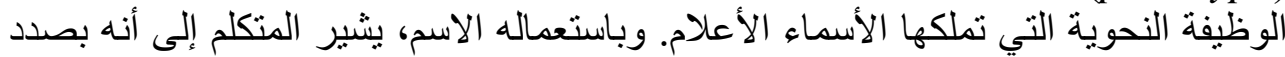

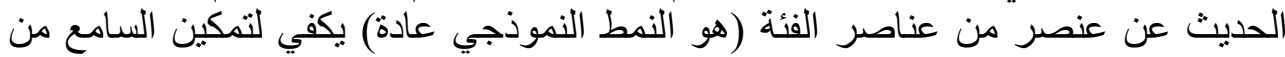
تعيين الموضوع المقصود في السياق."

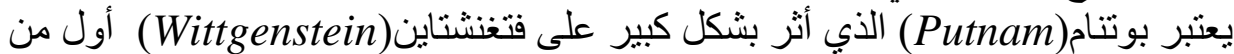

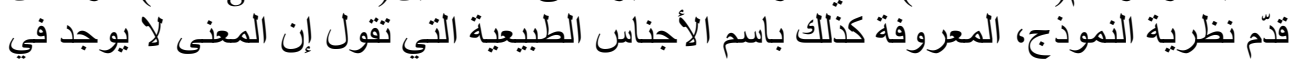

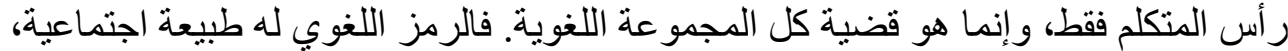

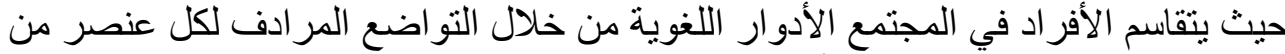

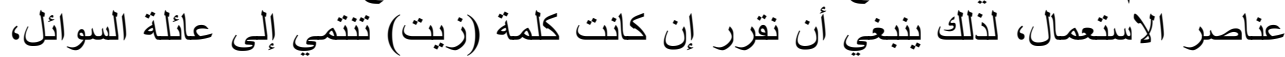

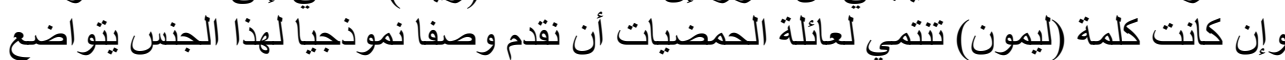

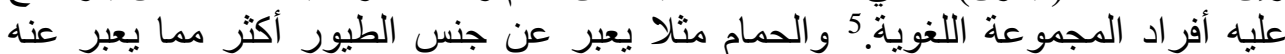

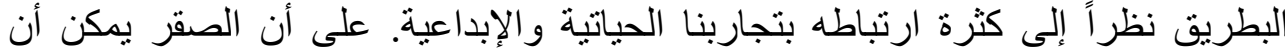

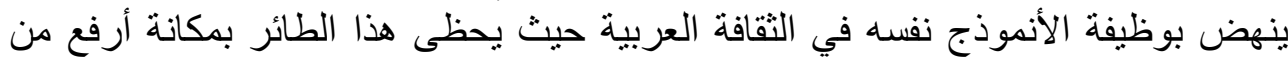

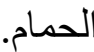
وتمثل الوحدة الدلالية الدنيا البصمة الدماغية التي تسجل فيها العلامة اللغوية أو الصلة بين

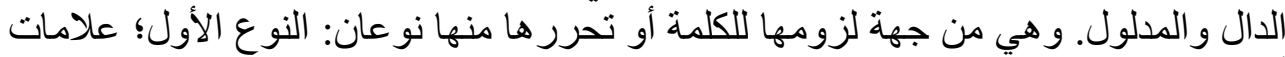

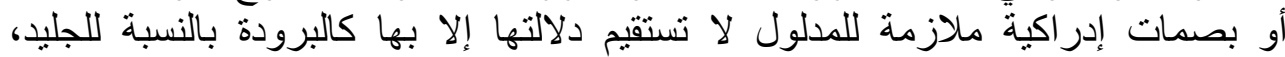

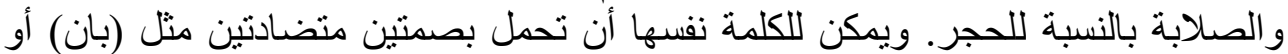
(رغب). و النوع الثاني؛ علامات تشترك فيها مجموعة من الكلمات مثل صفة البشرية بين

1-Rosch, Eleanor, Principles of Categorization, University of California, (1978),P.(First publised in: Rosch, Eleanor and Lloyd, Barbara B. (eds),

Cognition and categorization 27-48,Hillsdale, NJ:Lawrence Erlbaum.)

2 2 ـ يُنظر : السابق: ص325

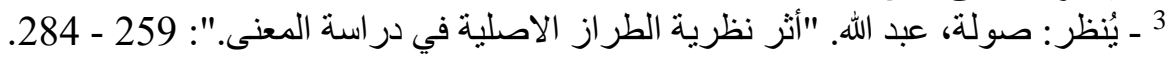

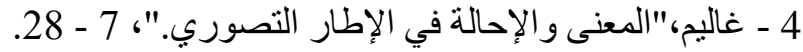

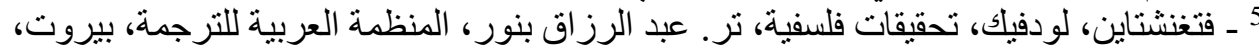

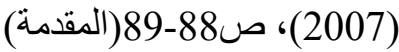




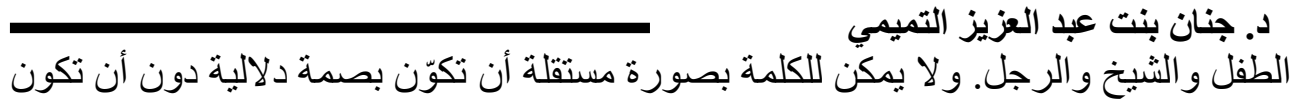

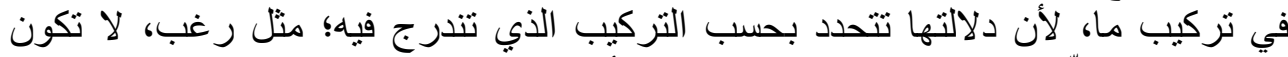

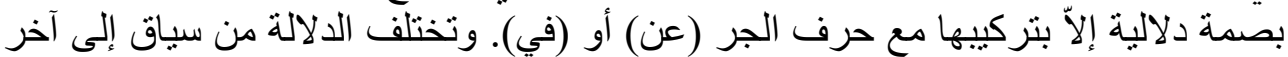

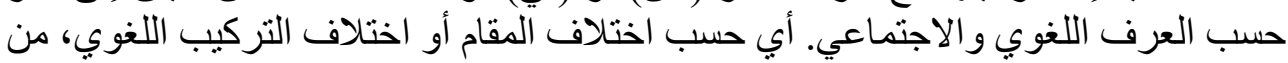

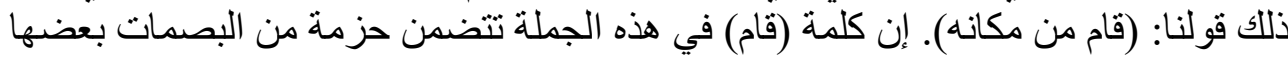

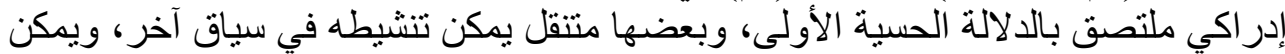

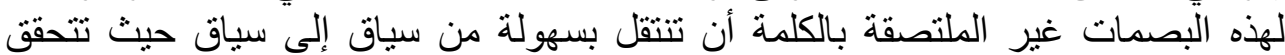

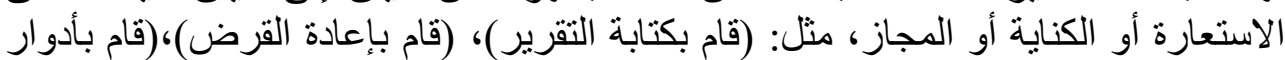

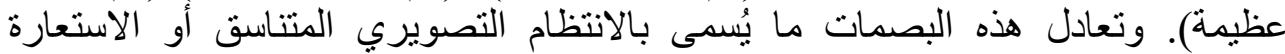
المركزية.

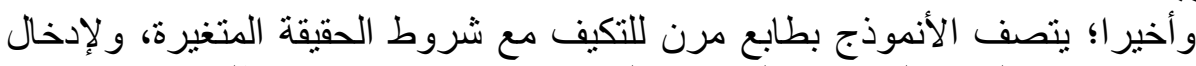

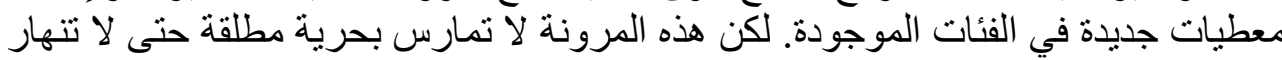

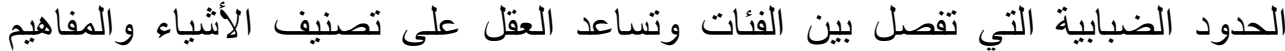

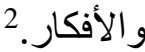

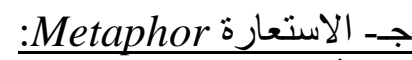

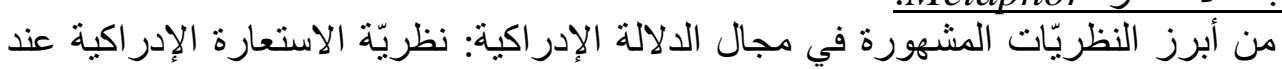
لايكوف وجونسون الغنين التي برهنت أن مكان الاستعار ات في التصورات وليس في (Lakoff\&Johnson)

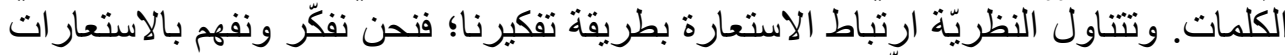

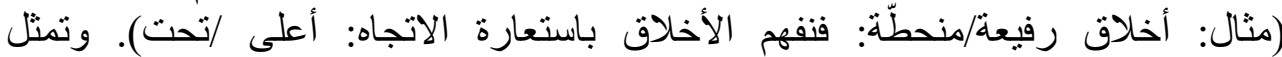

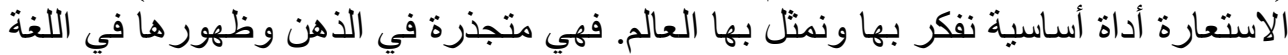

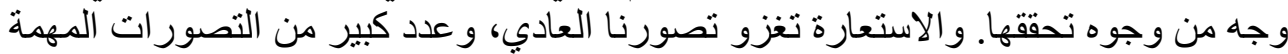

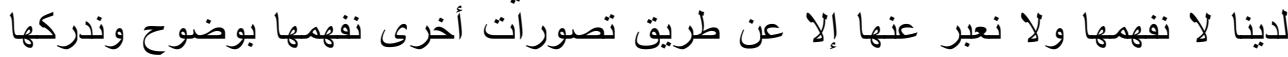

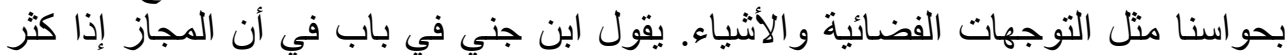

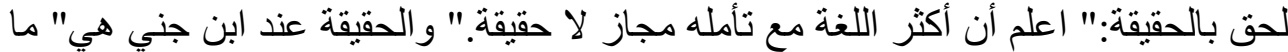

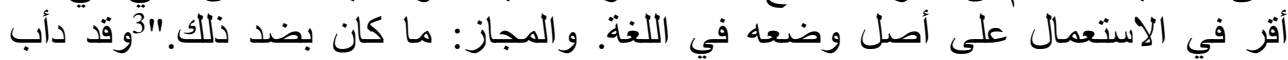

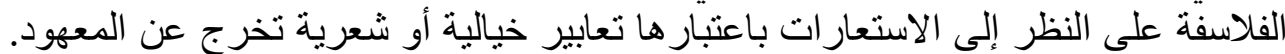

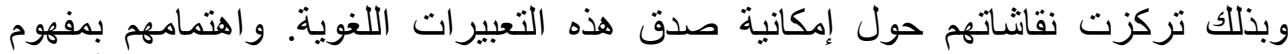

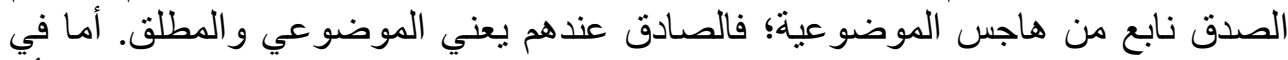

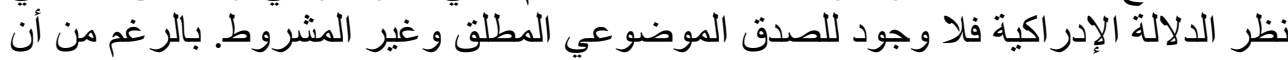

1ا-يُنظر : رمضان، صالح بن الهادي، التو اصل الأدبي من التداولية إلى الإدر اكية، النادي الأدبي،

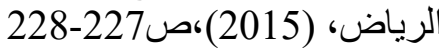

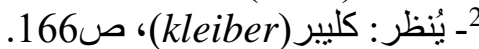

3 ــابن جني، أبو الفتح عثمان، الخصائص، الهيئة المصرية العامة للكتاب، تح. محمد النجار، ط4،

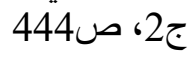


المعنى: من اللغة إلى الذهن

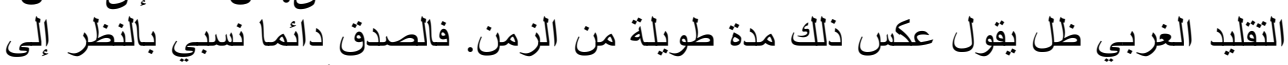

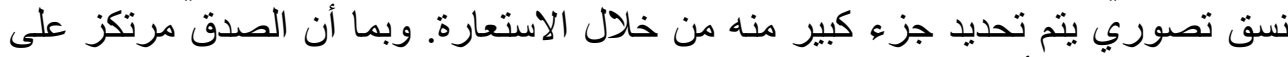

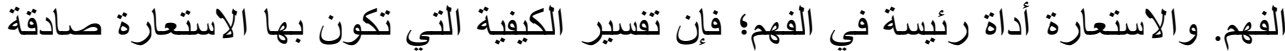

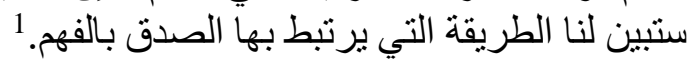

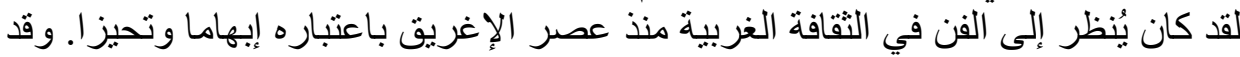

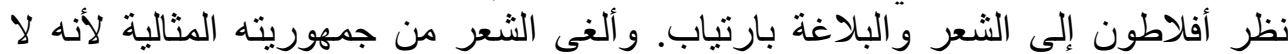

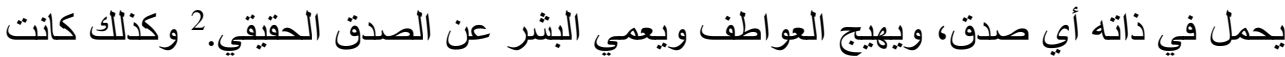

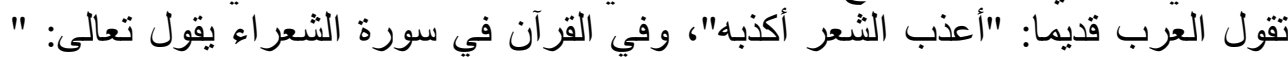

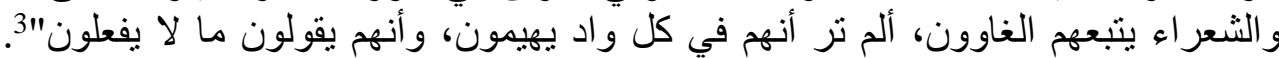

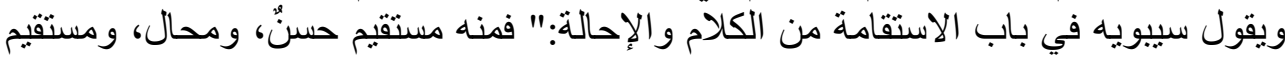

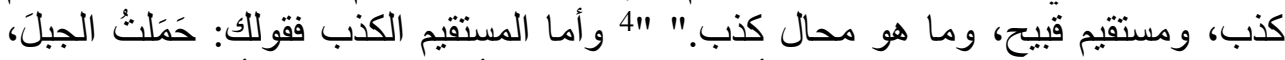

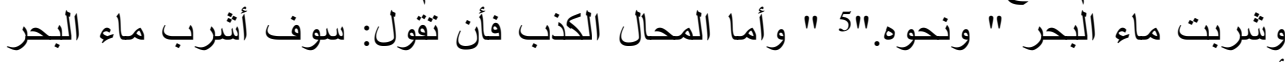

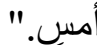

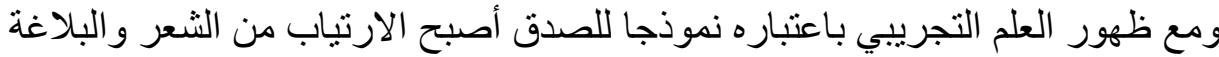

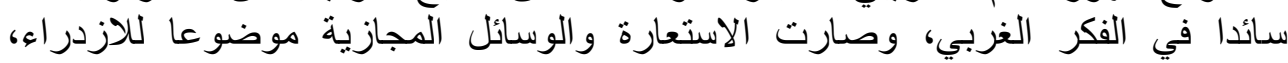

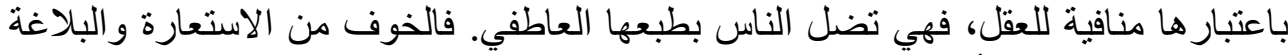
خوف من الذاتية. فالألفاظ ينظر لها باعتبار ها تحمل (معانٍ حقيقية) (صادقة). واستعمال

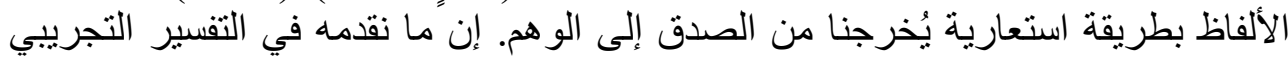

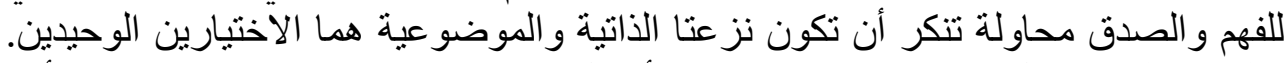

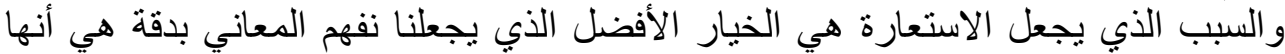

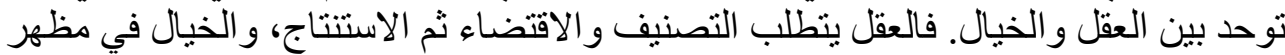

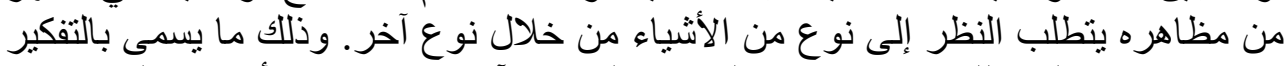

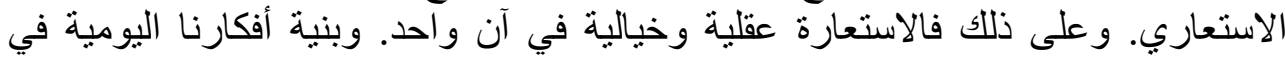

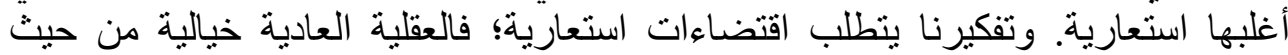

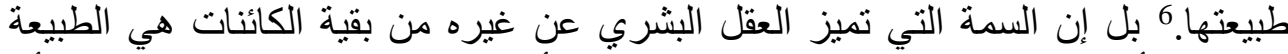

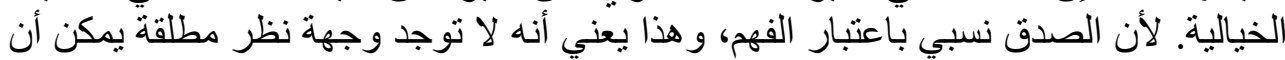

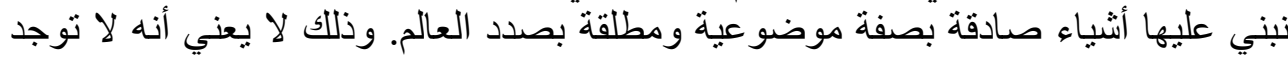
أثياء صادقة؛ ولكن الصدق نسبي بالنظر إلى نسقنا التصوري الذي يرتكز على تجاربنا

1ـ يُنظر : لايكوف و جونسن، (Lakoff\& Johnson)، الاستعار ات التي نحيا بها، ص163

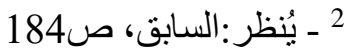

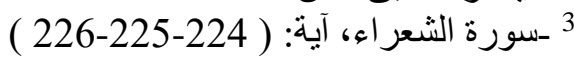

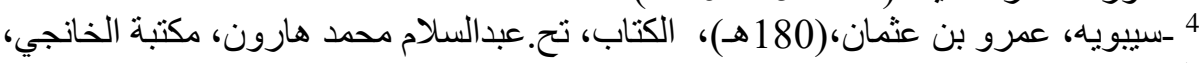

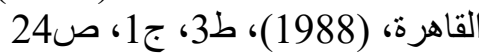

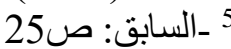

6-يُنظر: لايكوف و جونسن، (Lakoff\& Johnson)، ، الاستعار ات التي نحيا بها، ص186 


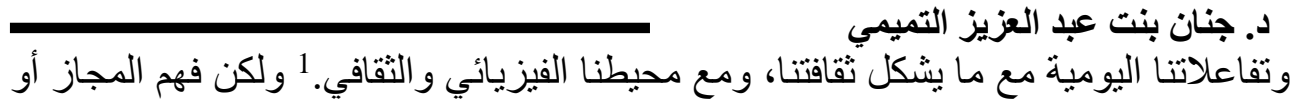

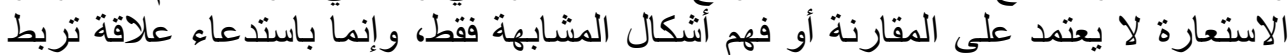

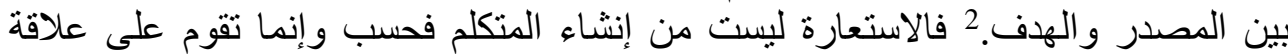

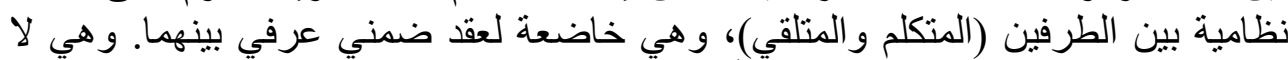

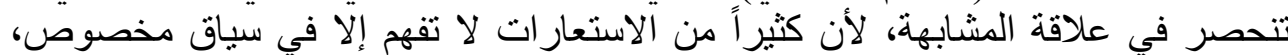
وذللك يؤكد أن مبدأ المشابهة لوحده غير كافٍ لمقاربة الاستعارة.

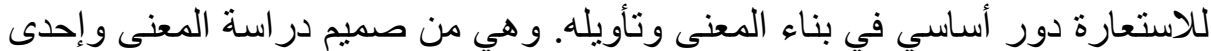

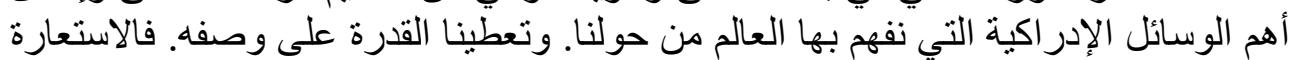

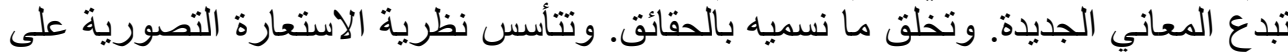

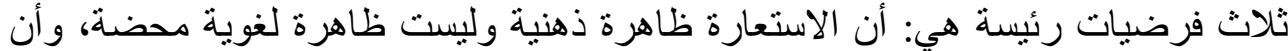

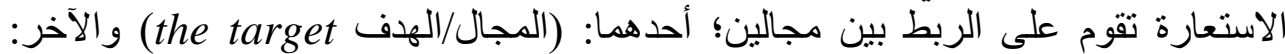

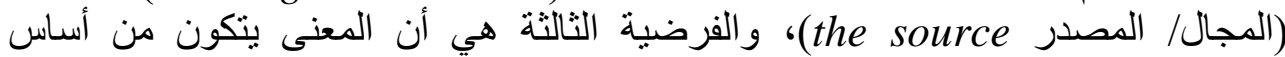

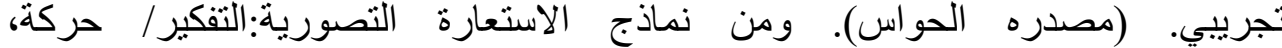

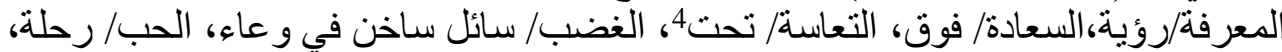

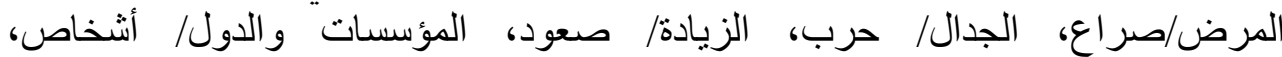
النظرية/بناء، السلطة و المنزلة الاجتماعية/فوق. ومن نماذج الاستعارة التصورية مفهوم الزمن في اللغة العربية وذللك من خلال تصنية تصويره بمفاهيم وعلاقات مستمدة من مجالات موجودة في البيئة المحيطة؛ المكان (طريق، الرئ أرض،

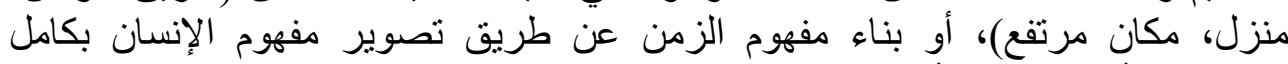

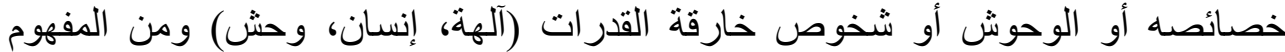

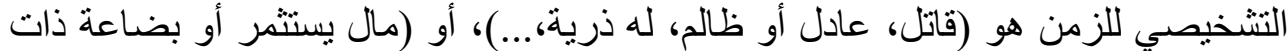

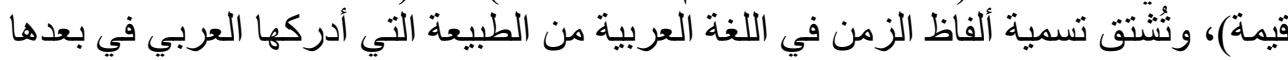

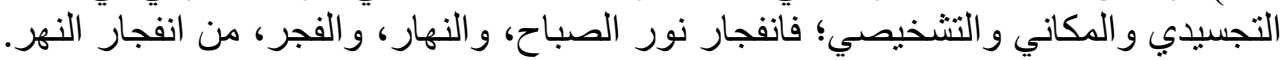

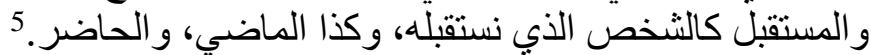

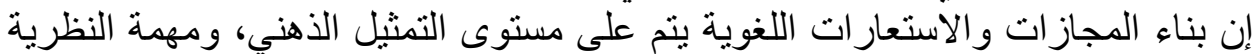

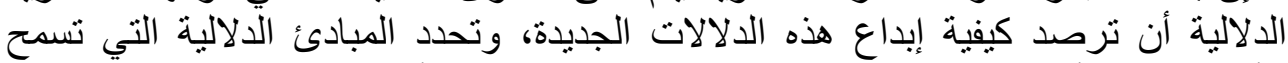

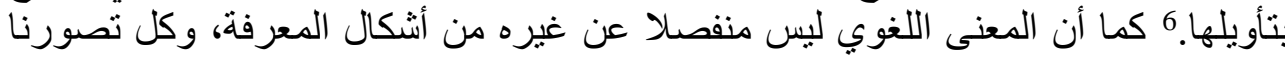

1

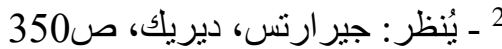

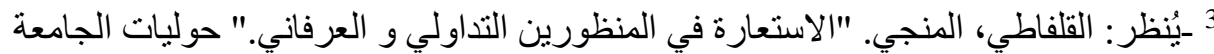
التونسية - تونس ع 57 (2012): 311 - 312 - 325. 4ـ ينظر : التميمي، جنان، السعادة و الاستعار ات الإدر اكية_در اسة لسانبة، مجلة كلية الآداب، جامعة

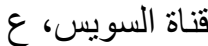
5 ـ يُنظر : التميمي، جنان، الزمن في العربيةِ من التعبير اللغوي إلى التمثيل الذهني: دراسة لسانية

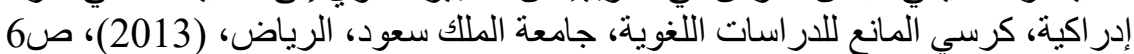

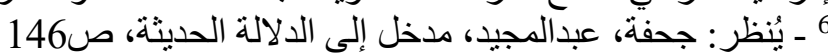


المعنى: من اللغة إلى الأهن

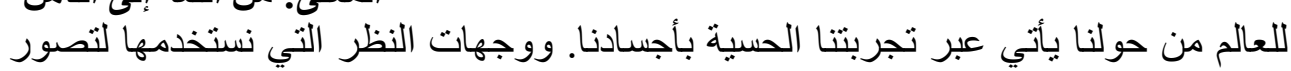

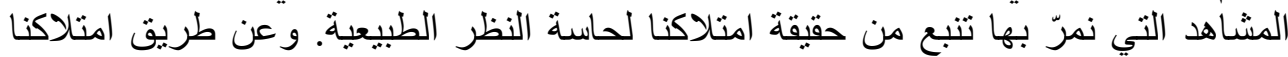

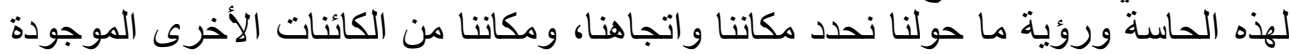

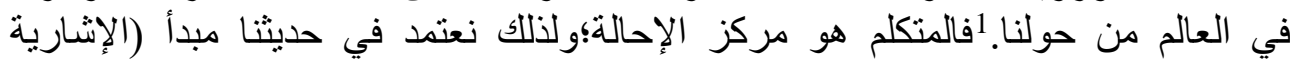
(indexicality

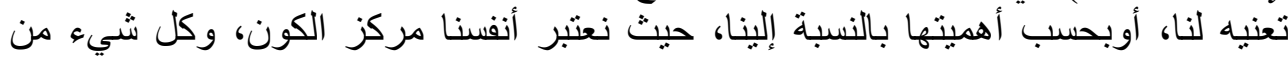

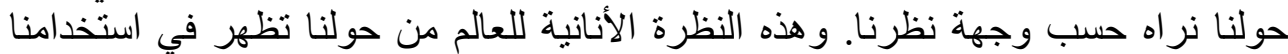

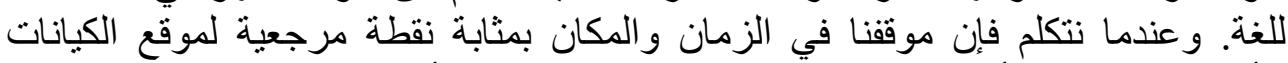

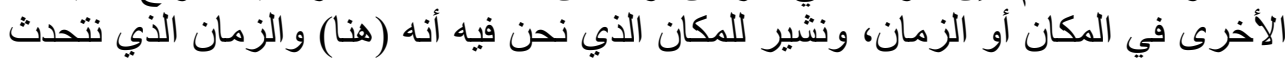

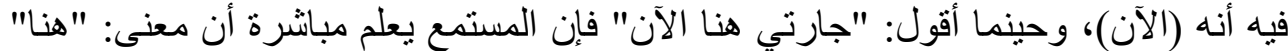

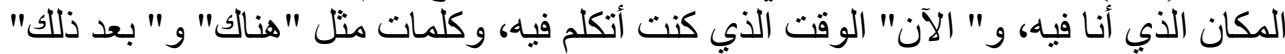

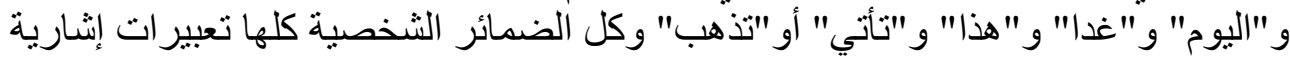
ت ت تصنل بالأنا الناطقة.

تعتمد الدلالة الإدر اكية على مركزية المعنى، وعلى الأساس التجسيدي للمعنى الذي تمثلك

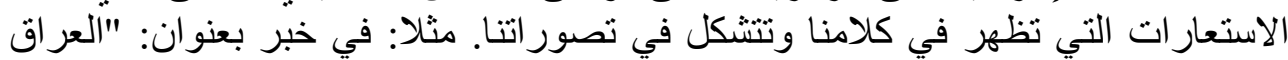

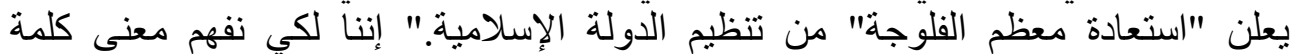

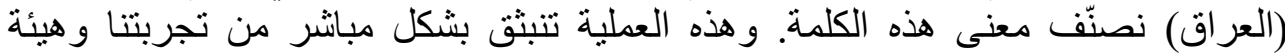

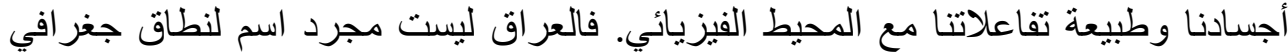

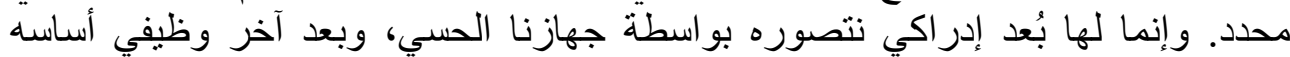

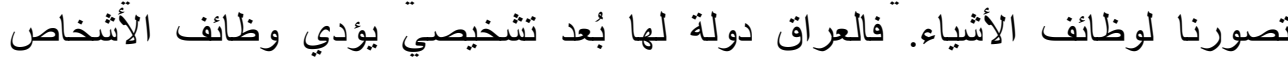

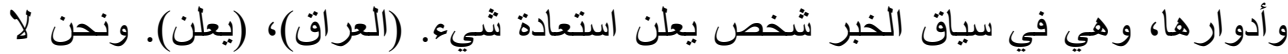

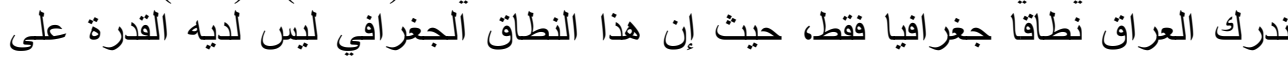

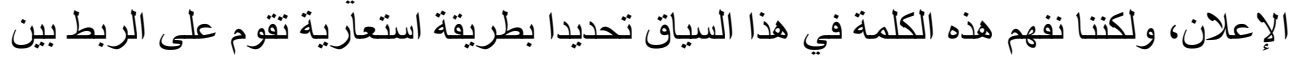
مجالين؛ أحدهما: (المجال/الهدف the target) و هو الدولة (العراق)، والآخر: (المجال/

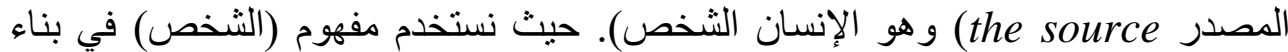

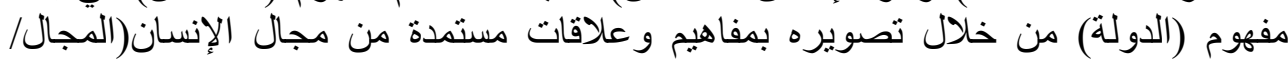
المصدر (the source).

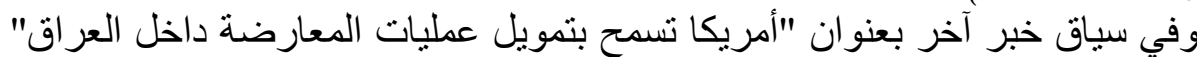

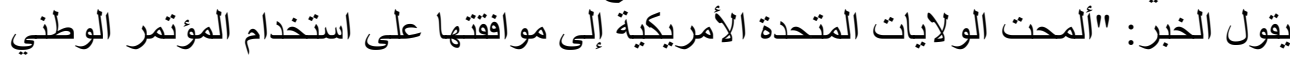

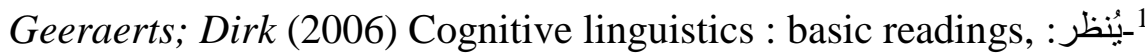

SelignowVerlagsservice, Berlin,p.5

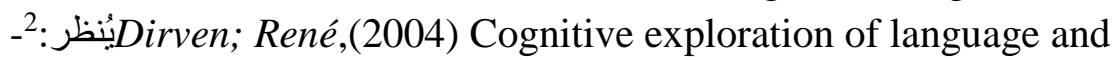
linguistics, John Benjamins Publishing Company,Amsterdam,p.5/Philadelphia 


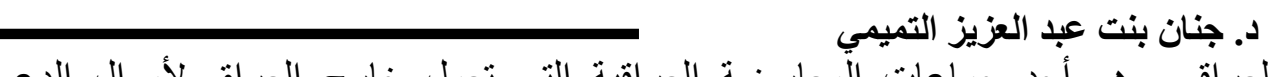

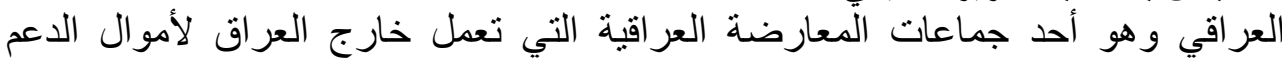

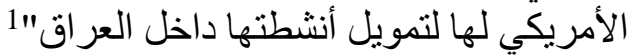
إن تحلُيل معنى كلمة العراق في هذا السياق يحيلنا إلى مفهوم (المكان)لبناء مفهوم:

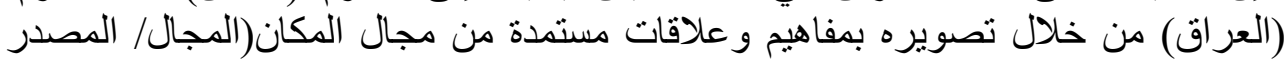

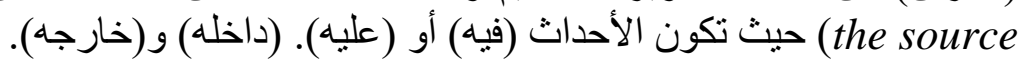

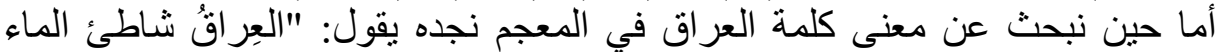

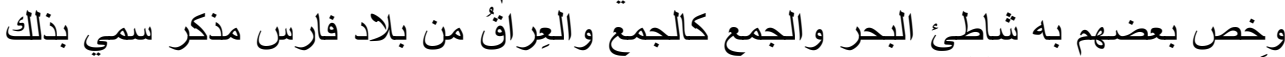

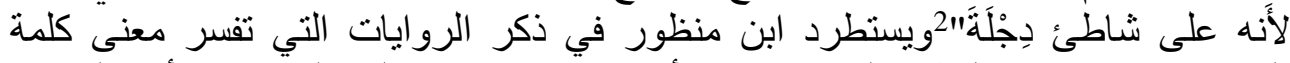

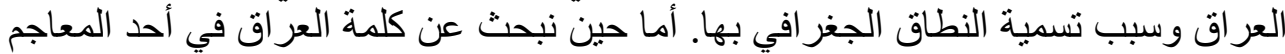

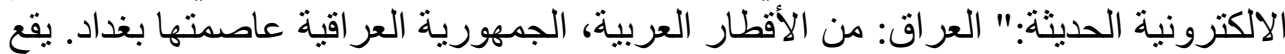

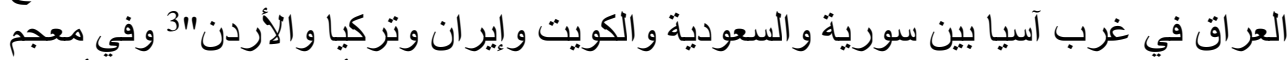

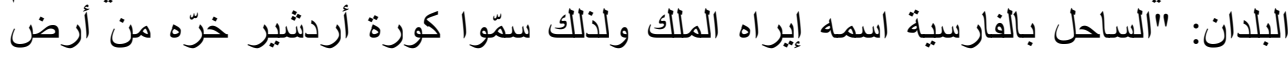

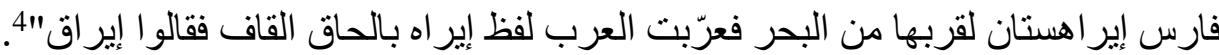

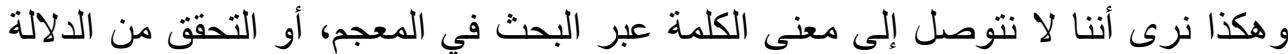

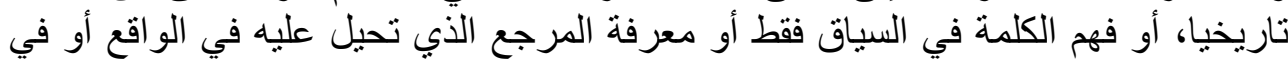

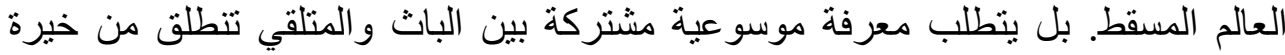

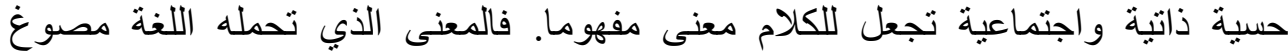

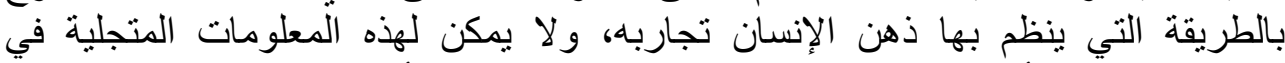

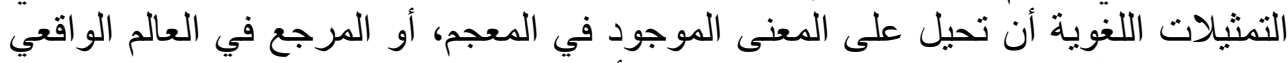

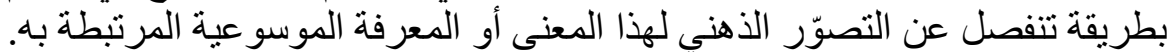
تشتبدل الدلالة الإدر اكية البحث عن القو انين العامة المفسرة للبنية الثكلية للغة، بالبحث خاتمة:

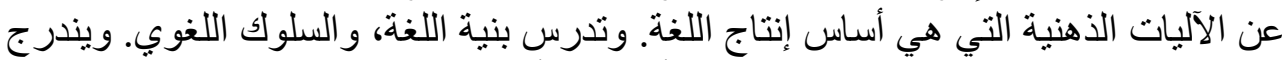

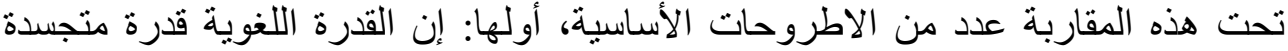

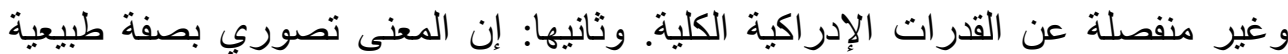

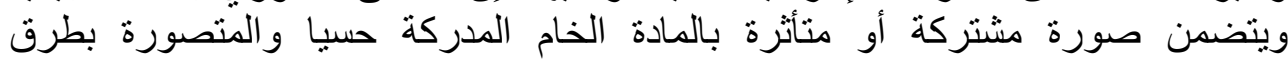
مخصوصة. وتتمسك الدلالة الإدر اكية بأن مقاربة شروط الصادة الصدق لانة تستطيع إعطاء تعليل

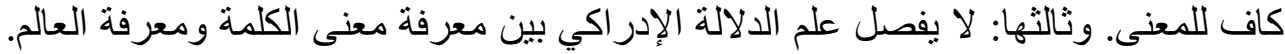

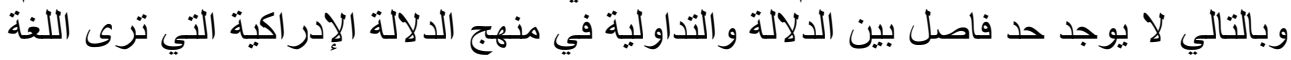

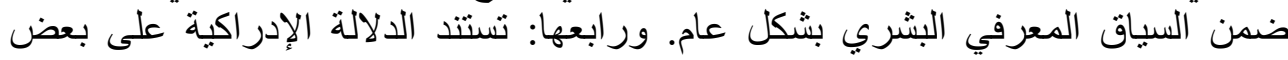

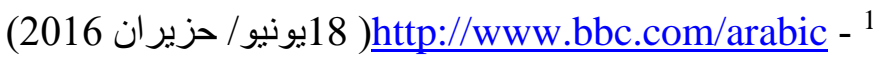

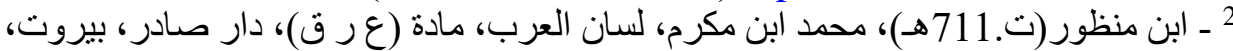

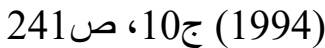
/http://www.almaany.com - 3 4 ـ ـ الحموي(ت.626هـ)، شهاب الدين ياقوت، معجم البلدان، دار صادر، بيروت، ط2، (1995)،

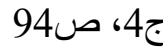


المعنى: من اللغة إلى الأهن

النظريات الإدر اكية لتفسير الآليات العقلية في بناء المعنى و إنتاجه أبرزها: عملية التصنيف، التهن،

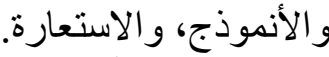

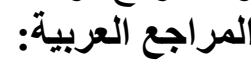

1. ابن جني، أبو الفتح عثمان، الخصائص، الهيئة المصرية العامة للكتاب، تح. محمد

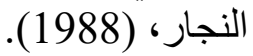

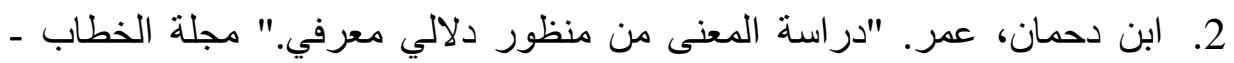
مخبر تحليل الخطاب - جامعة مولود معمري تيزي وزو ـ الجزائر عن عن (2012). 3. ابن فارس، أحمد، معجم مقاييس اللغة، تح. عبدالسلام هارون، دار الفكر، (1997). 4. ابن منظور(ت.711. هـ)، محمد ابن مكرم، لسان العرب، مادة (ع ر ق)، دار

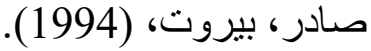

5. إيجلمان، ديفيد، الحيوات السرية للدماغ، تر.حمزة المزيني،جداول، الكويت،

6. الباهي، حسان، الذكاء الاصطناعي وتحديات مجتمع المعرفة، أفريقيا الثرق، الدار

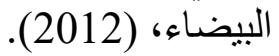

7. بلحاج، عبدالكريم، علم النفس المعرفي. قضايا النشأة والمفهوم. منشورات كلية الآداب و العلوم الانسانية. الرباط.(2004)

8. بن غريبة، عبدالجبار، مخل إلى النحو العرفاني، مسكلياني، نونس، (2010). 9. البوعمراني، محمد الصالح، دراسات نظرية وتطبيقية في علم الدلالة العرفاني، مكتبة علاء الدين، صفاقس، (2009).

10.بيكرتون، ديريك، (Derek Bickerton)، اللغة وسلوك الإنسان، تر. محمد زياد كبة، جامعة الملك سعود، (2001).

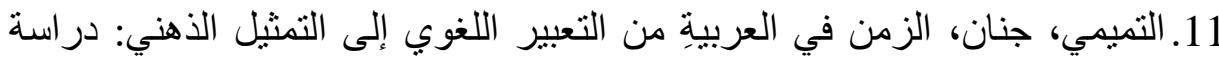
لسانية إدراكية، كرسي المانع للاراسات اللغوية، جامعة الملك سعود، الرياض،

12. التميمي، جنان، السعادة والاستعار ات الإدر اكية-در اسة لسانية، مجلة كلية الآداب،

جامعة قناة السويس، ع3، النعادة مارس، (2016).

13.جاكندوف، راي(Ray Jackendoff)، علم الدلالة والعرفانية، نر.عبدالرزاق

بنور، المركز الوطني للترجمة، نونس، (2010). 
د. جنان بنت عبد العزيز التميمي

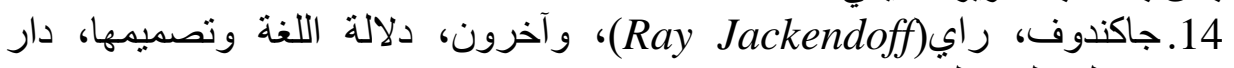

توبقال، الدار البيضناء، (2007)

15.جحفة ،عبدالمجيد وعبدالإله سليم لكتاب جورج لايكوف_حرب الخليج أو أولئ الاستعار ات التي تقتل، ط1 (2005).

16. جحفة، عبدالمجيد، مدخل إلى الدلالة الحديثة، دار توبقال، الدار البيضاء، (2014).

17.جيرارتس، ديريك،(Dirk Geeraerts )، نظريات علم الدلالة المعجمي، نر.

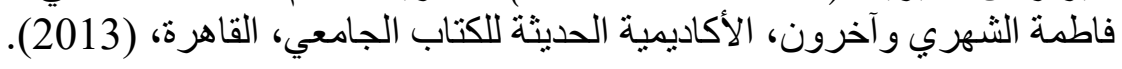

18. الحباثة، صابر، في المعنى: مباحث دلالية معرفية، المركز الثقافي العربي، الدار

البيضناء، (2008).

19. الحباثة، صابر، من قضايا الفكر اللساني في النحو والدلالة واللسانية، صفحات للار اسة و النشر، دمشق، (2009).

20. الحموي(ت.626هـ)، شهاب الدين ياقوت، معجم البلدان، دار صادر، بيروت، ط2،

21. خرما، نايف، أضواء على الدراسات اللغوية المعاصرة، عالم المعرفة، الكويت،

22.رمضان، صالح بن الهادي، التواصل الأدبي من التداولية إلى الإدراكية، النادي الأدبي، الرياض، (2015).

23.ز غبوش، بنعيسى، الذاكرة و اللغة، عالم الكتب الحديث، إربد، (2008).

24. الزغلول، رافع ، عماد، علم النفس المعرفي، دار الثروق، عمان، الأردن، ط1.

25. الزناد: الأزهر، نظريات لسانية عَرفَنيّة، الدار العربية للعلوم، بيروت، (2010).

26. سليم، عبد الإله. "بنيات المشابهة في اللغة العربية: مقاربة معرفية." مجلة أبحاث

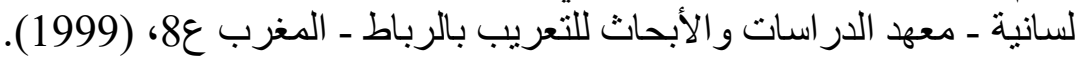

27.سييويه، عمرو بن عثمان،(ت.180هـ)، الكتاب، تح.عبدالسلام محمد هارون، (1988)،

مكتبة الخانجي، القاهرة، (1988).

28. الثمري، غسان. "عن أسس اللسانيات الإدراكية ومبادئها العامة." مجلة أبحاث

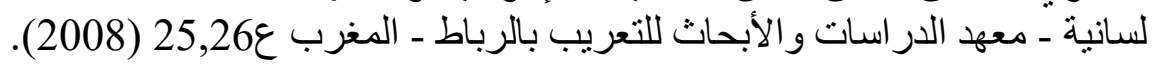


المعنى: من اللغة إلى الأهن

29. صولة، عبد الله. "أثر نظرية الطراز الاصلية في دراسة المعنى." حوليات الجامعة الفهن التونسية - تونس ع 45 (2001).

30. صولة، عبد الله. "المقولة في نظرية الطراز الاصلية." حوليات الجامعة التونسية ـ

$$
\text { تونس ع } 46 \text { (2002). }
$$

31. غاليم، محمد. "المعنى و الإحالة في الإطار التصوري." مجلة أبحاث لسانية ـ معهد

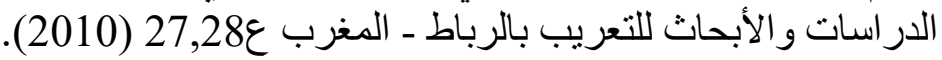

32.فتغنتناين، لودفيك، Wittgenstein) تحقيقات فلسفية، تر. عبد الرزاق بنور، المنظمة العربية للترجمة، بيروت، (2007).

33. الفخر اني، مصطفى أبو و الي. "نظرية الإعر اب الدلالية عند فيلمور ." مجلة جامعة اللغو الملك سعود (اللغات و الترجمة) - السعودية مج النية 15 (2003).

34.القلفاطي، المنجي. "الاستعارة في المنظورين التداولي و العرفاني." حوليات الجامعة التونسية - تونس ع 57 (2012).

35.كليبر(kleiber)، علم دلالة الإنموذجه: الفئات و المعنى المعجمي، تر. رينا خاطر،

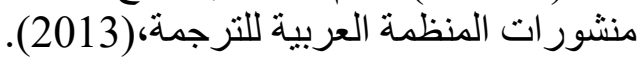

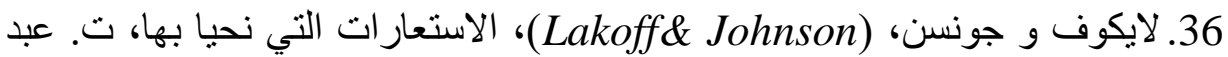
المجيد جحفة، دار توبقال، الدار البيضاء، (2009) ط2.

37. لايكوف و جونسن، (Lakoff\& Johnson)، الفلسفة في الجسد:الذهن المتجسد وتحديه للفكر الغربي، تر.عبد المجيد جحفة، الكتاب الجديد المتحدة،(2016).

38. لوينز، جون،(Lyons, John) اللغة و علم اللغة، تر. مصطفى التوني ، دار النهضة العربية، القاهرة، (1987).

39. محسب، محي الدين : "منهجية دراسة الاستعارة من الأساس اللغوي إلى التأسيس

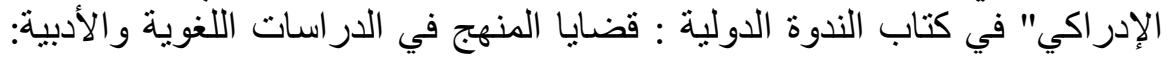

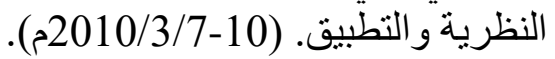

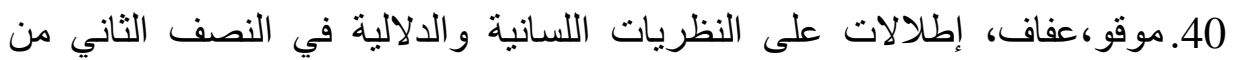

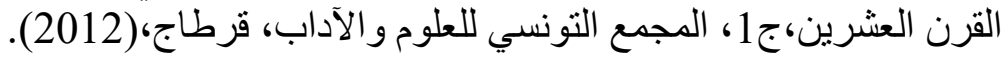

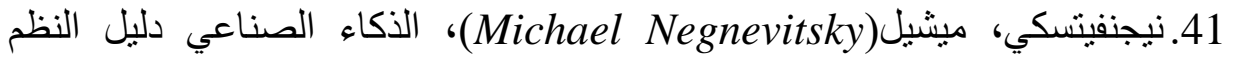

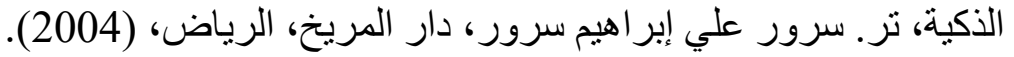




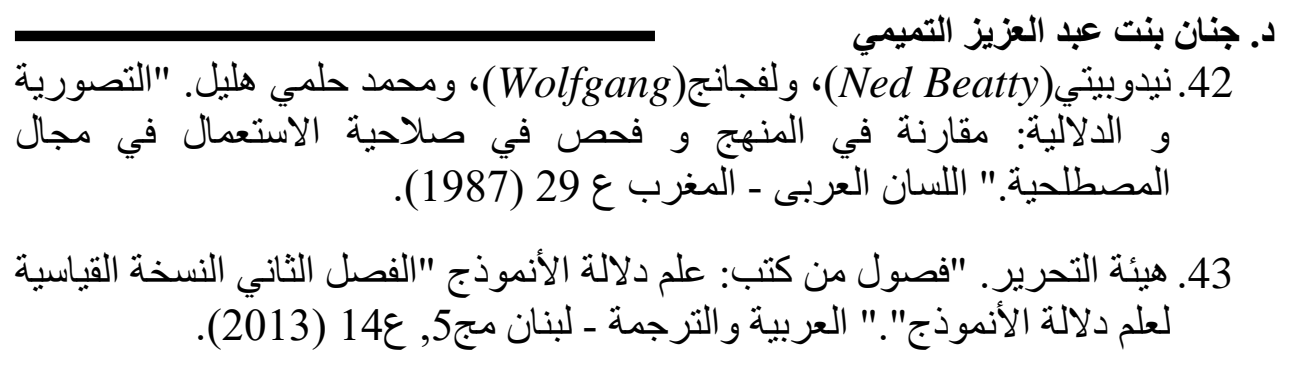

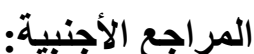

1- Geeraerts; Dirk , Cognitive linguistics : basic readings, SelignowVerlagsservice, Berlin,Cruse, Alan, A Glossary of. Semantics and. Pragmatics, Edinburgh University Press), 2006( 2-Dirven; René, Cognitive exploration of language and linguistics, John Benjamins Publishing Company,Amsterdam, (2004) 3-Evans, Vyvyan, How words mean, Oxford University Press,(2003).

,4-Evans: Vyvyan\& Green: Melanie, Cognitive Linguistics: An introductions, Edinburgh University Press,(2006).

5- Rosch, Eleanor, Principles of Categorization, University of California,P.(First publised in Rosch, Eleanor and Lloyd, Barbara B. (eds), Cognition and categorization 27-48,Hillsdale, NJ:Lawrence Erlbaum. (1978).

http://www.almaany.com

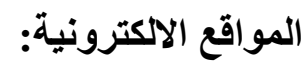
http://www.bbc.com/arabic http://www.intelligent-systems.com.ar 